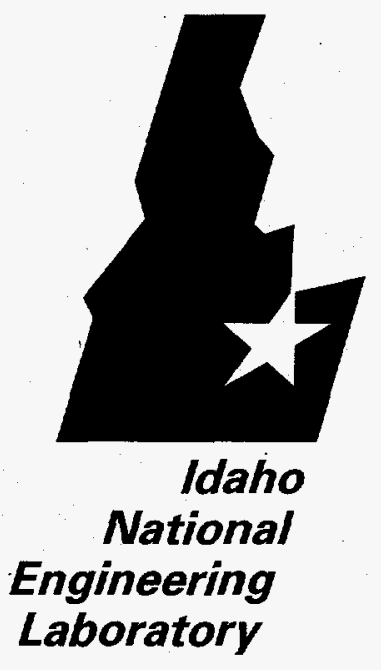

INEEL/EXT-98-00301

April 1998

\title{
Waste Generator Services Implementation Plan
}

\author{
RECEIVED \\ JUL $O$ Y 1998 \\ QSTI
}

Jeff Mousseau, P.E.

Mary Magleby, P.E.

Marty Litus

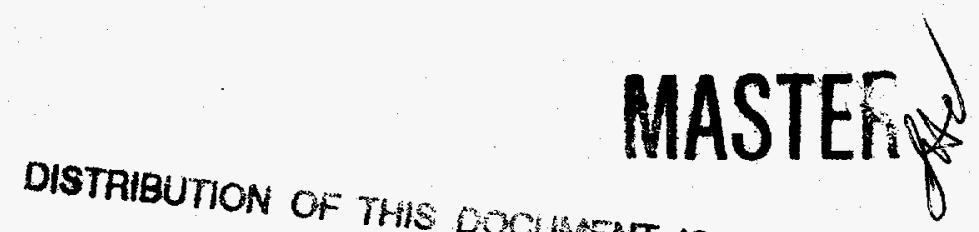

DISTAIBUTION OF THIS DOCUAVENT IS UNLMMTED

LOCKHEED MARTIN? 
INEELEXT-98-00301

\title{
Waste Generator Services Implementation Plan
}

\author{
Jeff Mousseau, P.E. \\ Mary Magleby, P. E. \\ Marty Litus
}

Published April 1998

\section{Idaho National Engineering and Environmental Laboratory \\ Lockheed Martin Idaho Technologies Company Idaho Falls, Idaho 83415}

\author{
Prepared for the \\ U.S. Department of Energy \\ Assistant Secretary for Environmental Management \\ Under DOE Idaho Operations Office \\ Contract DE-AC07-94ID13223
}




\section{DISCLAIMER}

This report was prepared as an account of work sponsored by an agency of the United States Government. Neither the United States Government nor any agency thereof, nor any of their employees, makes any warranty, express or implied, or assumes any legal liability or responsibility for the accuracy, completeness, or usefulness of any information, apparatus, product, or process disclosed, or represents that its use would not infringe privately owned rights. Reference herein to any specific commercial product, process, or service by trade name, trademark, manufacturer, or otherwise does not necessarily constitute or imply its endorsement, recommendation, or favoring by the United States Government or any agency thereof. The views and opinions of authors expressed herein do not necessarily state or reflect those of the United States Government or any agency thereof. 


\section{DISCLAIMER}

Portions of this document may be illegible in electronic image products. Images are produced from the best available original document. 


\section{ABSTRACT}

Recurring waste management noncompliance problems have spurred a fundamental site-wide process revision to characterize and disposition wastes at the Idaho National Engineering and Environmental Laboratory. The reengineered method, termed Waste Generator Services, will streamline the waste acceptance process and provide waste generators comprehensive waste management services through a single, accountable organization to manage and disposition wastes in a timely, cost-effective, and compliant manner. The Waste Generator Services organization will report through Waste Operations.

This report outlines the strategy for implementing Waste Generator Services across the INEEL. It documents the culmination of efforts worked by the LMICO Environmental Management Compliance Reengineering project team since October 1997. These efforts have included defining problems associated with the INEEL waste management process; identifying commercial best management practices; completing a review of DOE Complex-wide waste management training requirements; and involving others through an Integrated Process Team approach to provide recommendations on process flow, funding/charging mechanisms, and WGS organization. The report defines the work that will be performed by Waste Generator Services, the organization and resources, the waste acceptance process flow, the funding approach, methods for measuring performance, and the implementation schedule and approach. Field deployment will occur first at the Idaho Chemical Processing Plant in June 1998. Beginning in Fiscal Year 1999, Waste Generator Services will be deployed at the other major INEEL facilities in a phased approach, with implementation completed by March 1999.

The prime objective of this implementation plan is to eliminate noncompliant waste management conditions across the site. Attendant benefits will include a streamlined waste determination method; incentives for waste minimization; a structured supplier/customer partnership between Waste Generator Services and its customers -- the waste generators and the treatment, storage, and disposal facilities; single-point accountability, and a funding mechanism that is fair and workable.

The LMITCO Senior Salary Review Board approved WGS implementation on March 11, 1998. 


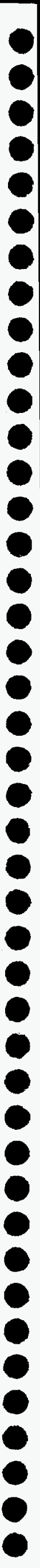




\section{CONTENTS}

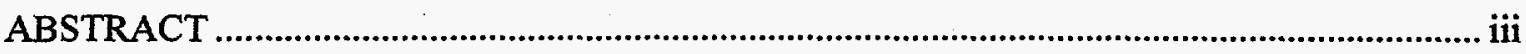

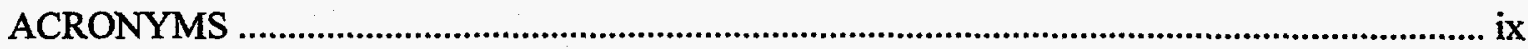

1. INTRODUCTION ..................................................................................................

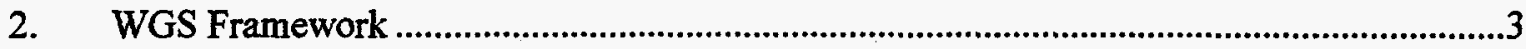

$2.1 \quad$ WGS Mission ....................................................................................................

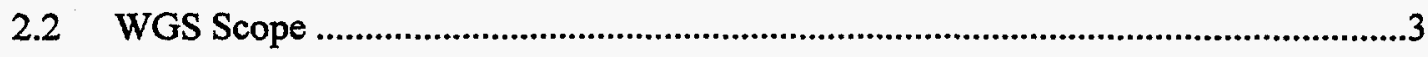

2.3 Work Breakdown Structure .........................................................................................

3. Improved Work Process..................................................................................................21

3.1 Process Flow Diagrams ..............................................................................................21

3.2 Waste Management Procedures...................................................................................27

3.3 Improvements in Laboratory Services......................................................................27

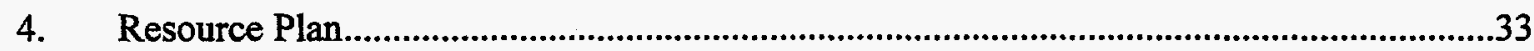

4.1 Organizational Breakdown Structure ……………….................................................3

4.1.1 Waste Characterization Chemistry and Determination .......................................33

4.1.2 Low-level Waste and Industrial Waste Management..........................................33

4.1.3 Hazardous and Mixed Waste Management ............................................................33

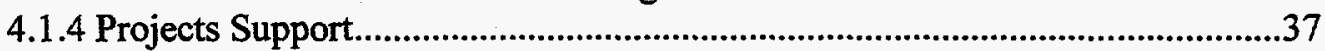

4.1.5 Technical Support....................................................................................................37

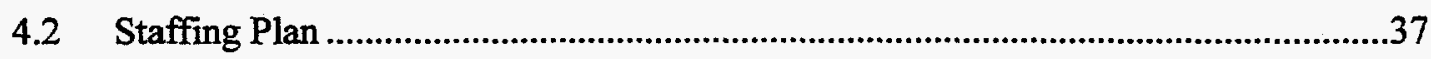

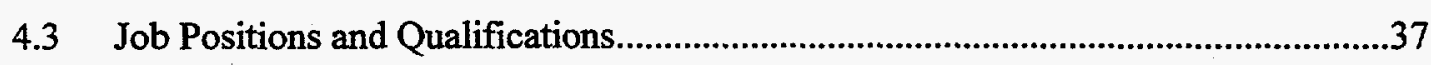

4.3.1 Waste Characterization Chemistry and Determination Facility Leads..............39

4.3.2 Low-level and Industrial Waste Management Supervisor.....................................40

4.3.3 Hazardous and Mixed Waste Management Supervisor ........................................41

4.3.4 Projects Support Supervisor ....................................................................................4

4.3.5 Technical Support Supervisor ............................................................................44

4.3.6 Characterization Chemist ......................................................................................45

4.3.7 RCRA Regulatory Specialist...............................................................................46

4.3.8 Deployment Manager ...................................................................................48

4.3.9 ES\&H Compliance Officer.....................................................................................50 


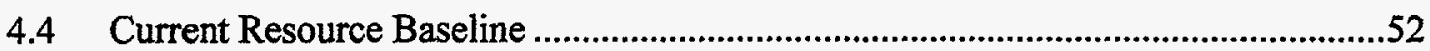

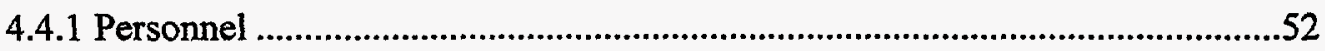

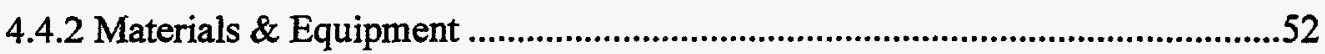

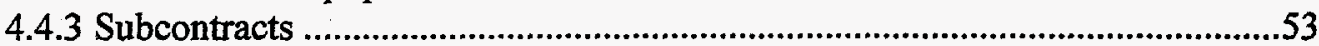

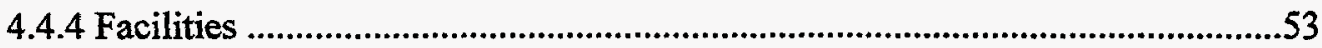

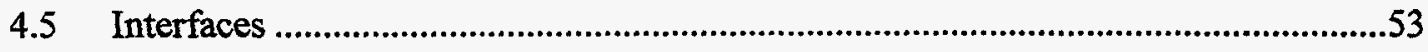

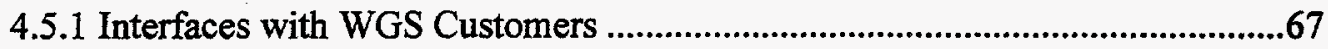

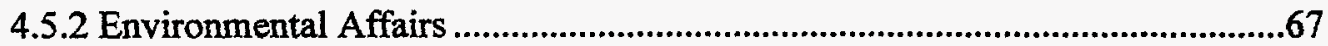

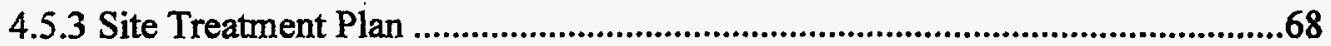

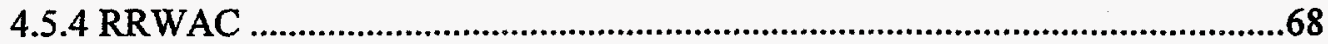

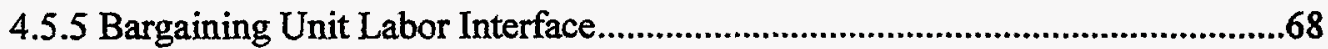

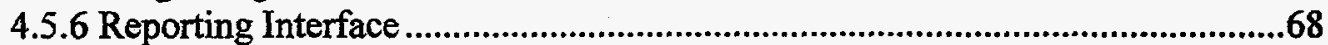

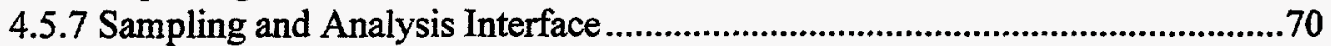

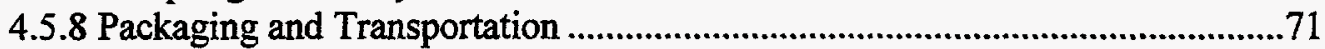

4.5.9 Safety \& Health Support................................................................................71

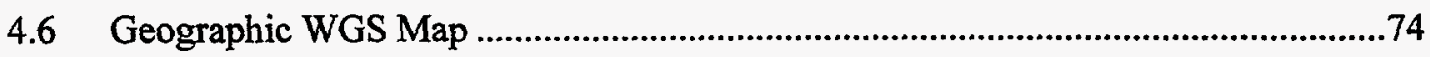

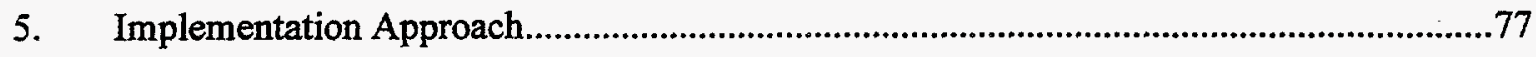

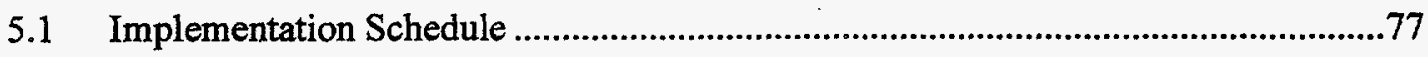

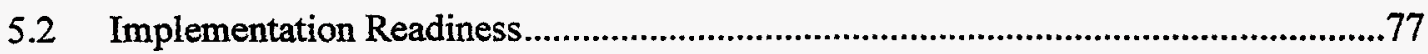

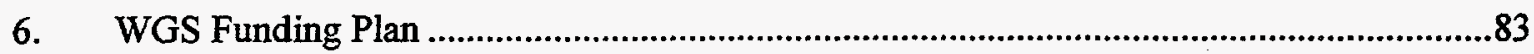

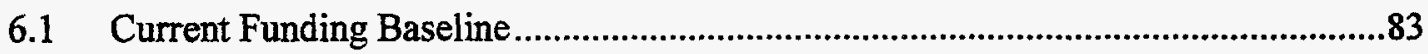

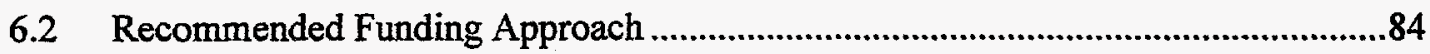

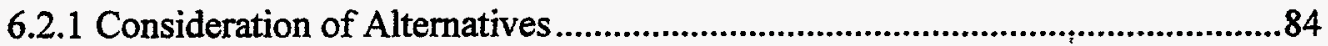

6.2.2 Recommendation for FY 1998 Funding Approach …..................................88

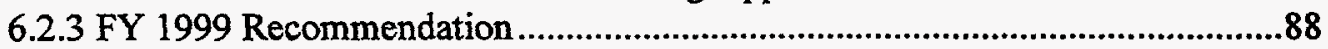

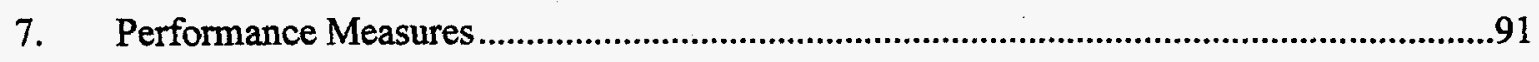

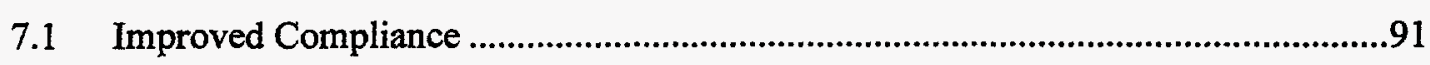

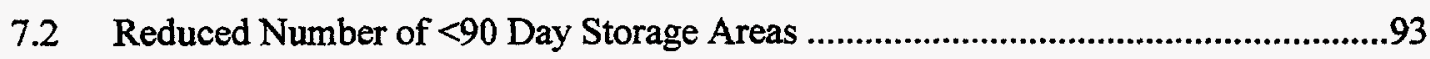

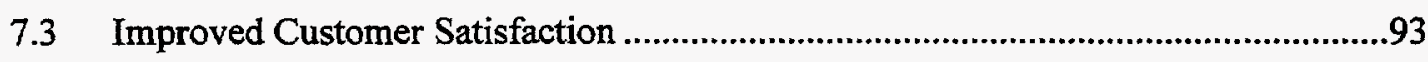

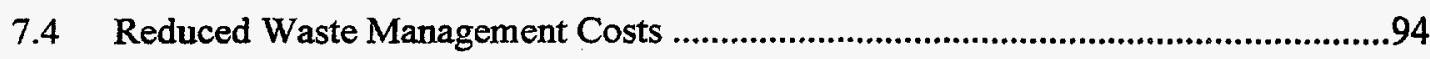




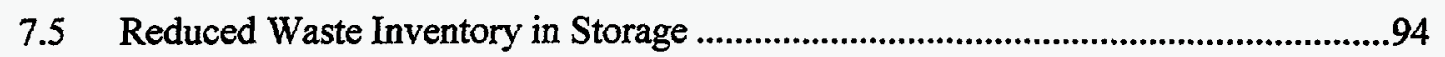

Appendix A - Personnel Currently Performing WGS Activities ...............................................95

\section{FIGURES}

Figure 2.1. Waste Generator Services Work Breakdown Structure.........................................5

Figure 3.1. Existing Process Flow - Waste Management .......................................................22

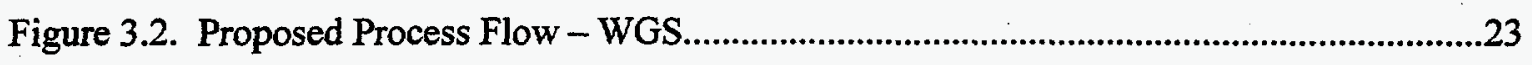

Figure 3.3. Newly-generated MLLW Process Flow Diagram.................................................25

Figure 4.1. Top Level Organization Chart. ................................................................................35

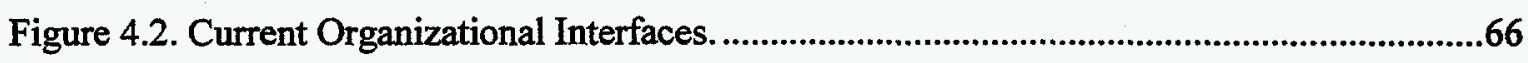

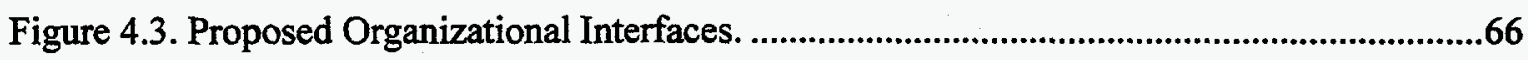

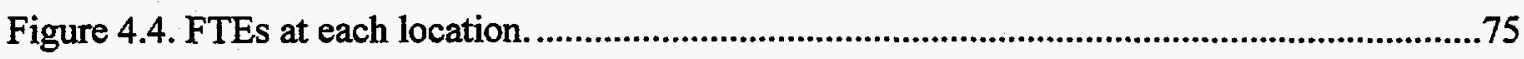

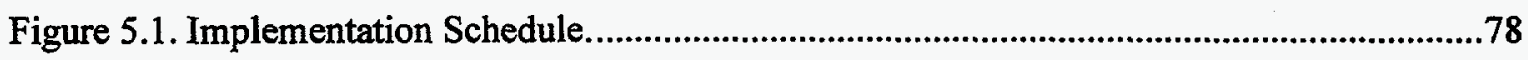

Figure 7.1. Number of Containers Exceeding the 90-day Storage Limit for TAAs......................93

\section{TABLES}

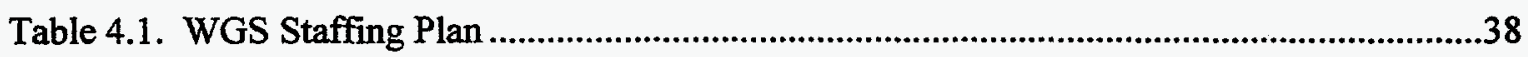

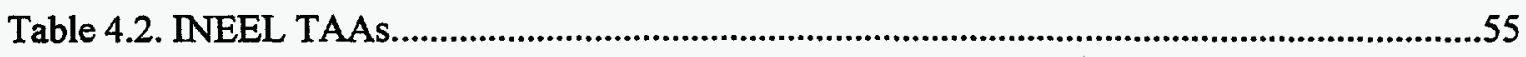

Table 4.3. Waste Generator Services Work Scope Transfer Matrix ...........................................72

Table 6.1. Current Costs for Projected WGS Activities..............................................................83

Table 7.2. Internal Audit Findings Associated with TAA Management. ...................................92 


\section{ACRONYMS}

\begin{tabular}{|c|c|}
\hline AEDL & Applied Engineering and Development Laboratory \\
\hline ALARA & as low as reasonably achievable \\
\hline ANL-W & Argonne National Laboratory-West \\
\hline AOC & area of contamination \\
\hline ASAP & Abbreviated Sampling and Analysis Plan \\
\hline BS & Bachelor of Science Degree \\
\hline CERCLA & Comprehensive Environmental Response, Compensation, and Liability Act \\
\hline CFA & Central Facilities Area \\
\hline CFR & Code of Federal Regulations \\
\hline CPP & (Idaho) Chemical Processing Plant \\
\hline D\&D & decontamination and decommissioning \\
\hline DOE & U.S. Department of Energy \\
\hline DOE-HQ & U.S. Department of Energy-Headquarters \\
\hline DOE-ID & U.S. Department of Energy-Idaho Operations Office \\
\hline DOT & U.S. Department of Transportation \\
\hline EFS & Environmental Field Support \\
\hline EM & Environmental Management \\
\hline EPA & U.S. Environmental Protection Agency \\
\hline ER & Environmental Restoration \\
\hline ES\&H & Environment, Safety and Health \\
\hline FTE & full-time equivalent \\
\hline FY & fiscal year \\
\hline G\&A & general and administrative \\
\hline ICPP & Idaho Chemical Processing Plant \\
\hline IH & Industrial Hygiene \\
\hline INEEL & Idaho National Engineering and Environmental Laboratory (after Jan 29, 1997) \\
\hline INEL & Idaho National Engineering Laboratory (before Jan 29, 1997) \\
\hline IPT & Integrated Process Team \\
\hline IS & Industrial Safety \\
\hline IWTS & (INEEL) Integrated Waste Tracking System \\
\hline LDR & land disposal restriction \\
\hline LLW & low-level waste \\
\hline LMITCO & Lockheed Martin Idaho Technologies Company \\
\hline MCP & Management Control Procedure \\
\hline MLLW & mixed low-level waste \\
\hline MOA & Memorandum of Agreement \\
\hline MS & Master's Degree \\
\hline MSDS & material safety data sheet (OSHA) \\
\hline MTS & Master Task Subcontract \\
\hline NOV & Notice of Violation \\
\hline NRF & Naval Reactors Facility \\
\hline OCAW & Oil, Chemical, and Atomic Workers (Union) \\
\hline OSHA & Occupational Safety and Health Administration \\
\hline P\&T & Packaging and Transportation \\
\hline PBS & Project Baseline Summary \\
\hline PCB & polychlorinated biphenyl \\
\hline PDD & Program Description Document \\
\hline PRD & Program Requirements Document \\
\hline
\end{tabular}


RCRA Resource Conservation and Recovery Act

RMA Radioactive Materials Area

RRWAC Reusable Property, Recyclable Materials, and Waste Acceptance Criteria

$S \& H$

SAA safety and health

SMC

SMO

SOW

Satellite Accumulation Area

SRMP

STP

Specific Manufacturing Capability

Sample Management Office

TAA

statement of work

Special Request Monitoring Program

TAN

Site Treatment Plan

TOS

Temporary Accumulation Area

Test Area North

TPR

Task Order Statement of Work

TRA

Technical Progress Review

TRU

Test Reactor Area

TSCA

TSD

TSDF

VPP

WAC

WBS

WCCD

WCT

WERF

WGI

WGS

WMA

WO

WROC

WTPP

transuranic

Toxic Substances Control Act

treatment, storage, disposal

treatment, storage, disposal facility

Voluntary Protection Program

waste acceptance criteria

Work Breakdown Structure

Waste Chemical and Characterization Determination

Waste Characterization Team

Waste Experimental Reduction Facility

Waste Generator Interface

Waste Generator Services

Waste Management Authority

Waste Operations

Waste Reduction Operations Complex

Waste Technology Planning and Project 


\section{Waste Generator Services Implementation Plan}

\section{INTRODUCTION}

Waste Generator Services (WGS) represents a step change solution for eliminating hazardous, low-level, industrial, and mixed waste compliance problems at the Idaho National Engineering and Environmental Laboratory (INEEL). These compliance problems have been and continue to be evidenced through the State of Idaho Division of Environmental Quality 1996 and 1997 Notices of Violation, the Lockheed Martin Corporate audits of INEEL waste generator facilities, and continuing waste management characterization and disposition work frustrations and emergency problems. WGS is a reengineering effort intended to streamline the waste acceptance process and to provide waste generators with turn-key waste management services through a single, accountable organization to manage and disposition wastes in a timely, cost-effective, and compliant manner. Successful implementation of the WGS approach at the INEEL will address the current waste-handling problems created by multiple organizational interfaces, poor definition of organization and personnel roles and responsibilities, limited organizational and personnel accountability, and unclear performance expectations.

The initial evolution of the WGS approach was developed by a core team funded through LMITCO Environmental Management Compliance Reengineering. Several waste management models were used in developing the WGS approach. These included the Department of Energy (DOE)-Hanford/Waste Management Federal Services integrated subcontract WGS approach, the Micron Technologies waste management system, other commercial practices, and DOE WGS programs established at Oak Ridge National Laboratory, Rocky Flats, and Lawrence Livermore National Laboratory. These concepts were tailored for INEEL implementation by an Integrated Process Team (IPT) comprised of representatives from the various organizations that are currently involved in or affected by the waste acceptance process.

The IPT meeting was held the week of January 19, 1998, with the objectives of understanding the problems related to the current waste acceptance process, and developing recommendations for improving the current process based around the WGS approach. The recommendations of the IPT were documented in the Waste Generator Services Integrated Process Team Recommendations Report, INEEL/INT-9800199. These recommendations form the basis for WGS implementation.

This report outlines the recommended strategy for implementing WGS at the INEEL. It defines the work that will be performed by WGS, the WGS organization and resources, the waste acceptance process flow, the funding approach, methods for measuring performance, and the implementation approach. WGS deployment is scheduled to begin at ICPP on June 1, 1998. Modifications to this plan are expected to occur through the WGS implementation period.

The prime objective of WGS will be to eliminate waste management noncompliance conditions. Other objectives include providing a streamlined approach to waste determination; providing an incentive for waste minimization, structuring a supplier/customer partnership between WGS and its customers, (the waste generators and the TSD); moving toward single-point accountability; and establishing a funding mechanism that is fair and workable, and cost-effective, overall.

The LMICO Senior Salary Review Board approved WGS for Implementation on March 11, 1998. 
0
0
0
0
0
0
0
0
0
0
0
0
0
0
0
0
0
0
0
0
0
0
0
0
0
0
0
0
0 


\section{WGS FRAMEWORK}

\subsection{WGS Mission}

The mission of WGS is to provide INEEL onsite and offsite waste generators with turn-key professional waste management services to disposition legacy and newly generated waste in a compliant, timely and cost-effective manner and to ensure all treatment/storage/disposal (TSD) waste acceptance criteria and other requirements are met.

\subsection{WGS Scope}

The WGS scope includes the waste management activities from the pre-generation planning phase, through acceptance at a TSD facility, and to ultimate waste disposition. The activities included in the WGS scope are shown on the process flow diagrams in Section 3 of this report.

The only waste types that are excluded from the WGS scope are:

- CERCLA waste management within the Area of Contamination (AOC). (WGS expertise may be used on a consulting basis.),

- Sanitary waste destined for the sewage plant (sludge generated by the sewage plant is included in WGS),

- Cafeteria and office waste,

- High-level waste,

- TRU waste, and

- Spent fuel.

Due to the need for consistent waste management practices, WGS may provide guidance and assist in implementation of waste management options for HLLW, TRU, and SNF on an as-needed basis. Certain functions for industrial waste will be retained by Industrial Waste Landfill Operations. This responsibility split will be finalized with the detailed process flow diagram. The process flow diagram for this waste type has not yet been finalized.

All other waste types are included in the WGS scope. The following waste types (or potential wastes) included in the WGS scope are listed for clarity.

- LLW,

- MLLW

- Hazardous waste,

- Special-Case wastes, 
- Recyclable materials,

- Excess materials,

- Liquid waste that remains in the facility, and

- Industrial waste.

Waste types not included may be reconsidered after the WGS organization and process has been established and is operational.

WGS will work both legacy and newly-generated waste. For legacy waste, this will include containerized wastes and exclude bulk-type wastes at facilities (i.e., stored in tanks).

WGS is also responsible for several support activities that are necessary for proper management of the waste. These include the selection of offsite TSDFs and the associated subcontract management, management of the Integrated Waste Tracking System (IWTS), and maintenance of the INEEL Reusable Property, Recyclable Materials, and Waste Acceptance Criteria (RRWAC), administration of waste management procedures, waste forecasting and reporting, the INEEL Site Treatment Plan, waste container management, and Special-Case performance acceptance.

\subsection{Work Breakdown Structure}

The Work Breakdown Structure for WGS is shown in Figure 2.1. The following Work Breakdown Structure dictionary sheets describe each major element. 


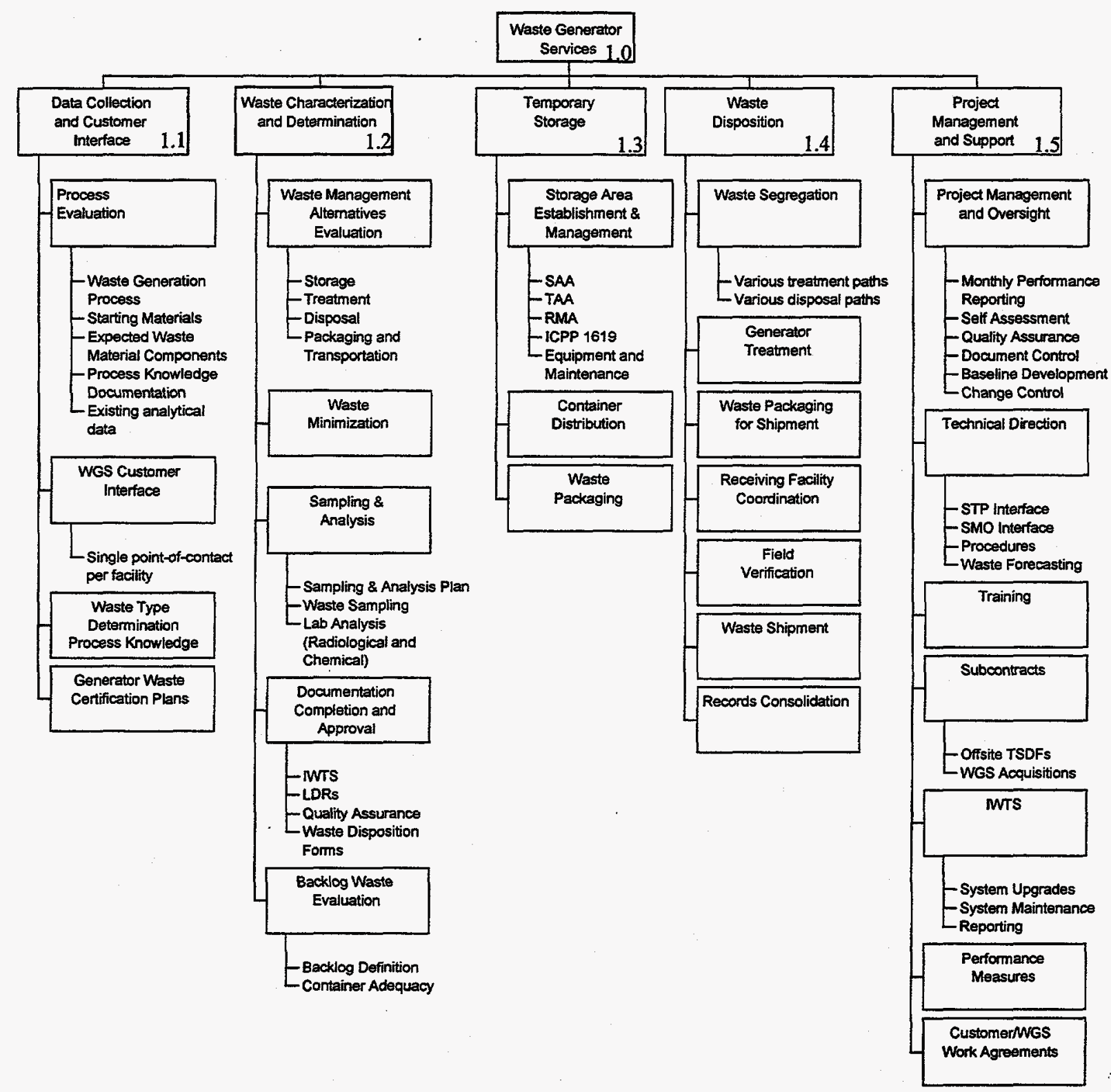

Figure 2.1. Waste Generator Services Work Breakdown Structure. 


\begin{tabular}{|c|c|}
\hline 1. WBS Element Code: 1.0 & $\begin{array}{l}\text { 2. WBS Element Title: Waste Generator } \\
\text { Services }\end{array}$ \\
\hline 3. Date: & 4. Project Title: Waste Generator Services \\
\hline \multicolumn{2}{|l|}{ Element Description } \\
\hline \multicolumn{2}{|c|}{$\begin{array}{l}\text { Conduct waste management activities from the pre-generation planning phase to ultimate disposition, } \\
\text { retaining overall responsibility for waste movement through the treatment, storage, and disposal (TSD) } \\
\text { facility(ies) to final dispositioning. (The TSD facilities are responsible for compliant waste } \\
\text { management within their facilities). Provide waste generators with waste management services as a } \\
\text { turnkey operation. }\end{array}$} \\
\hline \multicolumn{2}{|c|}{ Work Included: } \\
\hline \multicolumn{2}{|c|}{ 1) Provide waste acceptance services for all waste types except: } \\
\hline \multicolumn{2}{|c|}{$\begin{array}{l}\text { - CERCLA waste management within the Area of Contamination (AOC). WGS expertise may be } \\
\text { used on a consulting basis, } \\
\text { - Sanitary waste destined for the sewage plant (sludge generated by the sewage plant is included in } \\
\text { - High-level waste, } \\
\text { - TRU waste, } \\
\text { - Spent fuel, and } \\
\text { 2) Plan for management of each waste stream prior to generation to ensure that treatment, storage, } \\
\text { and disposal alternatives exist. }\end{array}$} \\
\hline \multicolumn{2}{|c|}{ 3) Characterize the waste by completing appropriate waste determination activities and } \\
\hline \multicolumn{2}{|c|}{ 4) Provide temporary storage for waste awaiting treatment or disposal. } \\
\hline \multicolumn{2}{|c|}{ 5) Verify that the waste meets the Waste Acceptance Criteria for the receiving facility. } \\
\hline \multicolumn{2}{|c|}{ 6) Arrange for shipment of the waste to the receiving facility. } \\
\hline \multicolumn{2}{|c|}{ 7) Provide the necessary project management activities to support WGS. } \\
\hline \multicolumn{2}{|c|}{ 8) Provide support activities, such as waste tracking and subcontract management, as required. } \\
\hline \multicolumn{2}{|l|}{ Customers: } \\
\hline \multicolumn{2}{|l|}{ 1) INEEL Waste Generators } \\
\hline \multicolumn{2}{|l|}{ 2) Offsite Waste Generators } \\
\hline \multicolumn{2}{|l|}{ 3) Department of Energy } \\
\hline \multicolumn{2}{|l|}{ 4) TSDFs } \\
\hline \multicolumn{2}{|l|}{ Products: } \\
\hline \multicolumn{2}{|l|}{ 1) Waste Disposition Forms } \\
\hline \multicolumn{2}{|l|}{ 2) Definition of waste backlog } \\
\hline \multicolumn{2}{|l|}{ 3) Waste Type Determinations } \\
\hline \multicolumn{2}{|l|}{ 4) RRWAC and Waste Management Procedures } \\
\hline \multicolumn{2}{|l|}{ 5) Performance measures } \\
\hline \multicolumn{2}{|l|}{ 6) Sampling and Analysis Plans } \\
\hline \multicolumn{2}{|c|}{ 7) Sampling and Analysis Results } \\
\hline \multicolumn{2}{|c|}{ 8) Waste Characterization/Determination Documentation } \\
\hline \multicolumn{2}{|c|}{ 9) Compliant temporary storage areas } \\
\hline
\end{tabular}


10) Properly packaged, marked, and labeled waste

11) Schedule coordinated with the receiving facility

12) Verification that waste meets waste acceptance criteria

13) Waste packaged, labeled, and shipped

14) Consolidated records for the waste stream

15) Current cost and schedule baseline

Work Excluded:

1) Subcontracting for laboratory services

2) Management of Satellite Accumulation Areas

3) Storage and treatment of wastes at TSDFs

\section{Interfaces:}

1) The waste generator and the receiving facilities are the customers of WGS. Interfaces exist with the waste generator for activities early in the process, and with the receiving facility later in the process.

2) Additional organizational interfaces include Environmental Affairs, Packaging and Transportation, Procurement, Radiological Controls, and the Sample Management Office.

Bases and Assumptions:

1) The product of this step, the Waste Disposition Form, will be understood and agreed to by the source and WGS.

2) Treatment, storage, and/or disposal options will be determined prior to waste generation. If treatment, storage, and/or disposal options do not exist for a waste stream, it will not be generated.

3) RCRA waste determinations and radiological analysis requirements will be standardized.

4) Current procedures and forms will be streamlined and standardized.

5) Lab turnaround time will be monitored and shortened.

6) WGS will have flexibility to determine the level of detail required in the analytical data.

7) Appropriate temporary storage can be established and will be accessible.

8) TAA management will be transferred to WGS.

9) WGS will perform all activities necessary to ensure that the waste meets the acceptance criteria. The receiving facility will not double-check that waste meets the waste acceptance criteria.

10) All transfers to a receiving facility will occur through WGS.

11) WGS reports to Waste Operations, and the cost and schedule control procedures for Waste Operations apply.

12) Waste stream records will be consolidated. 


\begin{tabular}{|ll|l|}
\hline 1. WBS Element Code: & 1.1 & $\begin{array}{l}\text { 2. WBS Element Title: Data Collection and } \\
\text { Customer Interface }\end{array}$ \\
\hline 3. Date: & $3 / 14 / 98$ & 4. Project Title: Waste Generator Services \\
\hline
\end{tabular}

\section{Element Description}

Collect waste data from the source and perform initial waste determination based on process knowledge. Provide single point-of-contact for the facility customer.

Work Included:

1) Collect all existing data on the waste stream to be generated including process knowledge information, MSDS information, and any existing analytical data.

2) Complete Process Knowledge Evaluation and initial waste determination to determine which waste type the waste stream fits into. Work with the source to:

-Identify the waste generation process,

-Identify the starting materials,

-Define expected waste material components, and

-Provide documentation of process knowledge.

3) Provide single point-of-contact interface for all WGS work at the facility.

4) Coordinate and maintain generator waste certification plan for the facility.

Customers:

1) INEEL Waste Generators

2) Offsite Waste Generators

3) WGS Waste Technical Specialist

4) Department of Energy

5) TSDFs

\section{Products:}

1) Process Knowledge documentation

2) Waste Type Determination

3) Generator Waste Certification Plan

\section{Work Excluded:}

\section{Interfaces:}

1) This element provides the critical single point-of-contact interface with the generator.

2) The process knowledge information documented through this element provides the basis for the Waste Characterization and Determination element.

3) The primary organizational interface required for this element is between the source and the WGS representative. Additional interfaces may include regulatory specialists and waste minimization. 


\section{Bases and Assumptions:}

1) This step will be incorporated into the project or activity schedule.

2) The source will understand their responsibility in working with WGS to provide required information on the waste.

3) Waste Generator Certification Plans will be maintained for each generator. 


\begin{tabular}{|ll|l|}
\hline 1. WBS Element Code: & 1.2 & $\begin{array}{l}\text { 2. WBS Element Title: Waste Characterization } \\
\text { and Determination }\end{array}$ \\
\hline 3. Date: & $3 / 14 / 98$ & 4. Project Title: Waste Generator Services \\
\hline
\end{tabular}

\section{Element Description}

Characterize the waste, including any necessary sampling and analysis, and document this characterization. Complete appropriate waste determination activities and documentation.

\section{Work Included:}

1) Based on the process knowledge evaluation completed in WBS Element 1.1, determine if waste can fit into an existing profile,

2) Determine if the waste can be eliminated or minimized by considering;

- Why the waste is being generated,

-What alternatives exist to generating this waste,

- Can generator treatment be used effectively,

-What regulatory constraints exist relative to minimizing the waste.

3) Complete and approve a Waste Disposition Form that includes the following type of information.

4) Evaluate what regulations will apply and whether the waste stream needs to be added to the Site Treatment Plan,

5) Evaluate alternatives for management of the waste by considering:

- how and where will the waste be generated,

- what are the anticipated end products (volume and characteristics),

- available pathways for treatment, storage, and disposal,

- the need for treatability studies, and

- packaged and transportation requirements.

6) Obtain and analyze waste samples only as necessary when insufficient process knowledge exists:

- Determine what sampling and analysis is required,

- write the abbreviated sampling and analysis plan (ASAP) including data quality objectives and sampling parameters

- consider alternatives, such as field screening, to meet analytical needs

- include radiological and hazardous constituent analyses

- Obtain laboratory services, working with the Sample Management Office to establish umbrella subcontracts for WGS sampling/analytical services personnel,

- Take samples as early in the process as possible,

- Ship samples the laboratory and track samples,

- Obtain results from laboratory,

- Receive and disposition sample returns, and

- Complete data validation, if needed. 
7) Complete and approve waste determination/characterization documentation (if not previously completed through process knowledge data).

- Complete IWTS entries,

- Assign LDRs,

-Evaluate "No Radioactivity Added" status per the Hazardous Waste Shipping Moratorium requirements,

- Complete DOT classification, and

- Determine if the waste disposition pathway is still appropriate based on any information gained through the sampling and analysis steps, and make changes if necessary.

8) For waste currently in storage (backlog waste), finalize the definition of "backlog" and reach agreement with company management and DOE.

9) Verify container adequacy for backlog wastes.

\section{Customers:}

1) INEEL Waste Generators

2) Offsite Waste Generators

3) Department of Energy

4) Onsite and offsite TSDFs

\subsection{Products:}

1) Waste Disposition Form, with supporting documentation, agreed to by the source (waste generator) and the Waste Generator Services representative.

2) Waste Minimization Evaluation

3) Sampling and Analysis Plan

4) Sampling and Analysis Results

5) Sampling Documentation (logbooks, chain-of-custody's, shipping documents)

6) Waste Characterization/Determination Documentation

7) IWTS Material and Container Profiles

8) Definition of waste backlog.

9) Identification of mixed waste in the Site Treatment Plan.

\section{Work Excluded:}

1) Subcontracting for laboratory services is managed through the Sample Management Office. Waste Generator Services will use these umbrella subcontracts.

\section{Interfaces:}

1) The waste characterization information gained through this work element is the basis for storage, treatment, and disposal. The Waste Disposition Form documents the waste management process for the waste stream. 
2) Organizational interfaces for this step exist with the Sample Management Office, RadCon, Packaging and Transportation, and Regulatory Specialists for special situations.

\section{Bases and Assumptions:}

1) Once waste disposition decisions are made, they will not be "second-guessed" or changed except through change control to the Waste Disposition Form.

2) The Waste Disposition Form will be understood and agreed to by the source and WGS.

3) If treatment, storage, and/or disposal options do not exist for a waste stream, it will not be generated.

4) Planning will be flexible to allow for varying levels of rigor for different waste types.

5) Waste determination documentation initiated early in the process is supplemented throughout the process, eliminating the multiple sets of documentation currently required.

6) RCRA waste determinations and radiological analysis requirements will be standardized.

7) Current procedures and forms will be streamlined and standardized.

8) Alternate methods to meet analytical needs may be feasible if the data is acceptable and qualified personnel perform field screening.

9) Resources will be available within WGS to physically sample the waste and provide needed support functions.

10) Umbrella subcontracts/task agreements will be set up by the Sample Management Office and will allow quick access to lab services.

11) Lab turnaround time will be monitored and shortened.

12) Samples that must be returned will be managed in a timely and compliant manner.

13) A strong working relationship will be established between WGS, the Sample Management Office, and the labs.

14) WGS will have flexibility to determine the level of detail required in the analytical data.

15) Data validation will be performed when necessary and only to the level required (Level B, C, or X will be specified in almost all instances).

16) Reducing data deliverables requirements (i.e., requesting Tier 3 data packages) will improve turnaround time.

17) The Waste Technical Specialists will have access to the Idaho Mixed Waste Information System for information related to the Site Treatment Plan. 


\begin{tabular}{|ll|l|}
\hline 1. WBS Element Code: & 1.3 & 2. WBS Element Title: Temporary Storage \\
\hline 3. Date: & $3 / 14 / 98$ & 4. Project Title: Waste Generator Services \\
\hline
\end{tabular}

\section{Element Description}

Provide temporary storage for wastes awaiting treatment or disposal. Manage the temporary storage facility and track the waste in temporary storage.

\section{Work Included:}

1) Work with the source to establish temporary storage areas including Satellite Accumulation Areas (SAAs), and manage Temporary Accumulation Areas (TAAs) or less-than-90-day storage areas, and TSCA storage areas. Coordinate efforts with source for other waste management storage areas including RMAs, CERCLA storage, etc.

2) Distribute appropriate containers for the waste to the source.

3) Package, bulk, labpack, mark, and label the waste.

4) Move waste to the appropriate storage area:

- Source places waste in an SAA,

- WGS picks up waste and moves it to a TAA, or

- WGS or the organization that manages that storage facility moves waste to another type of storage (CERCLA, TSCA, RMA, etc.).

5) Manage storage area per requirements

- Source manages SAAs, RMA, and CERCLA storage. (Note: WGS may operate some of these storage facilities through agreement with the source.)

- WGS manages TAAs and TSCA storage areas, and tracks all waste in these storage areas.

\section{Customers}

1) INEEL Waste Generators

2) Department of Energy

3) INEEL Treatment, Storage, and Disposal Facilities

4) Offsite TSDFs 

Products:
1) Compliant temporary storage areas
2) Tracking systems for waste in temporary storage
3) Waste containers supplied to source
4) Properly packaged, marked, and labeled waste

\section{Work Excluded:}

1) The source manages SAAs and the majority of the RMA and CERCLA storage areas. WGS will only manage these types of storage areas if a specific situation warrants this.

\section{Interfaces:}

1) Temporary storage will be based upon the approved Waste Disposition Form.

2) WGS will interface with facility operations to establish locations for storage areas.

\section{Bases and Assumptions:}

1) Appropriate temporary storage can be established and will be accessible.

2) Proper scheduling between WGS and the source must occur.

3) TAA management will be transferred to WGS.

4) A consistent tracking system (IWTS) will be used.

5) IWTS entries will occur at the TAA or other temporary storage locations. 


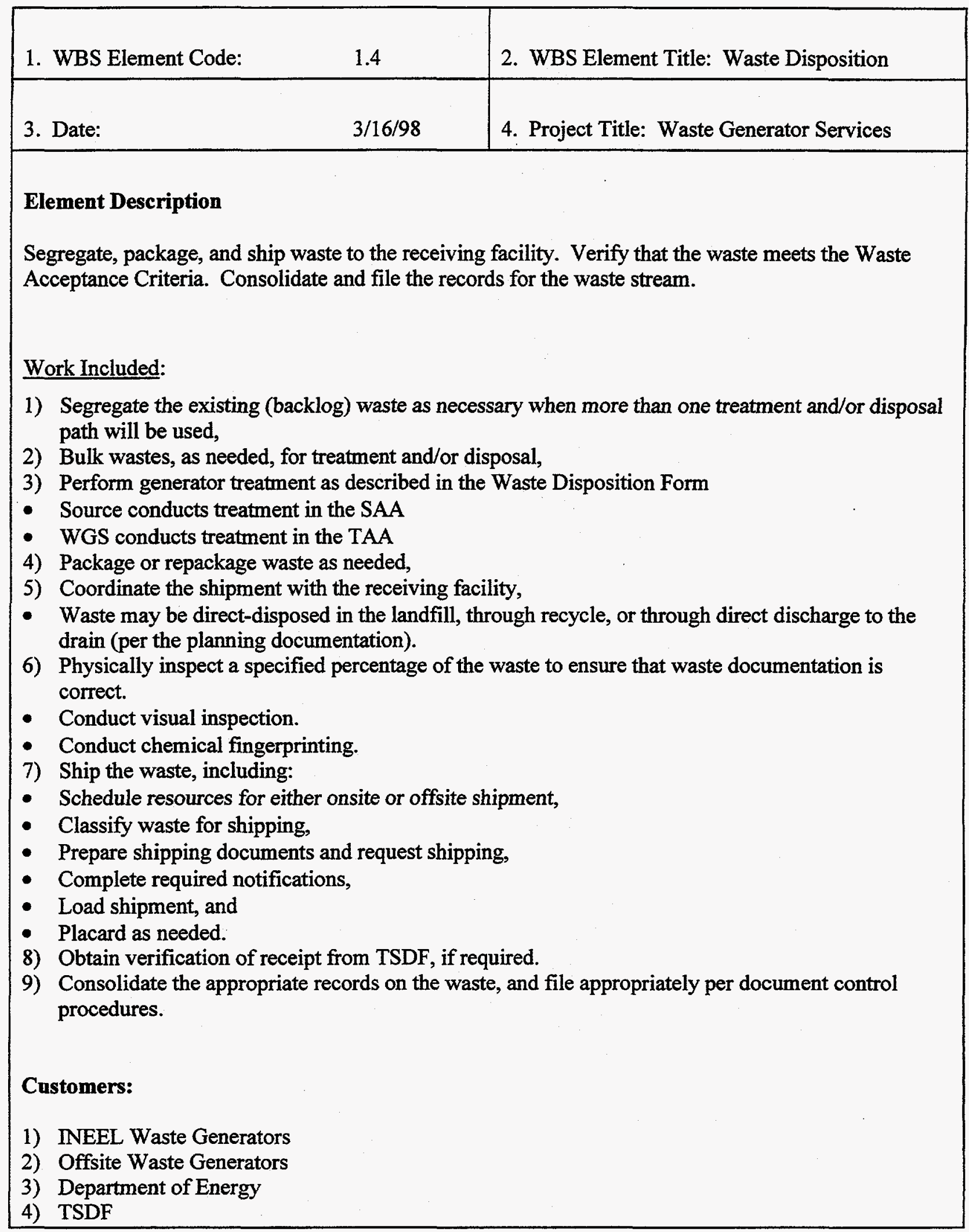




\section{Products:}

1) Coordinated schedule with the receiving facility

2) Verification that waste meets waste acceptance criteria

3) Waste treated using generator treatment, if appropriate

4) Waste packaged, labeled, and shipped

5) Finalized electronic waste and container profiles

6) Documentation verifying receipt at TSDF, if applicable

7) Consolidated records for the waste stream

\section{Work Excluded:}

1) Source performs generator treatment in the SAA. If generator treatment is required at the TAA, WGS will perform this function.

2) Shipments are generally performed by matrixed resources obtained through Packaging and Transportation. As Packaging and Transportation personnel are deployed at source locations, a matrix agreement will be developed to use the people in part-time capacity for waste shipments.

\section{Interfaces:}

1) The Waste Disposition element completes the activities listed in the Waste Disposition Form. Waste will generally be in temporary storage prior to shipment to the receiving facility.

2) The key organizational interface is with the onsite or offsite receiving facility. The Packaging and Transportation interface is also crucial to this work element.

Bases and Assumptions:

1) Packaging and Transportation experts are closely associated with, or work within, WGS.

2) Redundancy in the 435 forms is eliminated.

3) The receiving facility only checks that the shipment matches the waste manifest, chain of custody and shipping documentation. WGS will have previously performed all analyses to ensure that the waste meets the acceptance criteria. The receiving facility will not double-check that waste meets the waste acceptance criteria.

4) Independent verification by WGS will allow separate process assessments to be minimized or eliminated. Additional process assessments are minimized when the verification step is added to ensure that the overall process is cost-effective.

5) A defensible process is developed for waste verification after generation of the waste.

6) All transfers to a receiving facility must occur through WGS.

7) Waste stream records will be consolidated. 


\begin{tabular}{|ll|l|}
\hline 1. WBS Element Code: & 1.5 & $\begin{array}{l}\text { 2. WBS Element Title: Project Management and } \\
\text { Support }\end{array}$ \\
\hline 3. Date: & $3 / 16 / 98$ & 4. Project Title: Waste Generator Services \\
\hline
\end{tabular}

\section{Element Description}

Conduct the project management activities necessary to properly manage the work completed by WGS. Provide cost and schedule control, staff training, technical direction, and support activities such as waste tracking and subcontract management. Interface with LMITCO management and DOE.

\section{Work Included:}

1) Provide overall project management and oversight including:

- Monthly performance reporting

- Self-Assessment

- Quality Assurance

- Performance Measurement

- Document Control

2) Provide technical direction for WGS such as:

-Interface with the Site Treatment Plan

- Interface with the Sample Management Office to develop and maintain analytical laboratory subcontracts

-Preparation and maintenance of required procedures

-Waste Forecasting

3) Control the WGS cost and schedule

4) Provide required staff training including:

- Development of a training program

- Develop individual training plans

-Implement the training program

5) Manage subcontracts for use of offsite treatment, storage, and disposal facilities. Coordinate specifications and procurement acquisitions of WGS consumables.

6) Manage the INEEL Waste Tracking System including:

-System upgrades 
- System administration (hardware, software, installation, maintenance)

- Uniform waste data reporting

- Data and database administration (data QA, user support)

7) Performance measures, tracking and reporting

8) Waste volume forecasting

\section{Customers:}

1) INEEL Waste Generators

2) Offsite Waste Generators

3) WGS personnel

4) Department of Energy

5) TSDFs

\section{Products:}

1) Cost, scope, schedule baselines

2) Cost, scope, and schedule performance reporting

3) Properly-trained staff

4) Uniform waste data reporting

5) Waste production forecasts

6) Performance measures reporting

7) WGS/customer workscope agreements

8) Waste tracking

9) INEEL STP

10) Waste management procedures

11) Required reports

\section{Work Excluded:}

1) Procurement is responsible for awarding subcontracts for offsite TSD services; WGS provides the technical input, including developing the SOW and draft RFP, and performing facility audits.

\section{Interfaces:}

1) This element provides the project management and technical direction for all of the work under WGS.

2) Interfaces with the Sample Management Office and other organizations such as Environmental Affairs are included in this work element.

3) The subcontract management portion of this work element covers interfaces with offsite TSD facilities. 
Bases and Assumptions:

1) WGS reports to Waste Operations, and the cost and schedule control procedures for Waste Operations apply.

2) The INEEL Waste Tracking System will be the only waste tracking system used at the INEEL. 


\section{IMPROVED WORK PROCESS}

\subsection{Process Flow Diagrams}

Based upon problems identified in the existing waste management process, lessons learned from commercial waste management process reviews, and recommendations from the IPT reviews, the existing waste management process was significantly revised.

The existing process flow is summarized in Figure 3.1. Task boxes are color-coded indicating organizational responsibility. This flow chart indicates two significant problems. First, there is no single-point accountability except on the part of the waste generator, who is responsible for coordinating each of the functions with the external organizations. Second, there are two independent waste approval processes. The first is the Waste Management Authority (WMA) or equivalent pre-generation review process and the second is the Waste Generator Interface (WGI). The WMA approves waste generation by reviewing existing waste characterization data and specifying additional analysis with the objective of proper waste determination. The WGI function approves a waste stream for TSD acceptance based upon existing waste management data and specifies additional analysis needed to document compliance with the specific waste acceptance receipt criteria. These two functions were to be better integrated through application of the 435.28 waste determination form. However, due to numerous redundancies in the 435 series forms, full implementation was deferred until after implementation of WGS.

The proposed process flow is summarized in Figure 3.2. Task boxes are again color-coded indicating organizational responsibility. The interfaces for performing tasks have been minimized. The WGS organization performs a majority of the work. Interfaces only exist in the waste planning step with the waste generator, with lab services, and with scheduling and waste receipt at the TSD.

Objectives for revising the existing process include:

1) aligning personnel with a given waste stream such that they have responsibility and accountability for the waste stream from preplanning through final disposition,

2) incorporating waste stream pre-planning and approval including the waste minimization review,

3) eliminating redundant functions,

4) eliminating multiple verification and reviews, and

5) maintaining one generator/customer interface per facility that would act as a single point-ofcontact.

Implementation of this approach will realign the independent functions of waste determination, WMA approval, and WGI TSD approval into single-point accountability for a given waste stream. This approach supports LMITCO's goal of obtaining ISO 14000 certification.

Waste management process flow diagrams were developed for three of the waste types for which WGS will be responsible. One process flow diagram for mixed waste is included in this document as Figure 3.3 to show the improved flow and incorporation of the above-listed objectives. This diagram is representative of the other diagrams. The process flow diagrams will be the basis for the waste management waste type procedures to be developed for WGS. 


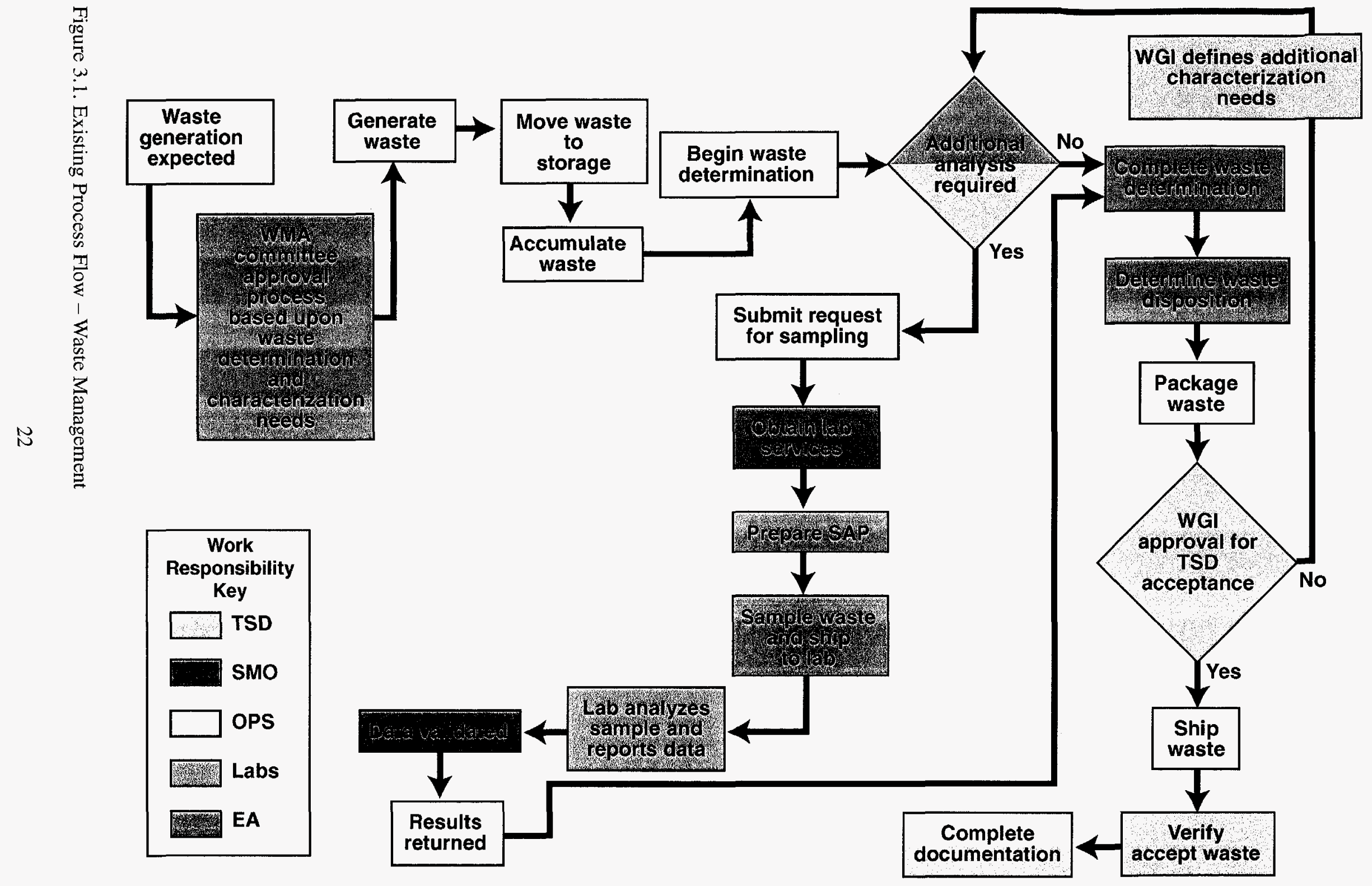




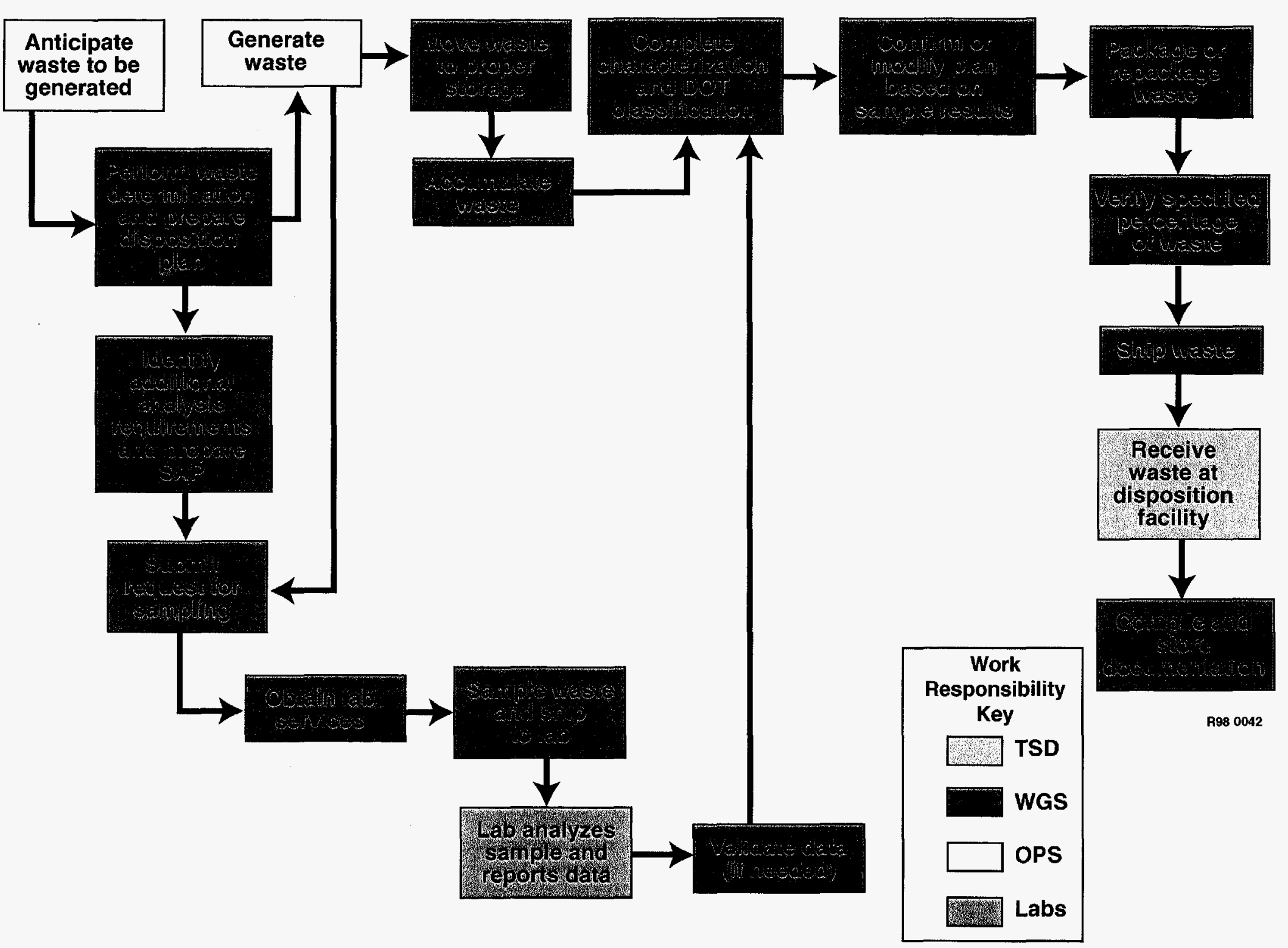


THIS PAGE INTENTIONALLY LEFT BLANK 


\section{WGS WCCP} Rep/Source gather process knowledge waste data

Facility EC

interface

- Identify process

- Identify starting

materials

- Define expected

waste components

- Obtain

documentation

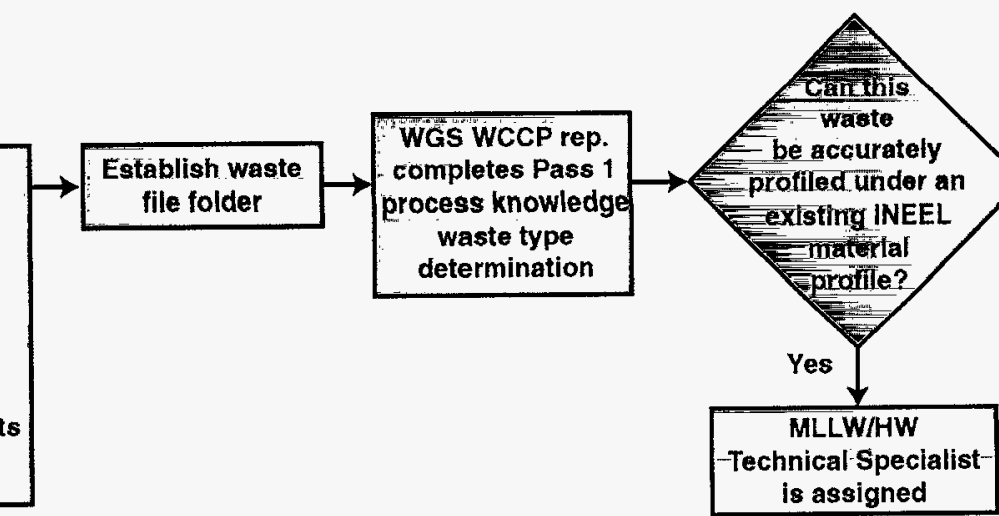

Obtain STP ID\#

for mixed waste

If additional analysis

is specified in the

Waste Disposition

form, WGS

prepares SAP
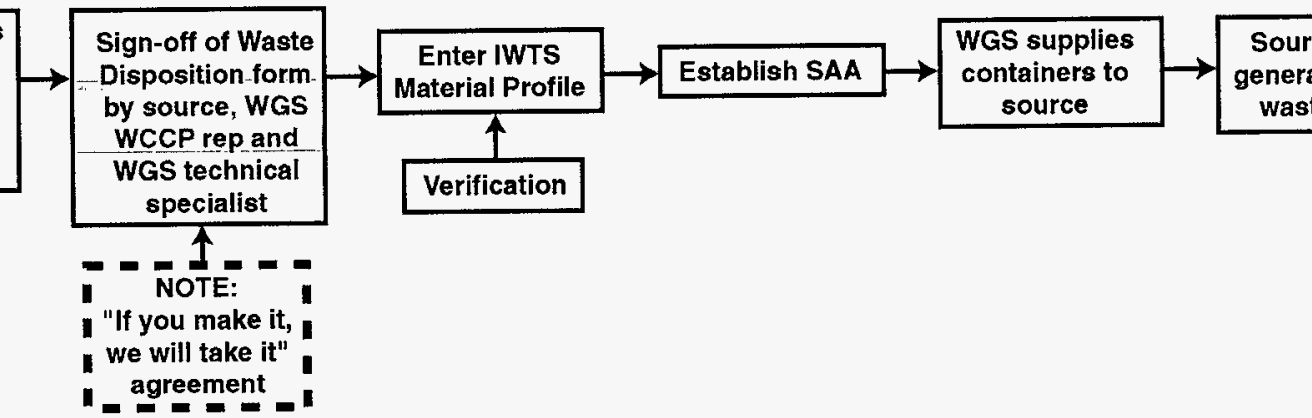
THIS PAGE INTENTIONALLY LEFT BLANK 
These flow diagrams depict how waste will be managed under WGS. The MLLW flow diagram has been color-coded to represent the organization or sub-organization responsible for the task. During the implementation phase of WGS, these flow diagrams will undergo further revision to ensure all necessary aspects of the waste management process have been incorporated and the process streamlined to the extent possible. Flow diagrams will be modified to incorporate legacy waste. These diagrams will be incorporated into the procedures for work performance.

\subsection{Waste Management Procedures}

The WGS team compiled the existing operating procedures including MCPs, PDDs, PRDs, TPRs, from across the INEEL that have been written and are in effect for waste management work. This list of procedures is presented in Table 3.1. This list of procedures, which have not been validated as the comprehensive list, are provided in this text to demonstrate the need for a consolidated, uniform set of procedures for waste management. These procedures will need to be validated, reviewed, and revised or eliminated based upon the standardized procedures developed by WGS for the waste management work. A subgroup of the WGS implementation team will be responsible for preparing the required uniform procedures for implementation at ICPP, (and other facilities upon WGS deployment) and making recommendations for changes to the existing procedures.

The waste management standardized procedures are to be developed around waste type, and will match the proposed process flow for each waste type. WGS will control these procedures after issue

The requests for sampling and analysis will be made by the waste technical specialists only after review of the available process knowledge. The goal is to obtain adequate process knowledge for waste characterization and minimize the amount of analysis performed. If analytical data is required, the waste technical specialist will specify analytical requirements in accordance with TSD WAC, waste determination needs, and the master task order and umbrella task order subcontract requirements. The goal of WGS-requested laboratory services will be a 21-day turnaround. Work practices and alternatives will be structured toward meeting this goal.

\subsection{Improvements in Laboratory Services}

In 1997, laboratory turnaround time was identified as a significant bottleneck for timely waste characterization. As a result, the INEEL Sample Management Office (SMO) has initiated several measures to reduce the time frame associated with analytical work.

Umbrella Task Order Statements of Work (TOSs) have recently been established for the Special Request Monitoring Program, which conducts the majority of waste characterization sampling at the INEEL. This measure should allow the sampling organization to make arrangements for analytical services directly with a number of subcontracted laboratories. Prior to the implementation of the umbrella TOSs, sampling and analysis was often delayed pending preparation of individual task order statements of work for each sampling activity.

The SMO has also delegated activities such as sample tracking and initial data completeness review to the Special Request Monitoring Program, eliminating additional process bottlenecks. The SMO has also approved the use of a new data deliverable, with a more flexible format that should reduce laboratory turnaround time. This was implemented at the suggestion of the laboratories, who reported that significant time was spent formatting the analytical data to meet INEEL specifications. 
Despite these improvements, there are still some issues that need to be addressed before the laboratory turnaround problem can be resolved.

A significant factor affecting lab turnaround time has been inadequate lab capacity due to the unanticipated closure of several subcontracted laboratories. For example, although an inorganic TOS has been established, the SRMP has not yet been able to utilize this laboratory because it is not accepting samples due to overcommitments. Also, it is often not possible to obtain a 21-day turnaround from the subcontracted laboratories due to laboratory workloads.

The SMO is currently evaluating the use of DOE laboratories at Hanford, Grand Junction, and Oak Ridge to alleviate this problem. In addition, the SMO is working to add analysis capabilities at the current master task subcontracted laboratories. For example, if a laboratory presently has a subcontract for organics analyses only, and that laboratory also has the capability to perform inorganics analyses, the inorganics analyses would be added to the existing subcontract. This measure will allow the SMO to quickly add three or four laboratories to the master task subcontract. The analytical services master task subcontract will be re-bid in late FY 1998, and the SMO hopes to significantly expand the number of available offsite laboratories at that time.

An additional need in the laboratory services area is a TOS for high-radioactivity samples. Although this need was identified over a year ago, TOSs cannot be prepared before award of a Master Task Subcontract (MTS) for these services. Preparing a statement of work and a Request for Proposal for a MTS requires extensive time and manpower, and the SMO workload has not allowed them to complete this task. Establishing this MTS has been further delayed due to the limited availability of acceptable laboratories doing this type of work. 
Table 3.1. Procedures Across the INEEL for Waste Management Activities.

\begin{tabular}{|c|c|c|}
\hline \multicolumn{3}{|c|}{$\begin{array}{c}\text { Procedures Across the INEEL for Waste Management } \\
\text { Activities }\end{array}$} \\
\hline Process & Procedure & Procedure \\
\hline Step & Number & Name \\
\hline \multirow[t]{17}{*}{ Overall } & AEDL-CE-04 & Excess Chemical, Recyclable, and Waste Management \\
\hline & CPP-PDD-3 & Waste Certification Program \\
\hline & CPP-PSD-4.4 & Solid Waste Management \\
\hline & $\begin{array}{l}\text { CPP-TPR- } \\
4.40 .1 .5\end{array}$ & Inspect, Collect, Transfer \& Pkg. Hazard. Waste \\
\hline & $\begin{array}{l}\text { CPP-TPR- } \\
4.40 .1 .6\end{array}$ & Inspect, Collect, Transfer \& Package Radioactive Waste \\
\hline & $\begin{array}{l}\text { CPP-TPR- } \\
4.40 .1 .7\end{array}$ & Inspect, Collect, Transfer \& Pkg. Mixed Waste \\
\hline & CPS-015 & Environment, Safety And Health \\
\hline & MCP-2739 & Material Handling, Storage, And Disposal \\
\hline & MCP-2748 & Hazardous Waste Operations And Emergency Response \\
\hline & MCP-446 & Small Quantity Generator Requirements \\
\hline & MCP-447 & Conditionally Exempt Small Quantity Generator Requirements \\
\hline & MCP-451 & Generator Treatment Plans \\
\hline & MCP-801 & Waste Approval \\
\hline & PDD-19 & $\begin{array}{l}\text { Program Description Document For Integrated Requirements } \\
\text { Management Program }\end{array}$ \\
\hline & PRD-181 & Systems Engineering \\
\hline & RRWAC & $\begin{array}{l}\text { INEL Reusable Property, Recyclable Materials, and Waste } \\
\text { Acceptance Criteria }\end{array}$ \\
\hline & STD-2 & Program Requirements Documents \\
\hline \multirow{13}{*}{$\begin{array}{l}\text { Characteri- } \\
\text { zation }\end{array}$} & CPP-TPR-2864 & (Undetermined) \\
\hline & ICPP-4098 & Oil Generator Notification Form \\
\hline & ICPP-5234x & Waste Stream Approval Form \\
\hline & ICPP-5351 & (Undetermined) \\
\hline & ICPP-5634x & Hazardous Waste Disposal Questionnaire \\
\hline & MCP-1141 & Waste Stream Approval Process \\
\hline & MCP-227 & $\begin{array}{l}\text { Sampling And Analysis Process For Environmental } \\
\text { Management Funded Activities }\end{array}$ \\
\hline & MCP-242 & $\begin{array}{l}\text { Obtaining Laboratory Services For Environmental } \\
\text { Management Funded Activities }\end{array}$ \\
\hline & MCP-243 & Assessment Of Analytical Laboratories \\
\hline & MCP-2864 & Sample Management \\
\hline & MCP-444 & $\begin{array}{l}\text { Characterization Requirements For Solid And Hazardous } \\
\text { Waste }\end{array}$ \\
\hline & MCP-SP-10.6.5.8 & TRA Waste Stream Management And Control \\
\hline & TPR-713 & Radioactive Contamination Added Determination \\
\hline
\end{tabular}


Table 3.1. Continued.

\begin{tabular}{|c|c|c|}
\hline Process & Procedure & Procedure \\
\hline Step & Number & Name \\
\hline \multirow[t]{22}{*}{ Waste Type } & Letter MSL-77-97 & Dispositioning RCRA Scrap Metal \\
\hline & MCP 4.8.0.15 & Collection of Used Oil and Used Oil Filters \\
\hline & $\overline{M C P-156}$ & Management Of Waste Aerosol Cans and Residues \\
\hline & MCP-157 & Management Of Used Oil and Oil Filters \\
\hline & MCP-1954 & Receiving, Storing and Handling Chemicals \\
\hline & MCP-2124 & Firearms and Range Clean-up \\
\hline & MCP-2468 & Management Of Precious Metals \\
\hline & MCP-2706 & Storage and Control Of Time Sensitive Chemicals \\
\hline & MCP-2720 & Lead \\
\hline & MCP-2756 & Nuclear Materials Control \\
\hline & MCP-308 & Nuclear Materials Management \\
\hline & $\mathrm{MCP}-4.1 .33$ & $\begin{array}{l}\text { Handle And Dispose of Empty Drums or Containers at } \\
\text { LMITCO Controlled Facilities }\end{array}$ \\
\hline & MCP-440 & Pesticide Management \\
\hline & MCP-453 & Management Of Unknown Materials \\
\hline & $\mathrm{MCP}-466$ & Septic Tank And Sludge Management \\
\hline & MCP-472 & Management Of Substances Regulated By TSCA \\
\hline & PRD-197 & Boiler Soot Disposal \\
\hline & PRD-2201 & Flammable And Combustible Liquid Storage \\
\hline & TPR-4.1.20 & Disposal of Nonradioactive Liquid Chemical Waste \\
\hline & TPR-4.2.4.1 & Collect and Transfer High Fluoride Liquid Waste \\
\hline & TPR-4.2.4.2 & Collect and Transfer Cadmium Liquid Waste \\
\hline & TPR-4651 & $\begin{array}{l}\text { Management of Waste From Laboratory and Experimental } \\
\text { Facilities }\end{array}$ \\
\hline \multirow[t]{6}{*}{ Records } & MCP-135 & Proposing, Evaluating, And Planning A DMCS Change \\
\hline & MCP-3016 & Records Management \\
\hline & PDD-11 & Records Management \\
\hline & PRD-111 & Records and Forms Management \\
\hline & PRD-138 & Document Management \\
\hline & TPR-5244 & Document Control \\
\hline \multirow[t]{4}{*}{ Logsheets } & $4089 x$ & CPP-1617 Operating Area Log Sheet \\
\hline & $4090 x$ & CPP-1619 Operating Area Log Sheet \\
\hline & $6943 x$ & RCRA Waste Container Number Log \\
\hline & $8151 x$ & $\begin{array}{l}\text { Record Of Transfer Of Hazardous Material From ICPP Waste } \\
\text { Storage Area }\end{array}$ \\
\hline \multirow[t]{2}{*}{ Packaging } & $3023 x$ & Hazardous Waste Tag \\
\hline & MCP-1144 & Preparing and Packaging Waste or Material for Collection \\
\hline \multirow[t]{3}{*}{ Marks/Labels } & $3000 x$ & Request For Single Use Packaging \\
\hline & $3020 x$ & Radioactive Waste Tag \\
\hline & $4101 x$ & Used Oil Container Label \\
\hline SAA & MCP-442 & Satellite Accumulation Areas Large Quantity Generators \\
\hline
\end{tabular}


Table 3.1. Continued.

\begin{tabular}{|c|c|c|}
\hline Process & Procedure & Procedure \\
\hline Step & Number & Name \\
\hline TAA & $\mathrm{MCP}-443$ & Temporary Accumulation Areas- Large Quantity Generators \\
\hline \multirow{4}{*}{ Shipping } & $3017 x$ & Request For Conditional Waste Shipment \\
\hline & MCP-1140 & Shipping and Receiving Hazardous Material \\
\hline & MCP-2669 & Hazardous Material Shipping \\
\hline & TPR-5242 & Shipping and Receiving Of Hazardous Material \\
\hline \multirow[t]{13}{*}{ TSD } & $5410 x$ & Spill Control Equipment Required For CPP-1617 \& -1619 \\
\hline & $6501 x$ & RCRA Inspection Checklist For CPP-1619 \\
\hline & $6581 x$ & RCRA Inspection Checklist For CPP-1617 \\
\hline & $\begin{array}{l}\text { CPP-MCP- } \\
\text { PO.67 }\end{array}$ & Safety, Housekeeping, And RCRA Inspections \\
\hline & $\mathrm{MCP}-448$ & Interim Status Treatment, Storage, and Disposal Facilities \\
\hline & MCP-449 & Permitted Treatment, Storage, and Disposal Facilities \\
\hline & PLN-154 & RCRA CPP-1617/1619 Interim Status Plans \\
\hline & TPR-4.40.1.8 & Collect, Transfer, Handle/Store Solid Waste Pending Analysis \\
\hline & TPR-4.40.1.0 & Operating Criteria for CPP-1617 \& CPP-1619 \\
\hline & $\begin{array}{l}\text { TPR-WERF- } \\
\text { 3.1.8.1 }\end{array}$ & $\begin{array}{l}\text { Shipping Of Radioactive, Hazardous or Mixed Waste From } \\
\text { WERF }\end{array}$ \\
\hline & $\begin{array}{l}\text { TPR-WERF- } \\
3.1 .8 .2\end{array}$ & Receipt, Inspection And Unloading Of Waste At WERF \\
\hline & $\begin{array}{l}\text { TPR-WROC- } \\
\text { SOP-3.1.5 }\end{array}$ & Waste Verification Sampling And Analysis For HW And MLLW \\
\hline & $\begin{array}{l}\text { TRP-WROC- } \\
\text { SOP-3.1.6 }\end{array}$ & $\begin{array}{l}\text { Waste Acceptance Procedure For WWSB, MWSF, And } \\
\text { MWSF-PSUs }\end{array}$ \\
\hline RMA & MCP-121 & Radioactive Material Areas For Storage \\
\hline $\begin{array}{l}\text { Audits/ } \\
\text { Assessments }\end{array}$ & MCP-348 & Waste Management Compliance Audits \\
\hline \multirow[t]{3}{*}{ Waste Min. } & MCP-2478 & $\begin{array}{l}\text { Disposing Of Nonproliferation Sensitive Government Personal } \\
\text { Property }\end{array}$ \\
\hline & MCP-454 & INEEL Recycling Procedure \\
\hline & $\mathrm{MCP}-475$ & Material Exchange Program \\
\hline Treat. Studies & $\mathrm{MCP}-452$ & Treatability Studies \\
\hline \multirow[t]{3}{*}{ Training } & MCP-445 & RCRA Training For Hazardous Waste Management \\
\hline & PDD-13 & Training And Qualification Program \\
\hline & RCRA-h-int & Interim Status ICPP RCRA Personnel Training Plan \\
\hline Misc. & $5506 x$ & Work Order \\
\hline
\end{tabular}




\section{RESOURCE PLAN}

\subsection{Organizational Breakdown Structure}

The WGS organization is comprised of five separate sections. These sections are 1) Waste Characterization Chemistry and Determination, 2) Low-level Waste and Industrial Waste Management, 3) Hazardous and Mixed Waste Management, 4) Projects Support, and 5) Technical Support. Figure 4.1 illustrates the WGS organizational breakdown structure and primary work elements. The overall roles and responsibilities of each section are described in detail below. The section layout and work responsibilities are summarized in Figure 4.1.

\subsubsection{Waste Characterization Chemistry and Determination}

This section is comprised of facility leads that will be established for ICPP, TRA, TAN/SMC, CFA, ER, Waste Operations, and town facilities. Facility leads will function as the waste generator customer representative, and be the primary interface between WGS. This position will meet the crucial customer requirement of having a single point-of-contact for each facility. Facility leads may be augmented with support on the basis of facility site and new waste streams. The personnel in this group will primarily function in the up-front process knowledge waste data gathering and waste determination work. Work with the source on a waste stream will include the key functions of: 1) Identify the waste generation process. 2) Identify the starting materials. 3) Define the expected waste material components. 4) Provide documentation of process knowledge. The facility leads will have responsibility for the generator waste certification plans required by DOE Order 5820.2A. See the facility lead job responsibilities and qualifications for additional information.

\subsubsection{Low-level Waste and Industrial Waste Management}

This section has responsibility and accountability for compliant cradle-to-grave management of low-level and industrial waste generated at the INEEL. Responsibilities begin with review and verification of the process knowledge waste determination and continue through final disposition. The work will include certifying LLW and conditional industrial waste to INEEL and offsite TSD waste acceptance criteria, shipping LLW from the generator/customer to the TSD, and ensuring the LLW is scheduled and dispositioned per the schedule at the TSD. The current landfill operations will retain the non-conditional industrial waste pickup and transportation to the landfill and container supply. Specific responsibilities for the remaining tasks for non-conditional industrial waste will be finalized with completion of the detailed process flow diagram. Waste stream assignments will be made to individual personnel in this group. This section will be led by a supervisor/project manager.

\subsubsection{Hazardous and Mixed Waste Management}

This section has responsibility and accountability for compliant cradle-to-grave management of hazardous waste and mixed low-level waste generated at the INEEL and offsite. Responsibilities begin with review and verification of the process knowledge waste determination and continue through final disposition. The focus of the work will be certifying hazardous and MLLW to INEEL and offsite TSD waste acceptance criteria, and shipping waste from the generator/customer to the TSD and ensuring the waste is scheduled and dispositioned at the TSD. Responsibilities are shown in Figure 4.1. Waste stream assignments will be made to individual personnel in this group. This section will be led by a supervisor/project manager. 
THIS PAGE INTENTIONALLY LEFT BLANK 


\section{Waste Characterization Chemistry and Waste Determination}

- Customer Representative

- First Point of Contact for planned or legacy waste

- Process knowledge data collection

- Waste generation process

-Starting materials

-Expected waste material components

- Documentation

- Compatibility analysis for storage

- Waste file folder

- Waste determination based upon process knowledge

- Classifies waste by type

- Coordinates assignment of waste type Technical Specialist

- Waste generator certification plans and assessment

- Waste forecasts

- Backlog waste container integrity

- Facility audits of waste management areas

- Coordinate cost/schedule/scope MOAs with waste generator customers

\section{Low-Level Waste} and Industrial Waste Management

- Review process knowledge

- Evaluation

- Review match to existing profile

- Prepare waste disposition form

- Waste minimization review

- Determine any additional analysis requirements for waste determination and/or WAC acceptance (physical, chemical, radiological)

- Prepare sample and analysis plans

- Waste container distribution

- Waste analysis and data interpretation

- Final waste characterization

- IWTS material and container profiles

- Waste temporary storage

- TSD scheduling coordination

- Waste verification

- Packaging and Transportation

- Records Management

- Special-Case Waste management

- Sample returns
$\mathrm{Ha} 2$ and

$\Lambda$

- Review

- Review

- Prepare

- Waste n

- Determi requiren and/or V chemica

- Prepare

- Waste a interpre1

- Final wi

- Waste c

- Manage

- Manage

- Manage

- Coordir

- IWTS n

- TSD scl requirer

- Waste $\mathbf{1}$

- Packagi

- Records

- Sample

- INEEL 


\section{ATOR SERVICES}

- Administrative Support

- ESH\&Q Officer

- Program Controls

RCRA Regulatory Specialist

\section{ardous Waste}

\section{Mixed Waste} anagement

ocess knowledge evaluation atch to existing profile aste disposition form fimization review any additional analysis nts for waste determination IC acceptance (physical, radiological) mple and analysis plans lysis, validation and ion

e characterization

tainer distribution

PP-1619

AAs

aste through TAAs

- SAAs with generator

erial and container profiles

luling and special

nts interface/coordination

fication

and Transportation

Ianagement

turns

e Treatment Plan

Figure 4.1. WGS Organization and Responsibilities Chart.

- Waste samplers

- Chemical and radiological analysis services

- Characterization Chemist

-Waste container management

- Waste data IWTS entry

- Transportation services

- Waste handler services

- SMO Interface

- Facility lead support services

\section{Technical Support}

- IWTS Deployment

- IWTS maintenance and improvements

- Offsite subcontract setup and audits

- Waste Management Procedures

- Coordinate treatability studies and technology developments

- Training

- Document Control

- Graphic arts and technical editing

-Waste management reports

- Performance measures 


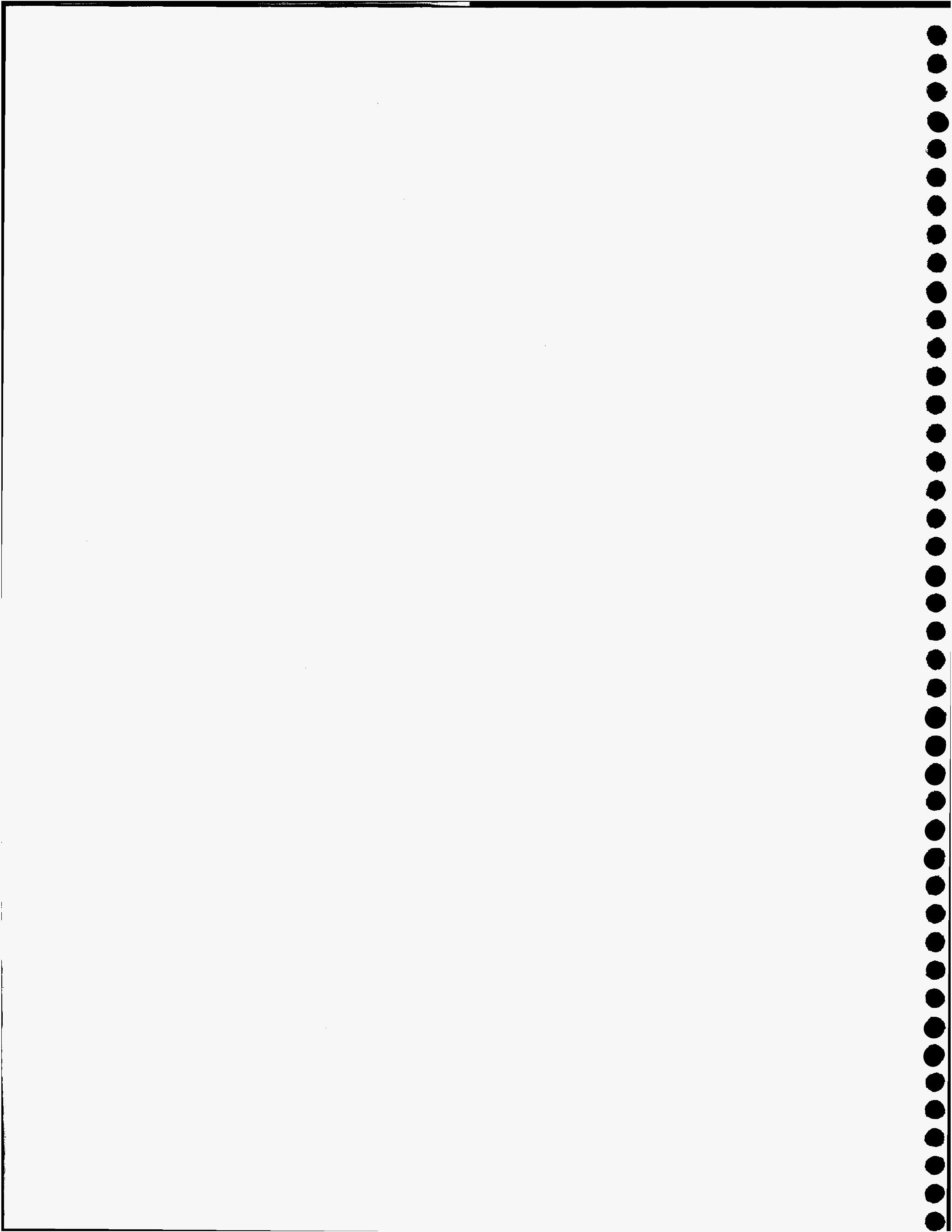




\subsubsection{Projects Support}

The Projects Support section is responsible for ensuring that the specialized needs of the Hazardous and Mixed Waste Management section and the Low-level and Industrial Waste Management section are met. This section is established because of the diverse geographical locations of personnel at NEEL facilities and part-time personnel needs between facility locations and between the waste management sections. Responsibilities will include waste sampling and analysis, waste container management, transportation, waste handler craft support, and facility lead support. This section will be led by a supervisor.

\subsubsection{Technical Support}

The Technical Support section is responsible for the management of stand-alone WGS support systems. These include IWTS deployment and maintenance, waste management process flow diagrams and waste management procedures, training records and training coordination, offsite TSD subcontract management, coordinating technology development needs including treatability studies, and document control. This section will be led by a supervisor.

\subsection{Staffing Plan}

The initial draft of the staffing plan is detailed in Table 4.1 for each of the sections, based upon initial customer location needs and functions. The types of positions and numbers of personnel may be adjusted based upon lessons learned from implementation at ICPP. Some support functions such as industrial hygiene, fire protection, and industrial safety will be matrixed as needed upon WGS implementation. With implementation of WGS across the INEEL, and experience in performing work to the WGS process, these staffing numbers are expected to decrease. The initial staffing represents $15 \%$ less FTE personnel than are currently performing this work. The staffing plan does not reflect backshift operations. This need would be evaluated upon implementation of WGS.

\subsection{Job Positions and Qualifications}

Each job position within WGS will have clearly-defined roles, responsibilities, and core requirements. Information determining qualifications was gathered from around the DOE Complex, and will be used in preparing the WGS staff job qualifications and training plans. The job positions for each group will include a mixture of engineer/scientist, technical specialist, and administrative functions. The job descriptions for the facility lead(s) and section supervisor positions are listed below and will be filled by posting.

The competency levels listed below define the minimum levels of expected knowledge and/or skill that an individual must possess to meet the intent of the qualification.

Familiarity Level : $\quad$ Understanding or awareness of general concepts or activities.

Working Level : $\quad$ The ability to perform activities.

Expert Level: $\quad$ Possess and demonstrate comprehensive knowledge of concepts or expert ability to perform activities. 
Table 4.1. WGS Staffing Plan

\begin{tabular}{|c|c|c|c|c|c|c|c|c|}
\hline $\begin{array}{l}\text { Customer/Core } \\
\text { Function }\end{array}$ & WGS & WCCD & LLW/Ind & MLLW/Haz & Projects & Technical & Total & Location \\
\hline ICPP & 0 & 1 & 2 & 8 & 1 & 0 & 12 & ICPP \\
\hline$\overline{\text { TAN }}$ & 0 & 1 & 1 & 3 & 0 & 0 & 5 & TAN \\
\hline TRA & 0 & 1 & 1 & 4 & 1 & 0 & 7 & TRA \\
\hline$\overline{\mathbf{C F A}}$ & 0 & 1 & 1 & 2 & 0 & 0 & 4 & CFA \\
\hline$\overline{\mathbf{E R}}$ & 0 & 1 & 2 & 2 & 1 & 0 & 6 & Town/CFA \\
\hline WO & 0 & 1 & 2 & 3 & 0 & 0 & 6 & RWMC/WROC \\
\hline Town Facilities & 0 & 1 & 0 & 1 & 0 & 0 & 2 & CFA/Town \\
\hline Offsite Facilities & 0 & 0 & 0 & 3 & 0 & 0 & 3 & Town \\
\hline Waste Handlers & 0 & 0 & 0 & 0 & 3 & 0 & 3 & CFA \\
\hline STP & 0 & 0 & 0 & 0 & 0 & 3 & 3 & Town/CFA \\
\hline $\begin{array}{l}\text { Offsite } \\
\text { Subcontracts }\end{array}$ & 0 & 0 & 0 & 0 & 0 & 2 & 2 & CFA \\
\hline $\begin{array}{l}\text { Container } \\
\text { Management }\end{array}$ & 0 & 0 & 0 & 0 & 1 & 0 & 1 & CFA \\
\hline $\begin{array}{l}\text { Sampling and } \\
\text { Analysis }\end{array}$ & 0 & 0 & 0 & 0 & 6 & 0 & 6 & $\overline{C F A}$ \\
\hline SMO Contracts & 0 & 0 & 0 & 0 & 2 & 0 & 2 & Town \\
\hline$\overline{\mathbf{P \& T}}$ & 0 & 0 & 0 & 0 & 4 & 0 & 4 & Site Facilities \\
\hline IWTS Data Entry & 0 & 0 & 0 & 0 & 4 & 0 & 4 & Site Facilities \\
\hline $\begin{array}{l}\text { IWTS Rpts and } \\
\text { Maint }\end{array}$ & 0 & 0 & 0 & 0 & 0 & 6 & 6 & Town \\
\hline Document Control & 0 & 0 & 0) & 0 & 0 & 1 & 1 & CFA/WROC \\
\hline Training & 0 & 0 & 0] & 0 & 0 & 1 & 1 & CFA \\
\hline Program Controls & 1 & 0 & 0 & 0 & 0 & 0 & 1 & CFA \\
\hline $\begin{array}{l}\text { Procedures and } \\
\text { RRWAC (RWMC) }\end{array}$ & 0 & 0 & 0 & 0 & 0 & 1 & 1 & CFA \\
\hline $\begin{array}{l}\text { Generator } \\
\text { Assessment/QA }\end{array}$ & 0 & 0 & 0 & 0 & 0 & 1 & 1 & $\overline{\mathrm{CFA}}$ \\
\hline $\begin{array}{l}\text { WO Projects } \\
\text { (SCW) }\end{array}$ & 0 & 0 & 0 & 0 & 0 & 1 & 1 & $\overline{C F A}$ \\
\hline Administrative & 2 & 0 & 0 & 0 & 0 & 2 & 4 & $\begin{array}{r}\text { CFA/Facilities/ } \\
\text { Town }\end{array}$ \\
\hline SDA Perf. Assess. & 0 & 0 & 0 & 0 & 0 & 1 & 1 & CFA \\
\hline Manager/Sup & 1 & 0 & 1 & 1 & 1 & 1 & 5 & $\overline{\mathrm{CFA}}$ \\
\hline RCRA Specialist & 1 & 0 & 0 & 0 & 0 & 0 & 1 & CFA \\
\hline ESH\&Q Officer & 1 & 0 & 0 & 0 & 0 & 0 & 1 & CFA \\
\hline Radcon/Rad Eng. & 0 & 0 & 1 & 1 & 1 & 0 & 3 & CFA/Facilities \\
\hline Deployment Mgr & 1 & 0 & 0 & 0 & 0 & 0 & 1 & CFA \\
\hline Char. Chemist & 0 & 0 & 0 & 0 & 1 & 0 & 1 & $\overline{C F A}$ \\
\hline $\begin{array}{r}\text { TOTAL } \\
\end{array}$ & 7 & 7 & 11] & 28 & 26 & 20 & 99 & \\
\hline
\end{tabular}




\subsubsection{Waste Characterization Chemistry and Determination Facility Leads}

Each facility lead will report to the WGS Manager. Facility leads will be established at ICPP, TRA, TAN/SMC, CFA, ER, Waste Operations, and town facilities. Facility leads will function as the waste generator customer representative, and be the primary interface between WGS and the generator. This position will meet the crucial customer requirement of having a single point-of-contact for each facility. The position primarily functions in the up-front waste data gathering and initial waste determination work, but acts as the customer interface for all WGS work at the facility. These positions will be posted in accordance with the deployment schedule for each of the generator facilities.

Job responsibilities are shown under the Waste Characterization Chemistry and Waste Determination section of WGS presented in Figure 4.1.

Candidates will be evaluated against these selection criteria:

1) Expert-level knowledge of represented facility processes and operations. Three years experience with CPP operations with environmental management focus.

2) Demonstrated ability to provide aggressive environmental and waste management support.

3) Working-level knowledge of chemistry and thermodynamic principles related to waste management.

4) Working-level knowledge of radiological risk management, ALARA principles, and radiological and chemical hazard assessment.

5) Expert-level ability to assess documentation in support of determining process knowledge basis for waste characterization.

6) Working-level knowledge of INEEL waste types.

7) Working-level knowledge of INEEL treatment/storage and disposal facilities and waste acceptance requirements.

8) Working-level abilities in verbal and written communication, and LMITCO computer software applications.

9) Excellent interpersonal and customer relations skills.

10) Familiarity with waste generator certification plans, the INEEL Site Treatment Plan, and waste forecasting.

11) Working-level ability to implement quality assurance requirements and to support auditing functions.

12) Working-level knowledge of problem analysis and problem resolution principles and skills. 


\subsubsection{Low-level and Industrial Waste Management Supervisor}

This position reports to the WGS manager, and has the overall responsibility for the compliant cradle-tograve management of low-level and industrial waste generated at the INEEL. The supervisor is responsible to manage and supervise a group of low-level and industrial waste technical specialists who begin work once the first-pass waste determination has concluded that the waste is most likely industrial or low-level waste. The supervisor will make personnel assignments for responsibility for both ongoing and newly/to-be-generated waste streams, and these personnel will retain responsibility for management of that waste through final disposition. This supervisor will be the primary interface in scheduling work with the facility leads. The supervisor will be the coordinating project manager ensuring proper disposition of INEEL-generated low-level waste and industrial waste.

Personnel reporting to this supervisor will be aligned with the major waste generator facilities, and located either at the generator facility or at the WGS CFA central location. Personnel working in the existing system that can be aligned to low-level or industrial waste will begin reporting to this supervisor prior to deployment at ICPP. This position will be posted and filled prior to WGS implementation at ICPP.

Job responsibilities of this section are shown in Figure 4.1. the supervisor is responsible for leading section personnel in performing these job responsibilities:

Candidates will be evaluated against these selection criteria:

1) Demonstrated ability to provide aggressive waste management and environmental management support.

2) Demonstrated ability to lead personnel to accomplish work group objectives.

3) Demonstrated ability to plan, execute, control, and close a project using project management principles. Ability to plan work based upon strategic objectives.

4) Familiarity-level knowledge of chemistry and thermodynamic principles related to waste management.

5) Working-level knowledge of radiological risk management, ALARA principles, and radiological hazard assessment.

6) Working-level knowledge of the LMITCO Safety and Health Program, procedures, and operational requirements.

7) Working-level ability to define radiological waste characterization needs.

8) Familiarity-level knowledge of hazardous waste characterization.

9) Working-level abilities for verbal and written communication and excellent customer relations skills.

10) Working-level knowledge of industrial and low-level waste types. 
11) Familiarity-level knowledge of waste packaging and transportation requirements for radioactive waste.

12) Familiarity-level knowledge with contracting and procurement for waste management services.

13) Working-level knowledge in developing plans, standards, operating procedures, and guidelines.

14) Working-level knowledge of the waste management capability and acceptance criteria for INEEL and offsite TSD facilities.

15) Familiarity with INEEL low-level waste generation processes and operations.

16) Working-level ability to implement quality assurance and waste verification functions.

17) Experience in nuclear facility operations.

18) Working-level knowledge of problem analysis and problem resolution principles and skills.

19) Working-level abilities with LMITCO database and word processing software.

20) Working-level knowledge of waste minimization principle and practices.

\subsubsection{Hazardous and Mixed Waste Management Supervisor}

This position reports to the WGS manager and has the overall level of responsibility for the compliant cradle-to-grave management of hazardous and mixed low-level waste generated both on and off the INEEL. The supervisor is responsible to manage and supervise a group of hazardous and mixed waste technical specialists who begin work once the first-pass waste determination has concluded that the waste is most likely hazardous or mixed waste. The supervisor will make assignments of personnel for responsibility for both ongoing and newly/to be generated waste streams. These personnel will then retain responsibility for management of that waste through final disposition. This supervisor will be the primary interface in scheduling work with the facility leads. The focus of the work will be certifying hazardous and mixed waste to INEEL and offsite TSD waste acceptance criteria, and shipping waste from the generator/customer to the TSD and ensuring the waste is scheduled and dispositioned at the TSD. Special projects may be undertaken within waste management TSDs to disposition waste in storage.

Personnel reporting to this supervisor will be aligned with the major waste generator facilities, and be located at either the generator facility or at the WGS CFA central location. Personnel working in the existing system that can be aligned to hazardous or low-level waste will begin reporting to this supervisor prior to deployment at ICPP. This position will be posted and filled prior to WGS implementation at ICPP.

Job responsibilities of this section are shown in Figure 4.1. The supervisor is responsible for leading section personnel in performing these duties:

Candidates will be evaluated against these selection criteria:

1) MS degree in environmental, chemistry, or waste management area prefer. 
2) Demonstrated ability to provide aggressive waste management and environmental management support.

3) Demonstrated ability to lead personnel to accomplish work group objectives.

4) Demonstrated ability to plan, execute, control, and close a project using project management principles. Ability to plan work based upon strategic ojectives.

5) Working-level knowledge of LMITCO Safety and Health Program, procedures, and operational requirements.

6) Working-level knowledge of chemistry and thermodynamic principles related to waste management.

7) Working-level knowledge of radiological risk management, ALARA principles, and radiological hazard assessment.

8) Working-level ability to define hazardous and radiological waste characterization needs.

9) Working-level abilities for verbal and written communication and excellent customer relations skills.

10) Working-level knowledge of hazardous and mixed waste types.

11) Working-level knowledge of the NEEL Site Treatment Plan.

12) Familiarity with DOE nuclear facilities operations.

13) Familiarity-level knowledge of RCRA TSD operational requirements.

14) Familiarity-level knowledge of waste packaging and transportation requirements for radioactive waste.

15) Familiarity-level knowledge with contracting and procurement for waste management services.

16) Working-level knowledge in developing plans, standards, operating procedures, and guidelines.

17) Working-level knowledge of the waste management capability and acceptance criteria for INEEL and offsite TSD facilities.

18) Familiarity with INEEL waste generation operations.

19) Familiarity with offsite waste shipments destined to the INEEL.

20) Working-level ability to implement quality assurance and waste verification functions.

21) Working-level knowledge of problem analysis and problem resolution principles and techniques.

22) Working-level abilities with LMITCO database and word processing software. 
23) Working-level knowledge of waste minimization principles and practices

\subsubsection{Projects Support Supervisor}

This position reports to the WGS manager. The supervisor is responsible for managing the personnel within the projects support section and ensuring that the specialized needs of the Hazardous and Mixed Waste Management section and the Low-level and Industrial Waste Management section operating at different INEEL geographical locations are met.

Job responsibilities for this section are shown in Figure 4.1. The supervisor is responsible for leading section personnel in performing these duties:

Candidates will be evaluated against these selection criteria:

1) Demonstrated ability to ability to provide aggressive waste management and environmental management support.

2) Demonstrated ability to lead personnel to accomplish work group objectives.

3) Working-level knowledge of sampling and analysis protocols regarding chemical and radiological waste characterization.

4) Working-level knowledge of federal and state environmental regulations with emphasis on RCRA regulations, and working-level knowledge of DOE Orders and LMITCO implementing procedures regarding waste management.

5) Working-level knowledge of LMITCO Safety and Health Program, procedures, and operational requirements.

6) Working-level knowledge of INEEL DOT and materials and waste packaging and transportation requirements.

7) Working-level knowledge of procurement, warehousing, and quality receipt inspection and quality assurance requirements.

8) Working-level abilities for verbal and written communication and excellent customer relations skills.

9) Working-level knowledge of industrial, hazardous, low-level, and mixed waste types.

10) Familiarity-level knowledge of LMITCO procurement system.

11) Working-level knowledge to develop plans, standards, operating procedures and guidelines.

12) Working-level ability with database and word processing software.

13) Familiarity-level knowledge of the Integrated Waste Tracking System (IWTS).

14) Working-level knowledge of problem analysis and problem resolution principles and skills. 
15) Familiarity with INEEL waste generation operations and INEEL waste types.

16) Working-level knowledge of chemistry and thermodynamic principles related to waste management.

17) Ability to schedule, assign, and monitor personnel under the matrix approach.

18) Working-level knowledge of Sample Management Office operations.

19) Familiarity with the INEEL Bargaining Agreement Contract.

20) Working-level knowledge of radiological risk management, ALARA principles, and radiological hazard assessment.

\subsubsection{Technical Support Supervisor}

This position reports to the WGS manager. The supervisor is responsible for managing the personnel within the technical support section to ensure that the base operations necessary for WGS operation are adequately met. These operations include data management systems, reporting, procedures, and document control.

Job responsibilities for this section are detailed in Figure 4.1. The supervisor is responsible for leading section personnel in performing these duties:

Candidates will be evaluated against these selection criteria:

1) Demonstrated ability to provide aggressive waste management and environmental management support.

2) Demonstrated ability to lead personnel to accomplish work group objectives.

3) Working-level knowledge of federal and state environmental regulations with emphasis on RCRA regulations, and working-level knowledge of DOE Orders and LMTCO implementing procedures regarding waste management.

4) Working-level knowledge of LMITCO Safety and Health Program, procedures, and operational requirements.

5) Working-level knowledge of specification writing, RFPs, auditing and LMITCO procurement requirements.

6) Working-level ability to plan, execute, control and close a project using project management principles.

7) Working-level knowledge of LMITCO document control, records management, and procedure development and approval.

8) Working-level knowledge with large database management and waste tracking systems including the INEEL IWTS system. 
9) Working-level abilities for verbal and written communication and excellent customer relations skills.

10) Working-level knowledge of industrial, hazardous, low-level, and mixed waste types.

11) Working-level knowledge to develop plans, standards, operating procedures and guidelines.

12) Working-level knowledge of problem analysis and problem resolution principles and skills.

13) Familiarity with LMITCO training programs, requirements and tracking systems.

14) Familiarity with INEEL waste generation operations and INEEL waste types.

15) Familiarity with chemistry and thermodynamic principles related to waste management.

16) Working-level knowledge of radiological risk management, ALARA principles, and radiological hazard assessment.

17) Familiarity with capabilities of offsite TSD facilities

\subsubsection{Characterization Chemist}

This position reports to the Projects Support Supervisor. This individual provides support to the Hazardous and Mixed Waste Management, the Low-level and Industrial Waste Management, and the Waste Characterization, Chemistry and Determination units for regulatory determinations and waste characterization, review of analytical data, chemical compatibility reviews, and specification of analytical protocols.

This individual will be located at the WGS central location. This position will be filled prior to operational WGS implementation.

Job responsibilities will include:

1) Review Sampling and Analysis Plans for chemical compatibility concerns, specify analytical protocols to be used, and interface with the SMO during preparation of MTS statements of work and umbrella TOSs to ensure analytical protocols meet WGS requirements.

2) Review Waste Disposition Forms for chemical compatibility concerns.

3) Support legacy or unknown waste compatibility for storage and waste determination.

4) Work with facility leads and RCRA regulatory expert to establish the facility process knowledge characterization.

5) Review proposed treatability studies and generator treatment plans to evaluate feasibility of proposed technologies.

6) Provide chemistry support for review of analytical data. 
7) Evaluate alternate analytical protocols, including field testing. Interface with SMO during preparation of MTS SOWs and umbrella TOSs to ensure analytical protocols meet WGS requirements.

Job qualifications will include:

1) BS degree in chemistry or chemical engineering.

2) MS degree in chemistry or chemical engineering preferred.

3) Expert ability to aggressively provide waste management support.

4) Expert-level knowledge of chemistry and thermodynamic principles related to waste management.

5) Expert-level knowledge of radiological risk management and hazard assessment.

6) Expert-level knowledge of waste sampling standards, procedures, and operations.

7) Expert-level knowledge of laboratory procedures, operations for waste analysis, and analytical method data validation.

8) Working-level knowledge of federal and State of Idaho environmental regulatory requirements, specifically RCRA, and familiarity-level knowledge with DOE Orders, LMITCO MCPs regarding waste management and nuclear facility management as they relate to waste determination/characterization and treatment.

9) Working-level abilities for verbal and written communication and customer relations skills.

10) Working-level knowledge of industrial, hazardous, low-level, and mixed waste types.

11) Working-level knowledge of subcontracting and procurement for analytical services.

12) Expert-level knowledge of analytical method data validation.

\subsubsection{RCRA Regulatory Specialist}

This position reports to the WGS manager and provides regulatory oversight and support to the entire WGS organization. This position is the primary interface with Environmental Affairs and serves as the WGS representative for activities requiring WGS participation in discussions with regulatory agencies. This individual provides support to the other WGS organizations for regulatory determinations and waste characterization, development of implementing procedures, regulatory reporting, and serves as the WGS representative during regulatory inspections.

This individual will be located at the WGS central location. This position will be filled prior to operational WGS implementation through either posting or matrix from Environmental Affairs. 
Job responsibilities will include:

1) Provide regulatory assistance to WGS groups for waste determinations and waste characterization; evaluate process knowledge and identify additional sampling required.

2) Provide RCRA regulatory advice to WGS groups and waste generators regarding accumulation and temporary storage of wastes.

3) Provide regulatory assistance in evaluating analytical data.

4) Review Waste Disposition Forms to identify compliance concerns or potential permitting issues and identify waste management requirements.

5) Support oversight/inspection of SAAs, TAAs and CPP-1619.

6) Serve as the interface between WGS organizations and Environmental Affairs.

7) Identify any permitting issues and work with Environmental Affairs for corrections.

8) Serve as the WGS representative for discussions with regulatory agencies.

9) Serve as the WGS point of contact for regulatory inspections.

10) Develop and provide informal environmental training related to waste management.

11) Oversee preparation of reports required by environmental regulations (e.g., RCRA Biennial Report, Idaho Waste Generator Reports, Treatability Studies Annual Reports)

12) Oversee preparation of Generator Treatment Plans, Treatability Studies notifications, and LDR notifications.

13) Conduct periodic oversight of WGS records to ensure regulatory requirements are met.

14) Coordinate and participate in environmental liability assessments of offsite TSD facilities.

15) Interface with Environmental Affairs for RCRA permitting actions and RCRA compliance oversight of 1619 .

Job qualifications will include:

1) BS degree in engineering, a physical science, or related science or equivalent by exception (a chemistry or chemical engineering background preferred).

2) Masters degree in an environmental/waste management discipline preferred.

3) Ten years of experience in environmental compliance related to management of hazardous and mixed waste.

4) Qualification as a waste determination specialist within three months of job acceptance. 
5) Expert ability to aggressively provide waste management support.

6) Familiarity with chemistry and thermodynamic principles related to waste management.

7) Expert-level knowledge of federal and State of Idaho environmental regulatory requirements, DOE Orders, LMITCO MCPs regarding waste management and nuclear facility management as they relate to waste generation, waste determination, and waste certification. Emphasis is RCRA regulations.

8) Familiarity-level knowledge of waste minimization principles and practices.

9) Expert-level ability to implement waste characterization and certification procedures.

10) Expert-level abilities for verbal and written communication and customer relations skills.

11) Working-level knowledge of industrial and low-level waste types.

12) Familiarity-level knowledge of waste packaging and transportation.

13) Working-level knowledge of subcontracting and procurement for waste management services.

14) Working-level knowledge to develop plans, standards, operating procedures, and guidelines.

15) Working-level knowledge of the waste management process at INEEL and offsite TSD facilities.

16) Working-level ability with database and word processing software.

17) Working-level knowledge of problem analysis and problem resolution principles and skills.

18) Specific environmental, OSHA, facility, environmental protection and radiological training.

\subsubsection{Deployment Manager}

This position reports to the WGS manager. This position is responsible for coordinating and overseeing activities required to implement the WGS concept across the INEEL. This person will be dispatched to develop the planning and complete the transition steps for implementation of WGS at successive INEEL locations. This will require communication with all of the waste generators, TSD facilities, and the five units within WGS.

This individual will be located at the WGS central location. This position will be filled prior to operational WGS implementation.

Candidates will be evaluated against these selection criteria:

1) Identify staffing requirements at each location, including facility leads and technical waste specialists. Establish cost estimates and negotiate agreement with facilities. Verify the current funding matrix and cross-walk existing funding to the proposed funding plan for each facility. Develop job descriptions and job postings, assist the WGS Manager in interviewing and selecting candidates. 
2) Develop facility-specific implementation plans and schedules for INEEL facilities;

3) Coordinate functional transfer of resources and develop interface agreements with other organizations.

4) Represent WGS in labor negotiations. Coordinate and work labor issues.

5) Finalize and approve the waste management process flow charts for both planned generation and legacy wastes for each of the waste types based upon any facility-specific needs.

6) Coordinate facility waste management procedure revisions for implementing the WGS process.

7) Coordinate work locations. Identify facility and equipment requirements, secure office and other needed facilities, coordinate relocation of personnel.

8) Coordinate the WGS staff training program and plans.

9) Develop WGS interface agreements with non-LMITCO operations at the INEEL (ANL-West and NRF).

10) Coordinate and facilitate communications between the five units in WGS during the implementation period.

13) Coordinate development and implementation of the customer satisfaction survey; identify opportunities for improvement in the waste management process; establish and lead improvement teams to develop recommendations to resolve specific issues as they arise.

14) Resolve issues between generator customers, the TSD facilities, and the WGS facility leads.

Job qualifications will include:

1) MS degree in environmental management or waste management preferred.

2) Clear understanding of the waste management process from cradle to grave.

3) Aggressively motivated to implement the Waste Generator Services process across the INEEL site.

4) Demonstrated ability to provide waste management and environmental management support.

5) Familiarity-level knowledge of waste sampling standards, procedures, and operations.

6) Demonstrated ability to lead personnel to accomplish work group objectives.

7) Working-level knowledge of federal and state environmental regulations with emphasis on RCRA regulations, and working-level knowledge of DOE Orders and LMITCO implementing procedures regarding hazardous and radioactive waste management.

8) Working-level knowledge of LMITCO Safety and Health Program, procedures, and operational requirements. 
9) Working-level ability to plan, execute, control and close a project using project management principles.

10) Working-level knowledge of LMITCO procedure change and approval process.

11) Working-level knowledge with large database management and waste tracking systems including the NNEEL IWTS system.

12) Working-level abilities for verbal and written communication, and excellent customer relations skills.

13) Working-level knowledge of industrial, hazardous, low-level, and mixed waste types.

14) Demonstrated success in problem solving through the use of negotiation skills.

15) Working-level knowledge of INEEL waste generation facilities and INEEL waste types.

16) Familiarity with chemistry and thermodynamic principles related to waste management.

17) Working-level ability with database and word processing software.

18) Familiarity-level knowledge of INEEL waste packaging and transportation.

\subsubsection{ES\&H Compliance Officer}

The ESH\&Q Compliance Officer will report to the WGS Department Manager. This position will serve as the primary interface with the ESH\&Q Branch, and have responsibility for WGS ESH\&Q performance. This position will be filled prior to WGS implementation.

Job responsibilities will include:

1) Direct and coordinate assigned radiological engineers and represented technicians in the proper radiological control practices necessary to support waste sampling, waste management, and waste shipments.

2) Ensure ALARA principles and goals are established and achieved.

3) Serve as the WGS point of contact with the ESH\&Q Branch. Communicate information from the ESH\&Q Branch to WGS employees and vice versa.

4) Coordinate Quality Engineering and Assurance activities to ensure compliance with regulations, DOE Orders and company procedures. Implement and assure conformance to the WGS Quality Assurance Plan.

5) Develop and implement the WGS self-assessment program.

6) Coordinate Emergency Preparedness activities for WGS.

7) Coordinate safety, health, and industrial hygiene activities for WGS. 
8) Serve as the WGS point of contact for VPP implementation, accident investigations, and occurrence reporting.

9) Serve as the WGS point-of-contact for ESH\&Q audits, assessments, and inspections. Coordinate development of audit responses and corrective action plans.

10) Develop and implement programs to ensure compliance with regulatory requirements, and to reduce injuries, exposures, illnesses, accidents and work delays.

11) Identify and secures ESH\&Q resources as needed to meet WGS objectives.

12) Coordinate environmental, safety and health, and quality reporting activities between WGS and ESH\&Q.

Job qualifications will include:

1) BS degree in engineering, a physical science, or related science or equivalent by exception.

2) Working-level facility and process knowledge of most major INEEL facilities including ICPP, TRA and TAN.

3) Five years of experience in coordinating ESH\&Q facility-based activities.

4) Working-level knowledge in radiological controls and industrial hygiene areas.

5) Working-level knowledge of DOE and LMITCO quality assurance programs and requirements with the ability to implement quality assurance, auditing, and training requirements.

6) Expert-level knowledge of LMITCO safety and health programs, requirements, and implementing procedures with emphasis on field requirements.

7) Aggressively support the INEEL VPP Program.

8) Working-level knowledge of federal and State of Idaho ESH\&Q regulatory requirements, DOE Orders, LMITCO procedures regarding waste management and nuclear facility management.

9) Working-level knowledge of radiological risk management and hazard assessment.

10) Working-level qualification for verbal and written communication and customer relations skills.

11) Working-level knowledge of industrial, hazardous, low-level and mixed waste types.

12) Familiarity with the waste management process and INEEL and offsite TSD facilities.

13) Working-level ability with LMITCO database and word processing software.

14) Working-level knowledge of problem analysis and problem resolution principles and skills. 
15) Specific environmental, OSHA, facility, environmental protection, and radiological training.

\subsection{Current Resource Baseline}

\subsubsection{Personnel}

A tabulation of INEEL personnel conducting WGS scope of work was compiled in February 1998. Approximately 230 individuals are currently involved in the waste management process for at least a portion of their time, for a total of 120 FTEs. Appendix A lists specific personnel.

The personnel conducting WGS scope of work are distributed across the INEEL as follows:

CFA

CPP

Idaho Falls Facilities

TAN

TRA

Env. Restoration

Env. Affairs (sitewide)

RWMC

WERF/WROC

Packaging \& Transportation

Waste Tech. \& Planning

Radiological Engineering $=\quad 6$ FTEs

$=\quad 20 \mathrm{FTES}$

$=\quad 2$ FTEs

$=\quad 7$ FTES

$=\quad 13$ FTEs

$=\quad 8$ FTES

$=\quad 9$ FTES

$=\quad 2$ FTES

$=\quad 19$ FTES

$=\quad 5$ FTEs

$=\quad 26$ FTEs

$=\quad 2$ FTEs

Approximately 50 individuals are in the Waste Operations Directorate, with 50 additional individuals in the Environmental Affairs Directorate. The remaining 130 individuals represent a variety of organizations including Nuclear Operations, Site Services, Environmental Restoration, and the Applied Engineering and Development Laboratory.

\subsubsection{Materials \& Equipment}

Materials used in the waste management process include sampling equipment and supplies, shipping containers, drums, packaging materials, pallets, labels, personal protective equipment, and various tools and office supplies.

Equipment used includes vehicles, trucks, haul carts, fork lifts, pallet movers, pallet jacks, hand trucks, cargo containers, tanks, waste bins, scales, and laboratory equipment used in sampling. Since the WGS personnel will be located at various site facilities, with a central support group at CFA, additional vehicles 
will be needed for onsite personnel transportation. Specific vehicle and equipment requirements will be identified during the implementation period.

\subsubsection{Subcontracts}

The INEEL Sample Management Office has several master task subcontracts in place for offsite analytical services. The Environmental Affairs Special Request Monitoring Group has one additional analytical subcontract, which has been extended until the SMO subcontracts add sufficient capacity.

Several of the facilities use subcontract personnel from local consulting companies to supplement their waste management staff. These individuals have been included in the personnel totals in Section 4.4.1.

Waste Operations has several subcontracts in place for offsite recycling, treatment and disposal facilities. In addition, the Packaging and Transportation organization uses subcontractors to provide trucking and transportation services.

\subsubsection{Facilities}

As of March 30, 1998, there were 40 active TAAs. A list of these TAAs is provided in Table 4.2. WGS will assume operation of most of these TAAs. Six of these TAAs are used to manage CERCLA waste. The TAAs used to manage CERCLA waste will continue to, be operated by ER. In addition, some TAAs are tank systems closely tied to operational activities; WGS role in the management of such units will be determined on a case-by-case basis. The WGS goal is to consolidate the many individual TAAs into significantly fewer centralized TAAs at each facility. Additional buildings, cargo containers, and other building improvements such as shelving and secondary containment may be needed to accomplish this.

WGS will also operate a pass-through TSDF located at CPP-1619. This TSDF is used to accumulate wastes prior to offsite shipment, and not for long-term waste storage.

There are currently 77 active SAAs at the INEEL. Most of these will continue to be managed by facility operations. However, there are ten centralized SAAs at CFA used to accumulate commonly-generated wastes such as batteries and light tubes from the entire facility. WGS will take over operation of those centralized SAAs.

Other WGS facility needs will include office space for the sitewide support groups at CFA and for staff at the major facilities; laboratory facilities for sample supply storage, sample preparation, sampling equipment maintenance, and maintenance of field screening equipment; and equipment storage areas. These facilities will be identified during the implementation period.

\subsection{Interfaces}

The current waste management process at the INEEL requires the waste generator to interface with many organizations in order to properly characterize and move waste into final storage and disposal. (See Figure 4.2.) As a result, the current process is cumbersome, time-consuming, and information related to the waste is not efficiently communicated along with the waste. 
THIS PAGE INTENTIONALLY LEFT BLANK. 


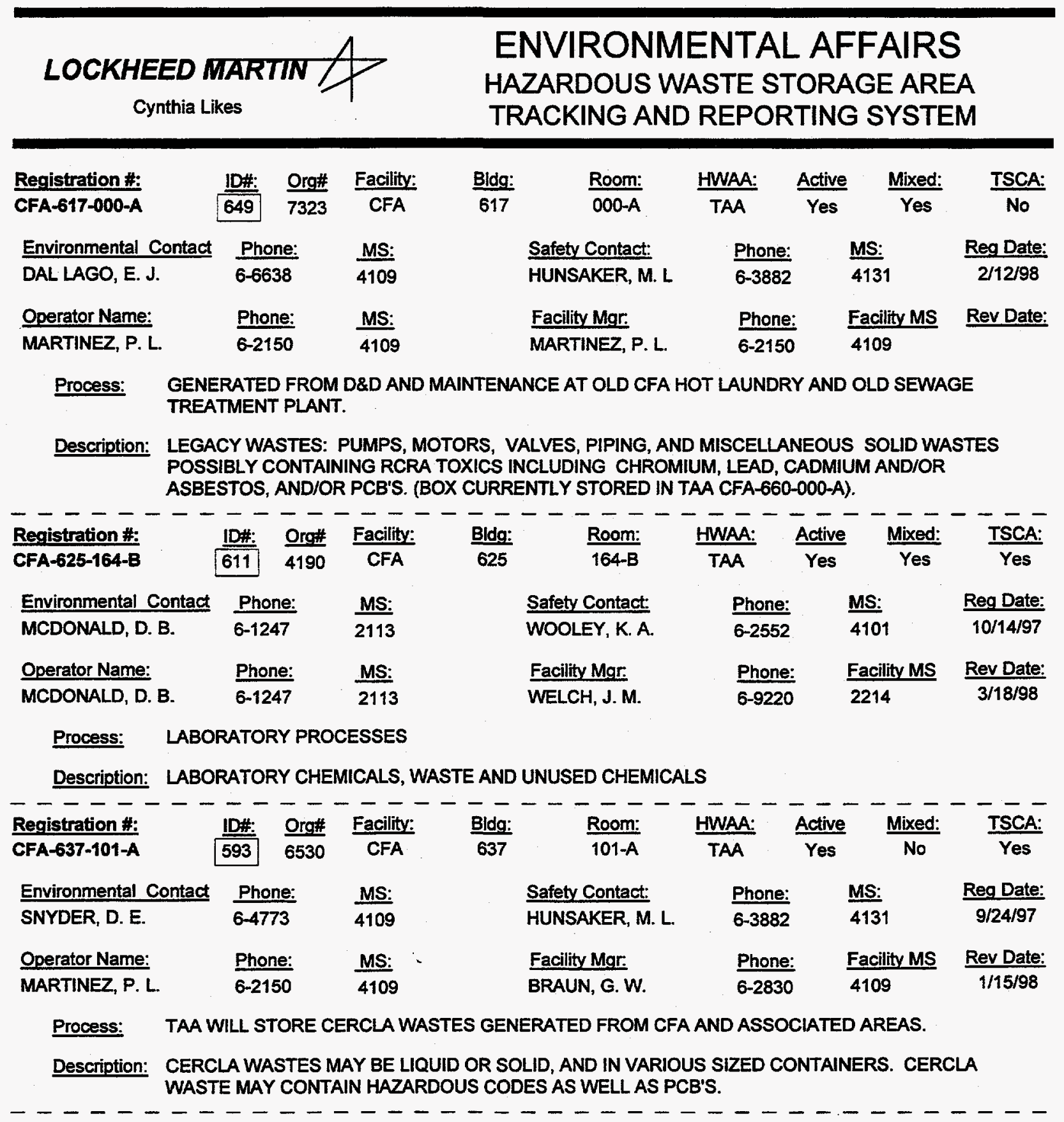

30-Mar-98 Current listing of ALL active TAA registrations located at the INEEL 


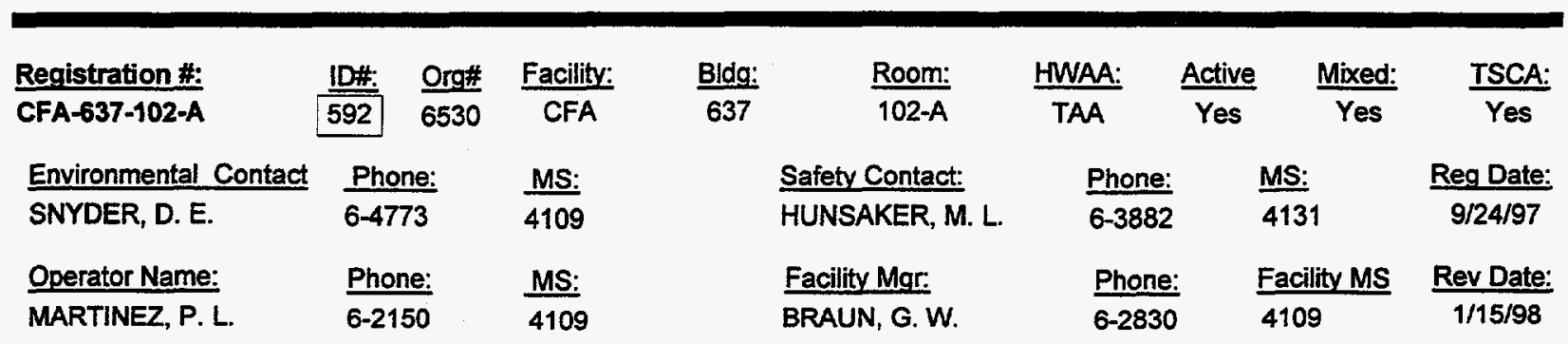

Process: WILL STORE HAZARDOUS AND MIXED WASTE GENERATED FROM CFA AND ASSOCIATED AREAS.

Description: WASTE WILL BE LIQUID OR SOLID, IN VARIOUS SIZED CONTAINERS, RCRA ACCEPTABLE CODES INCLUDE D001, D002. D004 THRU D043, AND F LISTED WASTES. WASTES MAY ALSO CONTAIN PCB'S AND RADIOLOGICAL CONTAMINATION.

\begin{tabular}{|c|c|c|c|c|c|c|c|c|c|}
\hline$\frac{\text { Registration \#: }}{\text { CFA-690-121-B }}$ & ID\#: & $\frac{\text { Org\# }}{9998}$ & $\frac{\text { Facility: }}{\text { CFA }}$ & $\frac{\text { Bldg: }}{690}$ & $\frac{\text { Room: }}{121-\mathrm{B}}$ & $\frac{\text { HWAA: }}{\text { TAA }}$ & $\frac{\text { Active }}{\text { Yes }}$ & $\frac{\text { Mixed: }}{\text { Yes }}$ & $\frac{\text { TSCA: }}{\text { Yes }}$ \\
\hline Environmental Contact & $\mathbf{P h}$ & & MS: & & Safety Contact: & Phone: & & MS: & Reg Date: \\
\hline POLE, S. B. & $6-9$ & & 2107 & & COE-LEAVITT, L. M. & $\overline{6-6085}$ & & 4149 & 3/20/97 \\
\hline Operator Name: & Pho & & MS: & & Facility Mgr: & Phone: & & Facility MS & Rev Date: \\
\hline POLE, S. B. & $6-9$ & & 2107 & & CARLSON, R. D. & $6-2143$ & & 4149 & \\
\hline
\end{tabular}

Process: WASTE MANAGEMENT. RCRA WASTE FROM THE RESL SAAS AND ELSEWHERE ARE RECEIVED INTO THE TAA AND PROCESSED FOR SHIPMENT AND DISPOSAL.

DEscription: PRIMARILY OLD OR SPENT CHEMICALS. ALSO MIXED WASTE.

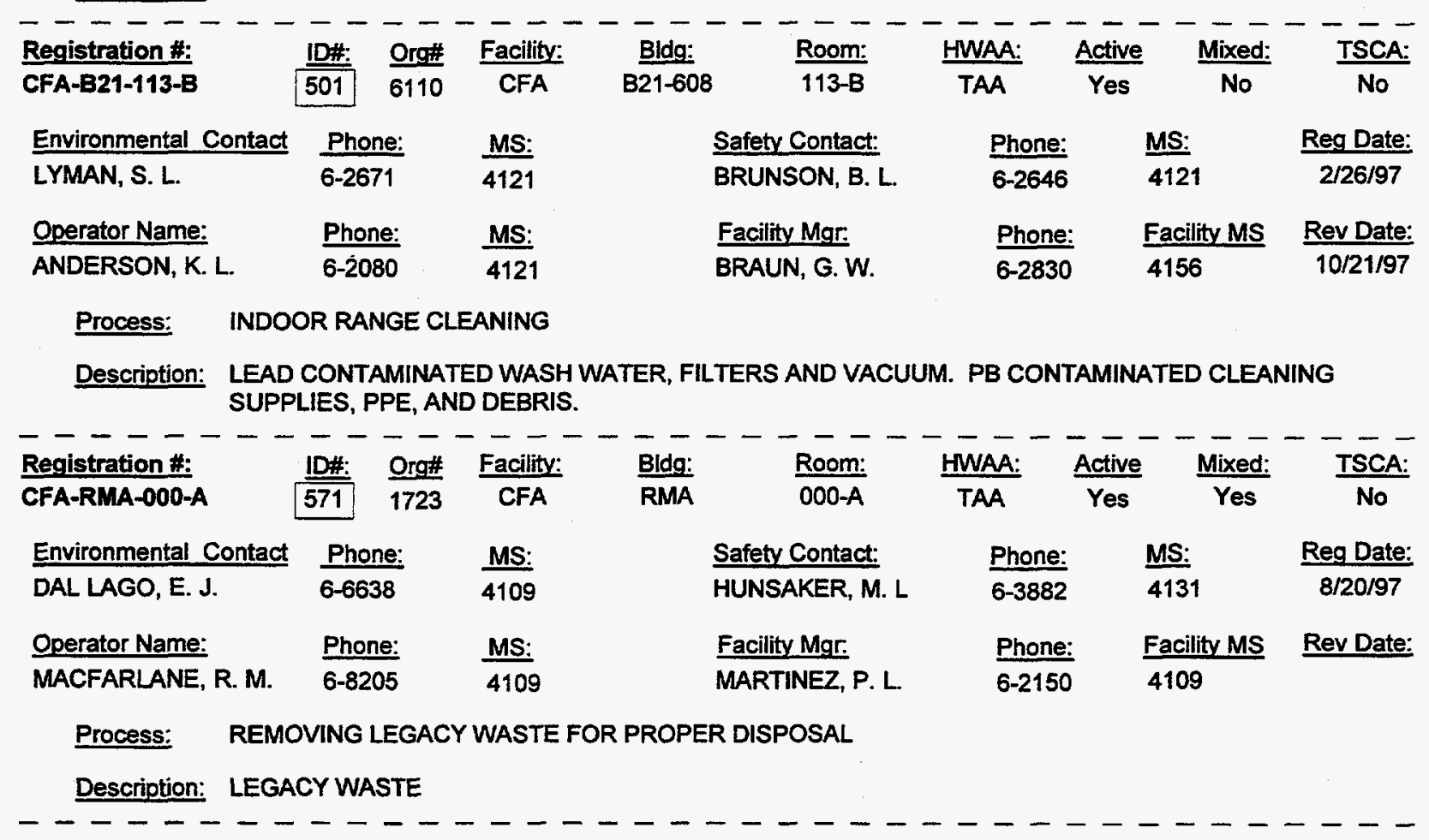




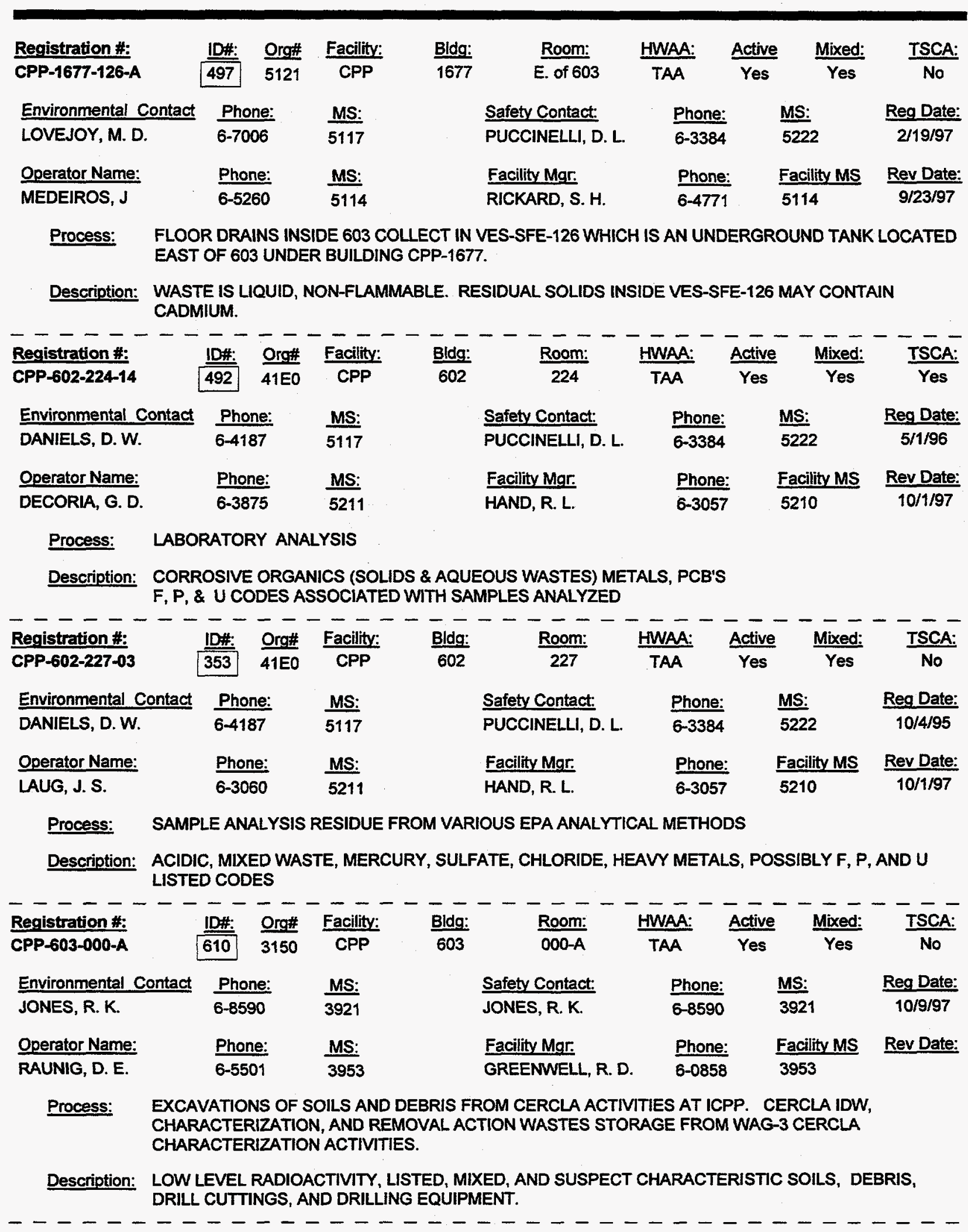




\begin{tabular}{|c|c|c|c|c|c|c|c|c|c|}
\hline$\frac{\text { Registration \#: }}{\text { CPP-604-WO-A }}$ & ID\#: & $\frac{\text { Org\# }}{5221}$ & $\frac{\text { Facility: }}{\text { CPP }}$ & $\frac{\text { Bldg: }}{604}$ & $\frac{\text { Room: }}{\text { WO-A }}$ & $\frac{\text { HWAA: }}{\text { TAA }}$ & $\frac{\text { Active }}{\text { Yes }}$ & $\frac{\text { Mixed: }}{\text { Yes }}$ & $\frac{\text { TSCA: }}{\text { No }}$ \\
\hline $\begin{array}{l}\text { Environmental Contact } \\
\text { GARLAND, M. M. }\end{array}$ & $\frac{\text { Pho }}{6-74}$ & & $\frac{\text { MS: }}{5117}$ & & $\frac{\text { Safety Contact: }}{\text { GAMACHE, S. R. }}$ & $\frac{\text { Phone: }}{6-2807}$ & & $\frac{M S:}{5222}$ & $\frac{\text { Reg Date: }}{7 / 17 / 97}$ \\
\hline $\begin{array}{l}\text { Operator Name: } \\
\text { RALPHS, D. C. }\end{array}$ & $\frac{\text { Phor }}{6-34}$ & & $\frac{\text { MS: }}{5104}$ & & $\frac{\text { Facility Mgr: }}{\text { WHITE, J. }}$ & $\frac{\text { Phone: }}{6-3862}$ & & $\frac{\text { Facility MS }}{5111}$ & Rev Date: \\
\hline
\end{tabular}

Process: MAINTENANCE ACTIVITY; VACUUMING LOOSE DIRT IN APS DUCT.

Description: DIRT, RUST AND PPE.

\begin{tabular}{|c|c|c|c|c|c|c|c|c|c|}
\hline $\begin{array}{l}\text { Registration \#: } \\
\text { CPP-620-HIBAY-02 }\end{array}$ & ID\#: & $\frac{\text { Org\# }}{5220}$ & $\frac{\text { Facility: }}{\text { CPP }}$ & $\frac{\text { Bldg: }}{620}$ & $\frac{\text { Room: }}{\text { HIBAY }}$ & $\frac{\text { HWAA: }}{\text { TAA }}$ & $\frac{\text { Active }}{\text { Yes }}$ & $\frac{\text { Mixed: }}{\text { No }}$ & $\frac{\text { TSCA: }}{\text { No }}$ \\
\hline Environmental Contact & Ph & & $\underline{\text { MS: }}$ & & Safety Contact: & Phone: & & MS: & Reg Date: \\
\hline CUNNINGHAM, P. R. & $6-5$ & & 5117 & & PUCCINELLI, D. L. & $6-3384$ & & 5222 & 2/6/95 \\
\hline Operator Name: & $\mathrm{Ph}$ & & MS: & & Facility Mgr: & Phone: & & Facility MS & Rev Date: \\
\hline O'BRIEN, B. H. & $6-3$ & & $\overline{5218}$ & & CROSON, D. V. & $6-3402$ & & 5218 & $11 / 13 / 97$ \\
\hline
\end{tabular}

Process: DEVELOPMENT ACTIVITIES FOR ICPP PROCESSES, CORROSION STUDIES, AND OTHER LAB STUDIES FROM PILOT PLANTS, MOCK UPS,AND LAB STUDIES IN CPP-637/620

Description: ACIDIC OR NEUTRALIZED ACIDIC RCRA TOXIC METAL LIQUID WASTE, SOLID RCRA TOXIC METAL WASTE

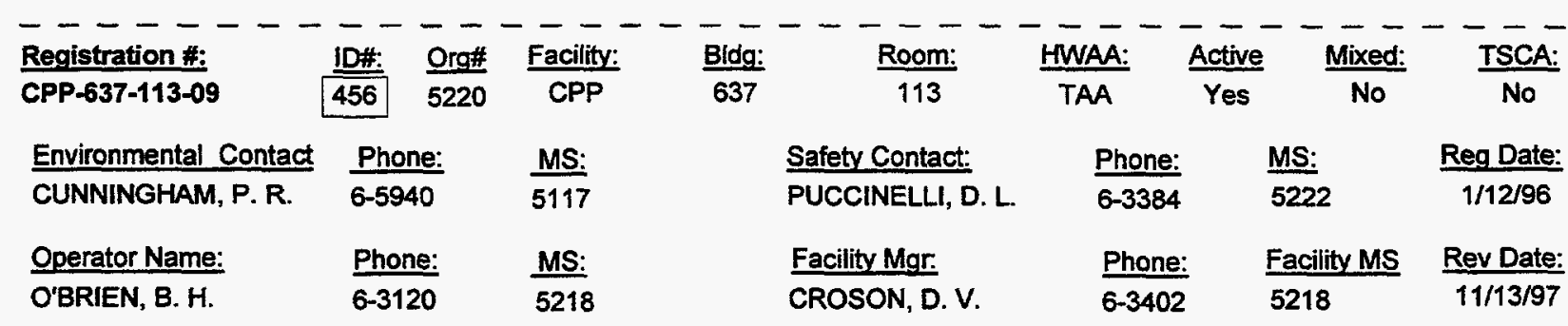

Process: CPP-637 PILOT PLANT AND LABORATORY EXPERIMENTS, NEUTRALIZATION OF CORROSIVE HEAVY METAL WASTE - GTP ON FILE.

DEScription: CORROSIVE WASTE - RCRA TOXIC METALS

\begin{tabular}{|c|c|c|c|c|c|c|c|c|c|}
\hline$\frac{\text { Registration \#: }}{\text { CPP-637-HILO-16 }}$ & ID\#: & $\frac{\text { Orgit }}{5220}$ & $\frac{\text { Facility: }}{\text { CPP }}$ & $\frac{\text { Bldg: }}{637}$ & $\frac{\text { RoOm: }}{\text { HILOBAY }}$ & $\frac{\text { HWAA: }}{\text { TAA }}$ & $\frac{\text { Active }}{\text { Yes }}$ & $\frac{\text { Mixed: }}{\text { No }}$ & $\frac{\text { TSCA: }}{\text { No }}$ \\
\hline $\begin{array}{l}\text { Environmental Contact } \\
\text { CUNNINGHAM, P.R. }\end{array}$ & $\frac{P h c}{6-59}$ & & $\frac{\text { MS: }}{5117}$ & & $\frac{\text { Safety Contact: }}{\text { PUCCINELLI, D. L. }}$ & $\frac{\text { Phone: }}{6-3384}$ & & $\frac{\text { MS: }}{5222}$ & $\frac{\text { Reg Date: }}{8 / 8 / 96}$ \\
\hline$\frac{\text { Operator Name: }}{\text { O'BRIEN, B. H. }}$ & $\frac{\text { Pho }}{6-31}$ & & $\frac{\text { MS: }}{5218}$ & & $\frac{\text { Facility Mgr. }}{\text { CROSON, D. V. }}$ & $\frac{\text { Phone: }}{6-3402}$ & & $\frac{\text { Facility MS }}{5218}$ & $\frac{\text { Rev Date: }}{11 / 13 / 97}$ \\
\hline
\end{tabular}

Process: DEVELOPMENT ACTIVITIES FOR ICPP PROCESSES, COROSION STUDIES, AND OTHER LAB STUDIES FROM PILOT PLANTS, MOCK-UPS, AND LAB STUDIES IN CPP-637/620.

Description: GENERALLY ACIDIC OR NEUTRALIZED ACIDIC RCRA TOXIC METAL LIQUID WASTE AND SOLID WASTE CONTAINING RCRA TOXIC METALS. ALSO UNKNOWN OR PARTIALLY CHARACTERIZED WASTE PENDING ANALYSIES AND UNUSED LAB CHEMICALS. 


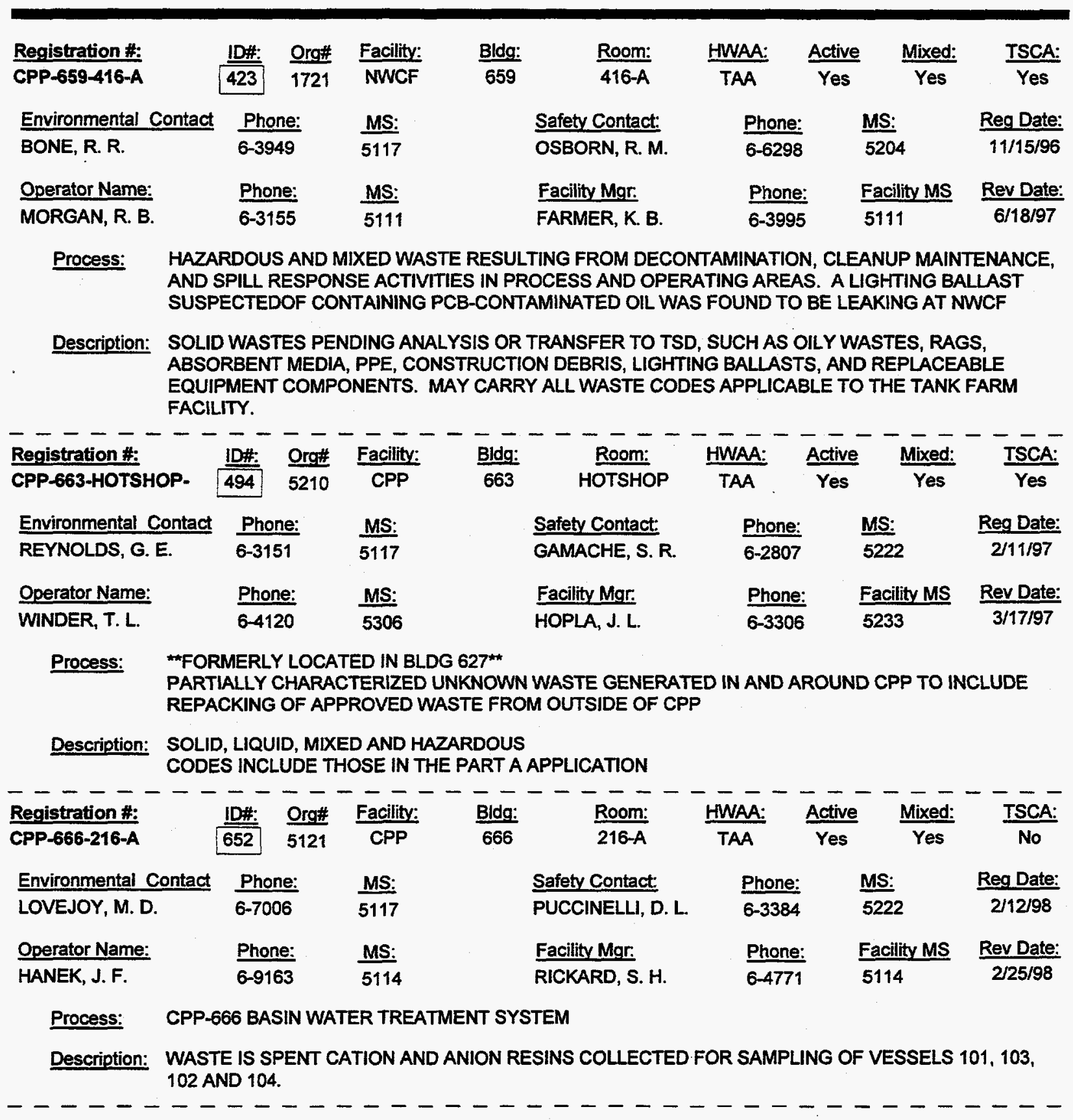

\footnotetext{
30-Mar-98 Current listing of ALL active TAA registrations located at the INEEL
} 


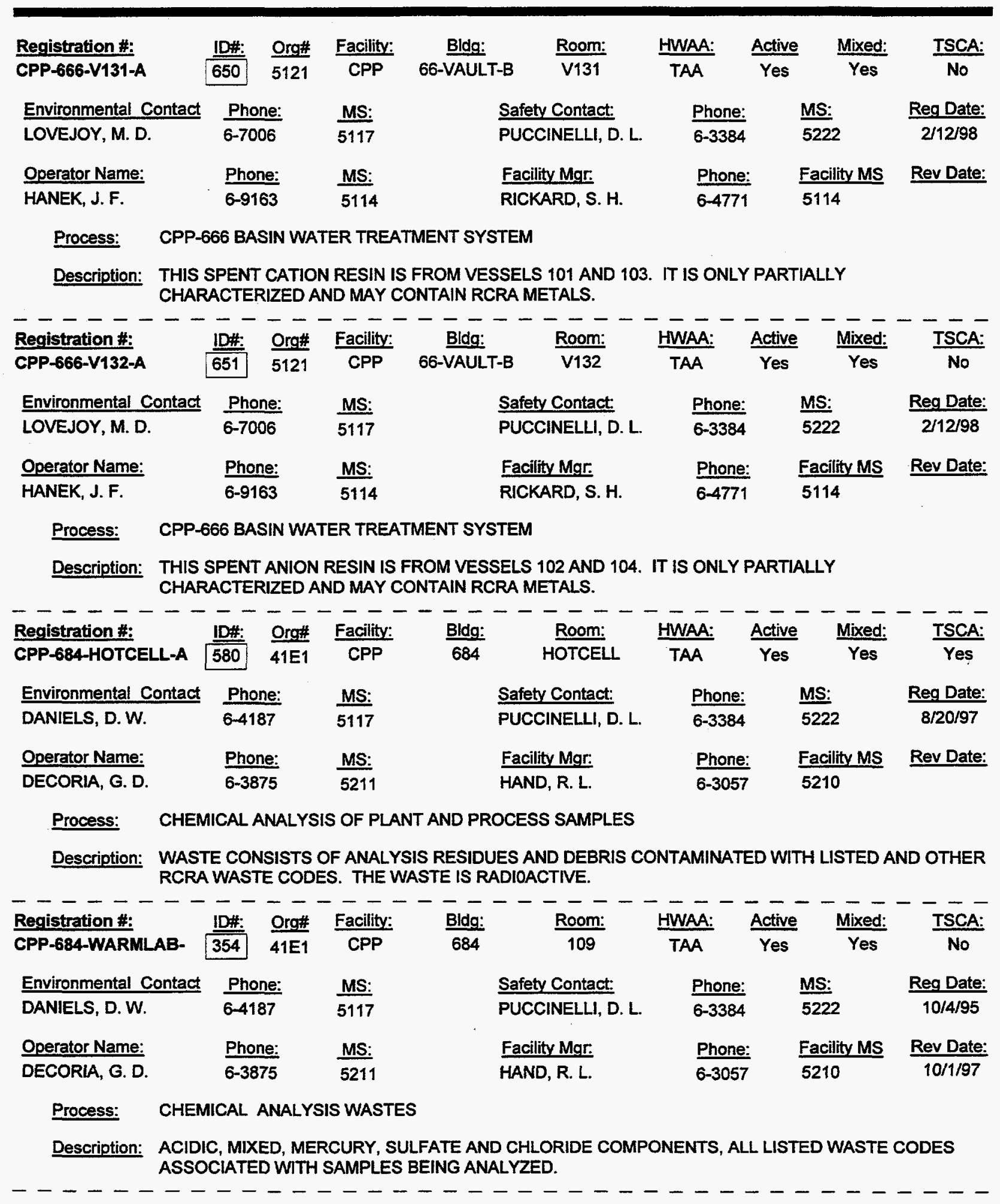




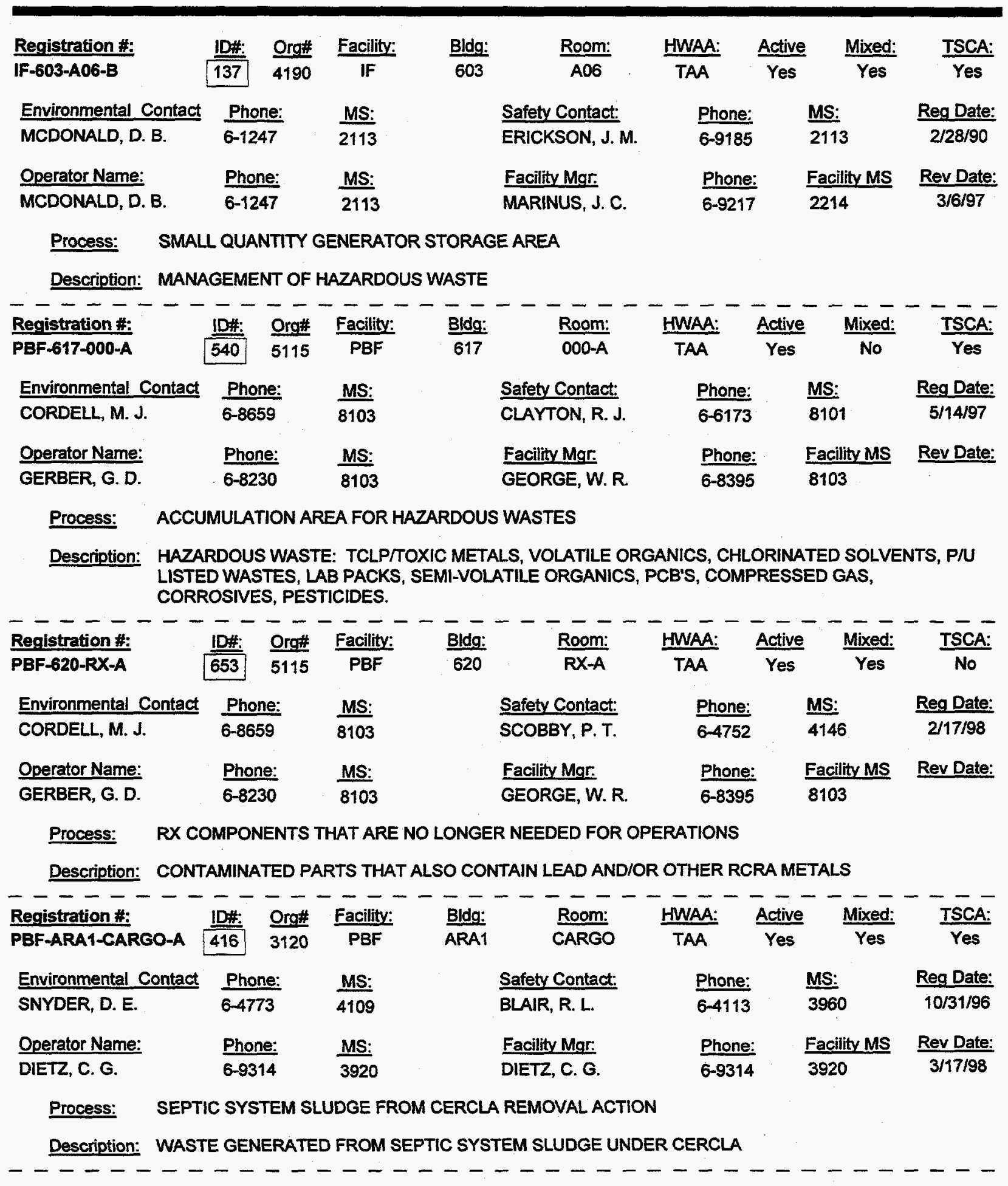

\footnotetext{
30-Mar-98 Current listing of ALL active TAA registrations located at the INEEL
} 


\begin{tabular}{|c|c|c|c|c|c|c|c|c|c|}
\hline$\frac{\text { Registration \#: }}{\text { PBF-ARA1-CON1-B }}$ & ID\#: & $\frac{\text { Org\# }}{3110}$ & $\frac{\text { Facility: }}{\text { PBF }}$ & $\frac{\text { Bldg: }}{\text { ARA1 }}$ & $\frac{\text { Room: }}{\text { CONNEX1 }}$ & $\frac{\text { HWAA: }}{\text { TAA }}$ & $\frac{\text { Active }}{\text { Yes }}$ & $\frac{\text { Mixed: }}{\text { Yes }}$ & $\frac{\text { TSCA: }}{\text { Yes }}$ \\
\hline Environmental Contact & \multicolumn{2}{|c|}{ Phone: } & MS: & & Safety Contact: & Phone: & \multicolumn{2}{|r|}{ MS: } & Reg Date: \\
\hline HOWELL, W. F. & \multicolumn{2}{|c|}{$6-6530$} & $\overline{4109}$ & & CARNES, W. B. & $\overline{6-8090}$ & \multicolumn{2}{|r|}{4146} & $11 / 20 / 97$ \\
\hline Operator Name: & \multicolumn{2}{|c|}{ Phone: } & MS: & & Facility Mgr: & Phone: & \multicolumn{2}{|r|}{ Facility MS } & Rev Date: \\
\hline PELL, G.P. & \multicolumn{2}{|c|}{$6-0451$} & $\overline{3921}$ & & NELSON, R. V. & $6-9863$ & & 3921 & \\
\hline
\end{tabular}

Process: FACILITY D\&D AND SAMPLING WASTE OF THE ARA-I AND ARA II FACILITIES

Description: MIXED WASTE, TSCA WASTE AND POTENTIALLY REACTIVE WASTE AS WELL AS UNKNOW WASTES PENDING SAMPLING AND ANALYSIS.

\begin{tabular}{|c|c|c|c|c|c|c|c|c|c|}
\hline$\frac{\text { Registration \#: }}{\text { RWMC-CC/027-SDA- }}$ & ID\#: & $\frac{\text { Org\# }}{3100}$ & $\frac{\text { Facility: }}{\text { RWMC }}$ & $\frac{\text { Bldg: }}{\mathrm{CC} / 027}$ & $\frac{\text { Room: }}{\text { SDA-A }}$ & $\frac{\text { HWAA: }}{\text { TAA }}$ & $\frac{\text { Active }}{\text { Yes }}$ & $\frac{\text { Mixed: }}{\text { Yes }}$ & $\frac{\text { TSCA: }}{\text { No }}$ \\
\hline Environmental Contact & & & MS: & & Safety Contact: & Phone: & & MS: & Reg Date: \\
\hline JONES, R. K. & $6-8$ & & 3921 & & JONES, R. K. & $6-8590$ & & 3921 & $3 / 25 / 97$ \\
\hline Operator Name: & $\underline{P h}$ & & MS: & & Facility Mgr. & Phone: & & Facility MS & Rev Date: \\
\hline CONNOLLY, J. M. & $6-1$ & & 3910 & & JORGENSEN, D. K. & $6-7022$ & & 3920 & $5 / 8 / 97$ \\
\hline
\end{tabular}

Process: CERCLA INVESTIGATION DERIVED WASTE FROM WAG 7 (RWIM) CERCLA ACTIVITIES (INCLUDING PIT 9 AND PAD A).

Description: LOW LEVEL RADIOACTIVE AND MIXED-LISTED/CHARACTERISTIC TCLP METALS, VOLATILE ORGANICS, SEMIVOLATILE ORGANICS SOILS AND DEBRIS AND PARTIALLY CHARACTERIZED DECONTAMINATION WATER EXPECTED TO BE NON-RCRA WITH TRACE LOW LEVEL.

\begin{tabular}{|c|c|c|c|c|c|c|c|c|c|}
\hline$\frac{\text { Registration \#: }}{\text { RWMC-WMF-602-A }}$ & ID\#: & $\frac{\text { Org\# }}{3230}$ & $\frac{\text { Facility: }}{\text { RWMC }}$ & $\frac{\text { Bldg: }}{\text { WMF }}$ & $\frac{\text { Room: }}{602-A}$ & $\frac{\text { HWAA: }}{\text { TAA }}$ & $\frac{\text { Active }}{\text { Yes }}$ & $\frac{\text { Mixed: }}{\text { Yes }}$ & $\frac{\text { TSCA: }}{\text { Yes }}$ \\
\hline $\begin{array}{l}\text { Environmental Contact } \\
\text { CASFY CF }\end{array}$ & $\frac{P h}{G-1}$ & & MS: & & Safety Contact: & Phone: & & $\frac{\text { MS: }}{4201}$ & $\frac{\text { Reg Date: }}{2 / 18 / 98}$ \\
\hline & & & 4201 & & UBRIEN, J.r. & $6-5179$ & & & 270190 \\
\hline Operator Name: & Phe & & MS: & & Facility Mgr: & Phone: & & Facility MS & Rev Date: \\
\hline CASEY, C.E. & $6-4$ & & 4201 & & KVAMME, J. C. & $6-8667$ & & 4201 & \\
\hline
\end{tabular}

Process: ROUTINE RWMC OPERATIONS

Description: LIGHT BULBS, CONTAMINATED PPE, WIPES, AND PLASTIC, OUTDATED CHEMICALS, PAINT RELATED WASTE, WASTE LIQUIDS INCLUDING FLAMMABLES.

\begin{tabular}{|c|c|c|c|c|c|c|c|c|c|}
\hline$\frac{\text { Registration \#: }}{\text { TAN-604-108-A }}$ & $\frac{\text { ID\#: }}{485}$ & $\frac{\text { Org\# }}{2410}$ & $\frac{\text { Facility: }}{\text { TAN }}$ & $\frac{\text { Bldg: }}{604}$ & $\frac{\text { Room: }}{108-A}$ & $\frac{\text { HWAA: }}{\text { TAA }}$ & $\frac{\text { Active }}{\text { Yes }}$ & $\frac{\text { Mixed: }}{\text { No }}$ & $\frac{\text { TSCA: }}{\text { No }}$ \\
\hline Environmental Contact & & & MS: & & Safety Contact: & Phone: & & MS: & Reg Date: \\
\hline CONRAD, R.W. & $6-6$ & & 0302 & & BRUNSON, T.M. & $6-6420$ & & 0313 & $1 / 27 / 97$ \\
\hline Operator Name: & $\underline{P h}$ & & MS: & & Facility Mgr: & Phone: & & Facility MS & Rev Date: \\
\hline CONRAD, R.W & $6-6$ & & 0302 & & HUMPHRIES, D. L. & $6-4736$ & & 9204 & \\
\hline
\end{tabular}

Process: $\quad$ LEGACY SAMPLES AND UNKNOWN OR PARTIALLY CHARACTERIZED WASTE STREAMS

Description: UNKNOWNS WAITING SAMPLING AND ANALYSIS

30-Mar-98 Current listing of ALL active TAA registrations located at the INEEL 


\begin{tabular}{|c|c|c|c|c|c|c|c|c|}
\hline$\frac{\text { Registration \#: }}{\text { TAN-607-108-A }}$ & $\frac{\text { ID\#: }}{657}$ & $\frac{\text { Org\# }}{5114}$ & $\frac{\text { Facility: }}{\text { TAN }}$ & $\frac{\text { Bldg: }}{607}$ & $\frac{\text { Room: }}{108-A}$ & $\frac{\text { HWAA: }}{\text { TAA }}$ & $\frac{\text { Active }}{\text { Yes }}$ & $\frac{\text { TSCA: }}{\text { Yes }}$ \\
\hline $\begin{array}{l}\text { Environmental Contact } \\
\text { BANISTER M. W }\end{array}$ & $\frac{P h C}{6-25}$ & & $\frac{M S:}{9206}$ & & $\frac{\text { Safety Contact: }}{\text { FIRTH R. B }}$ & & $\frac{\text { MS: }}{9206}$ & $\frac{\text { Reg Date: }}{2 / 25 / 98}$ \\
\hline $\begin{array}{l}\text { Operator Name: } \\
\text { BANISTER, M. W }\end{array}$ & $\frac{\text { Pho }}{6-25}$ & & $\frac{M S:}{9206}$ & & $\begin{array}{l}\text { Facility Mgr: } \\
\text { STREEPER, K. E. }\end{array}$ & $\frac{\text { Phone: }}{6-6151}$ & $\frac{\text { Facility MS }}{9206}$ & Rev Date: \\
\hline
\end{tabular}

Process: INVESTIGATIVE DERIVED WASTE FROM CERCLA ACTIVITIES ASSOCIATED WITH THE TAN V-TANK SYSTEM. MAY INCLUDE SAMPLES, PPE, AND SAMPLES TO BE RETURNED TO THE ORIGINAL AREA OF CONTAMINATION.

Description: SAMPLES AND PPE MAY CONTAIN F LISTED WASTE, TSCA REGULATED MATERIALS AND RADIOACTIVE CONTAMINATION INCLUDING FISSILE MATERIALS.

\begin{tabular}{|c|c|c|c|c|c|c|c|c|c|}
\hline$\frac{\text { Registration \#: }}{\text { TAN-607-115-A }}$ & $\frac{\text { ID\#: }}{127}$ & $\frac{\text { Org\# }}{5100}$ & $\frac{\text { Facillity: }}{\text { TAN }}$ & $\frac{\text { Bldg: }}{607}$ & $\frac{\text { Room: }}{115-A}$ & $\frac{\text { HWAA: }}{\text { TAA }}$ & $\frac{\text { Active }}{\text { Yes }}$ & $\frac{\text { Mixed: }}{\text { Yes }}$ & $\frac{\text { TSCA: }}{\text { No }}$ \\
\hline Environmental Contact & \multicolumn{2}{|c|}{ Phone: } & MS: & & Safety Contact: & Phone: & \multicolumn{2}{|r|}{ MS: } & Reg Date: \\
\hline BANISTER, M. W. & \multicolumn{2}{|c|}{$6-2591$} & $\overline{9206}$ & & BRUNSON, T. M & \multicolumn{2}{|l|}{$\overline{6-6420}$} & $\overline{0313}$ & $2 / 28 / 90$ \\
\hline Operator Name: & \multicolumn{2}{|c|}{ Phone: } & MS: & & Facility Mgr: & \multirow{2}{*}{\multicolumn{2}{|c|}{$\frac{\text { Phone: }}{6-6151}$}} & Facility MS & Rev Date: \\
\hline BANISTER, M. W & \multicolumn{2}{|c|}{$\overline{6-2591}$} & $\overline{9206}$ & & STREEPER, K. E. & & & 9208 & $11 / 14 / 96$ \\
\hline Process: & \multicolumn{4}{|c|}{90 DAY TEMPORARY ACCUMULATION } & & & & & \\
\hline \multicolumn{10}{|c|}{ Description: VARIOUS } \\
\hline Registration \#: & ID\#: & $\overline{\text { Org\# }}$ & Facility: & Bldg: & Room: & HWAA: & Active & $-\overline{\text { Mixed: }}$ & TSCA: \\
\hline TAN-616-000-B & 620 & 1350 & TAN & 616 & $000-B$ & TAA & Yes & Yes & Yes \\
\hline Environmental Contact & Phe & & MS: & & Safety Contact: & Phone: & & MS: & Reg Date: \\
\hline JORGENSEN, M. D. & $\overline{6-38}$ & & $\overline{4109}$ & & FIRTH, R. B. & $\overline{6-6450}$ & & $\overline{4109}$ & 10/30/97 \\
\hline $\begin{array}{l}\text { Operator Name: } \\
\text { BLACKMORE, c. s. }\end{array}$ & $\frac{\text { Pho }}{6-93}$ & & $\frac{\text { MS: }}{3953}$ & & $\frac{\text { Facility Mgr: }}{\text { STREEPER, K. E. }}$ & $\frac{\text { Phone: }}{6-6151}$ & & $\frac{\text { Facility MS }}{9208}$ & $\frac{\text { Rev Date: }}{11 / 12 / 97}$ \\
\hline
\end{tabular}

Process: TO SUPPORT SAMPLING AND D\&D ACTIVITIES FOR TAN-616 AND ASSOCIATED V-TANKS.

Description: PPE (ANTI-C'S, GLOVES, BOOTIES, RESPIRATORS, ETC.) SAMPLING EQUIPMENT (I.E. COLIWASE, CONTAINERS, WIPES), DRY MATERIAL SUCH AS CLOTHES (ANTI-C'S), ETC.

\begin{tabular}{|c|c|c|c|c|c|c|c|c|c|}
\hline$\frac{\text { Registration \#: }}{\text { TAN-624-000-A }}$ & ID\#: & $\frac{\text { Org\# }}{3150}$ & $\frac{\text { Facility: }}{\text { TAN }}$ & $\frac{\text { Bldg: }}{624}$ & $\frac{\text { Room: }}{\text { 000-A }}$ & $\frac{\text { HWAA: }}{\text { TAA }}$ & $\frac{\text { Active }}{\text { Yes }}$ & $\frac{\text { Mixed: }}{\text { Yes }}$ & $\frac{\text { TSCA: }}{\text { Yes }}$ \\
\hline Environmental Contact & Pho & & MS: & & Safety Contact: & Phone: & & MS: & Reg Date: \\
\hline JORGENSEN, M. D. & $6-38$ & & 4109 & & JONES, R. K. & $6-8590$ & & 3921 & 9/25/97 \\
\hline $\begin{array}{l}\text { Operator Name: } \\
\text { BLACKMORE, C. S. }\end{array}$ & $\frac{\text { Pho }}{6-93}$ & & $\frac{\text { MS: }}{3953}$ & & $\frac{\text { Facility Mgr. }}{\text { GREEN, T. S. }}$ & $\frac{\text { Phone: }}{6-9420}$ & & $\frac{\text { Facility MS }}{3953}$ & $\frac{\text { Rev Date: }}{11 / 25 / 97}$ \\
\hline
\end{tabular}

Process: VARIOUS CERCLA REMEDIATION PROJECTS AT TAN. THE WASTES INCLUDE NON-LIQUID WASTES CURRENTLY STORED IN TAN 624.

Description: MIXED WASTES: LOW LEVEL RAD WASTES, RECENTLY CLASSIFIED AS MIXED WASTES DUE TO THE DISCOVERY OF LISTED SOLVENTS.

30-Mar-98 Current listing of ALL active TAA registrations located at the INEEL 


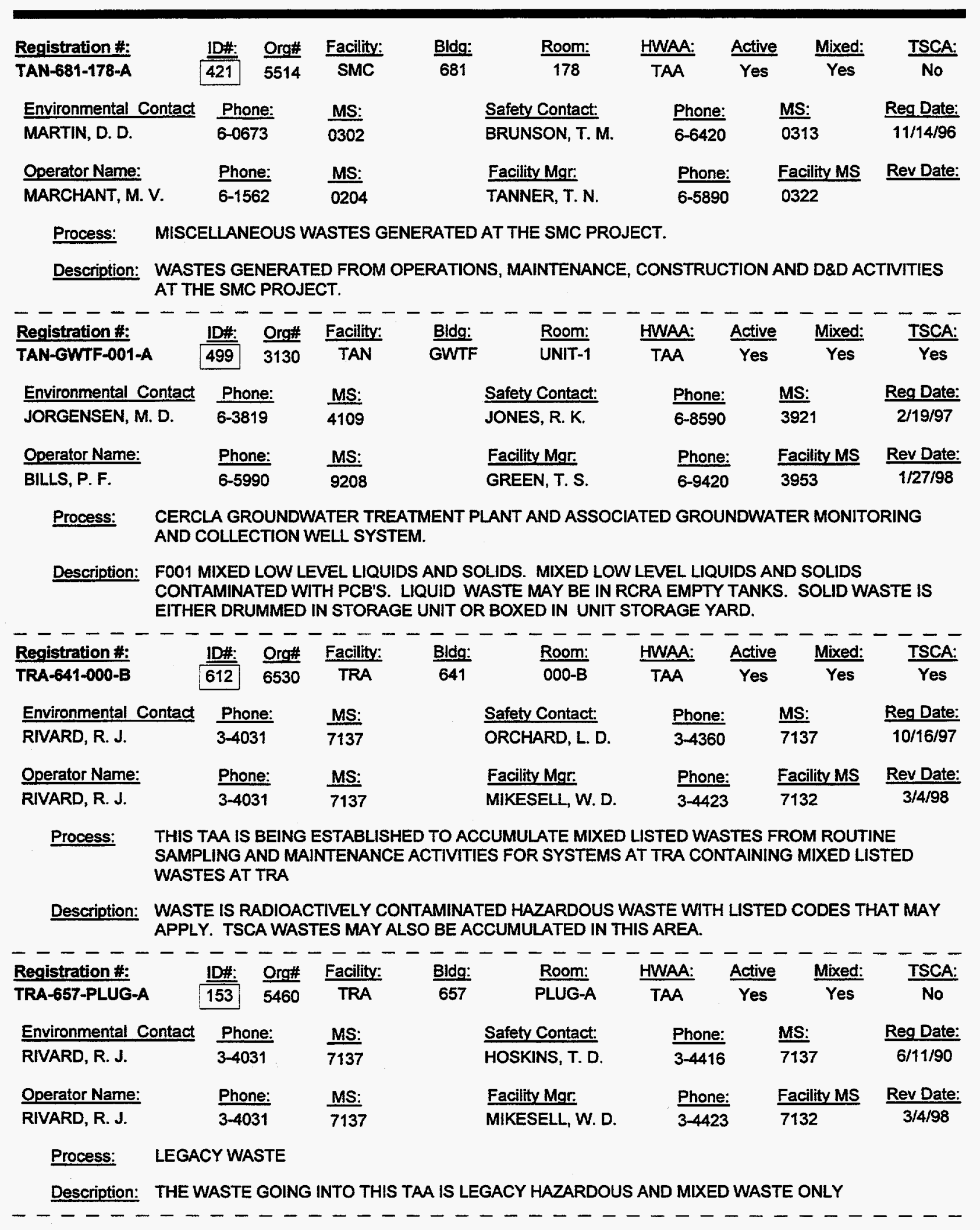




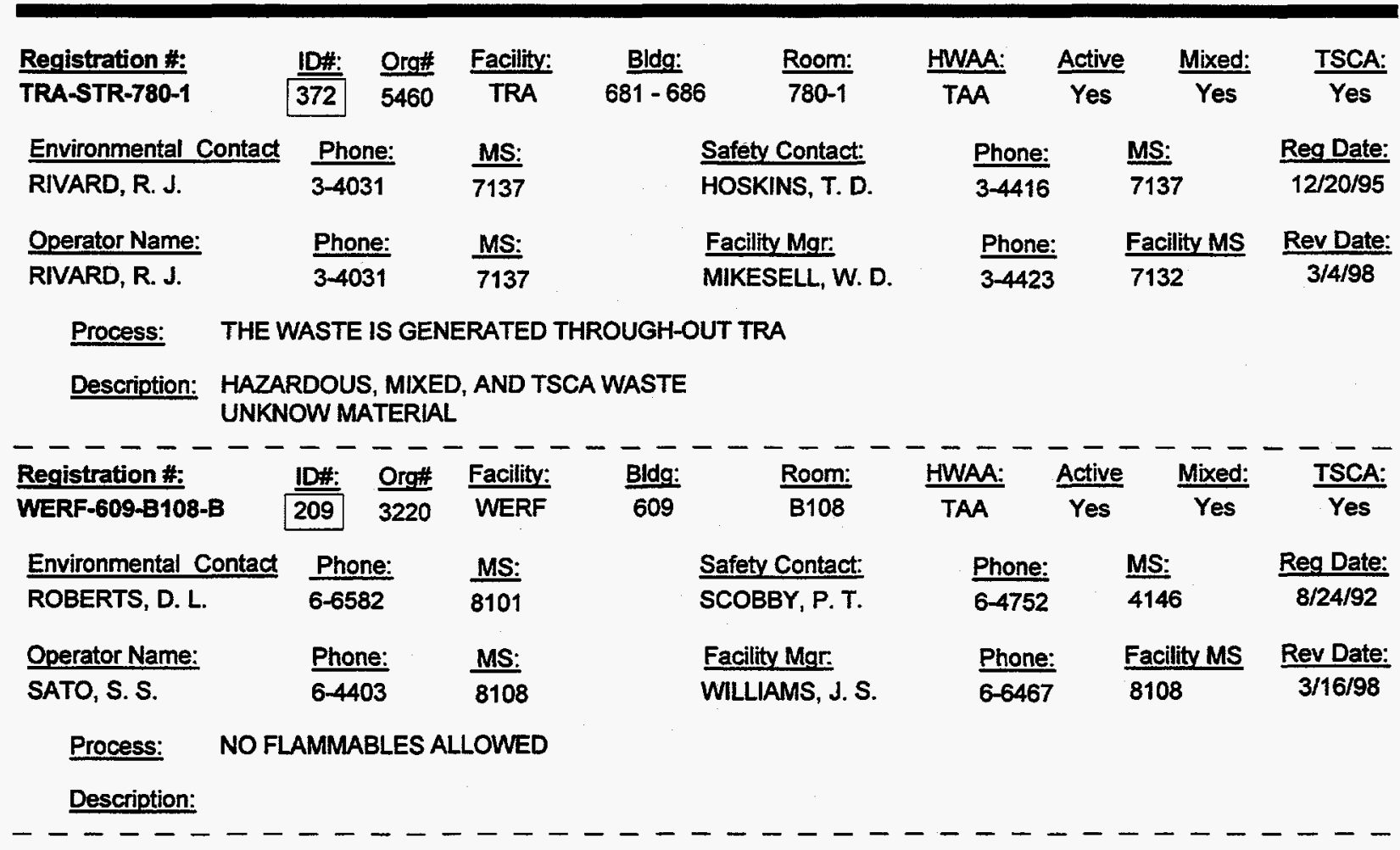

MASTER LIST.... Please notify Darrell Lake 6-7005 of any changes to this report 


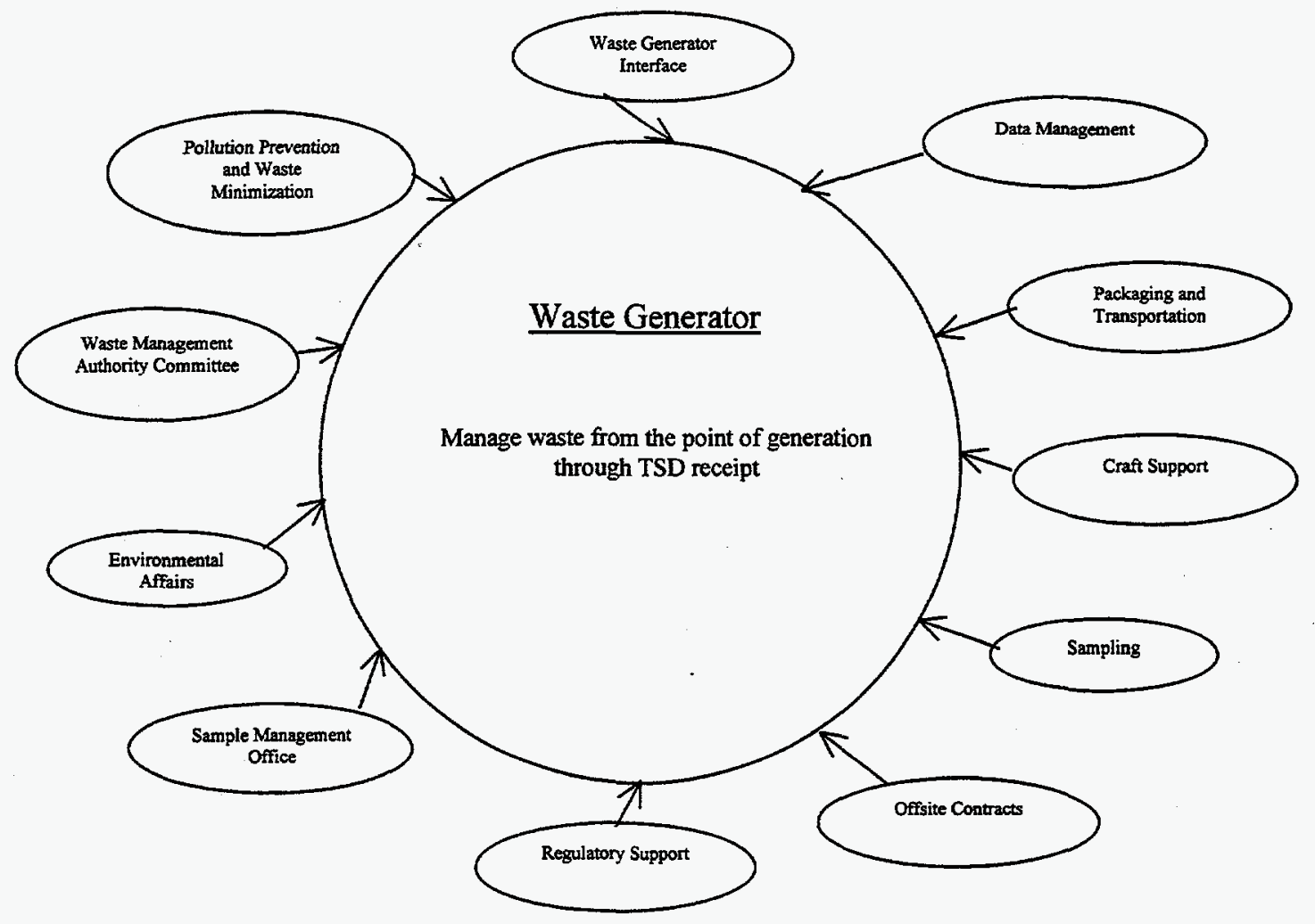

Figure 4.2. Current Organizational Interfaces.

A key to the success of the Waste Generator Services concept is the minimization of interface functions with external organizations. Moving crucial waste management functions within one organization will streamline processes and enhance communications and efficiencies. (See Figure 4.2). Figure 4.3 illustrates the proposed WGS organizational interfaces.

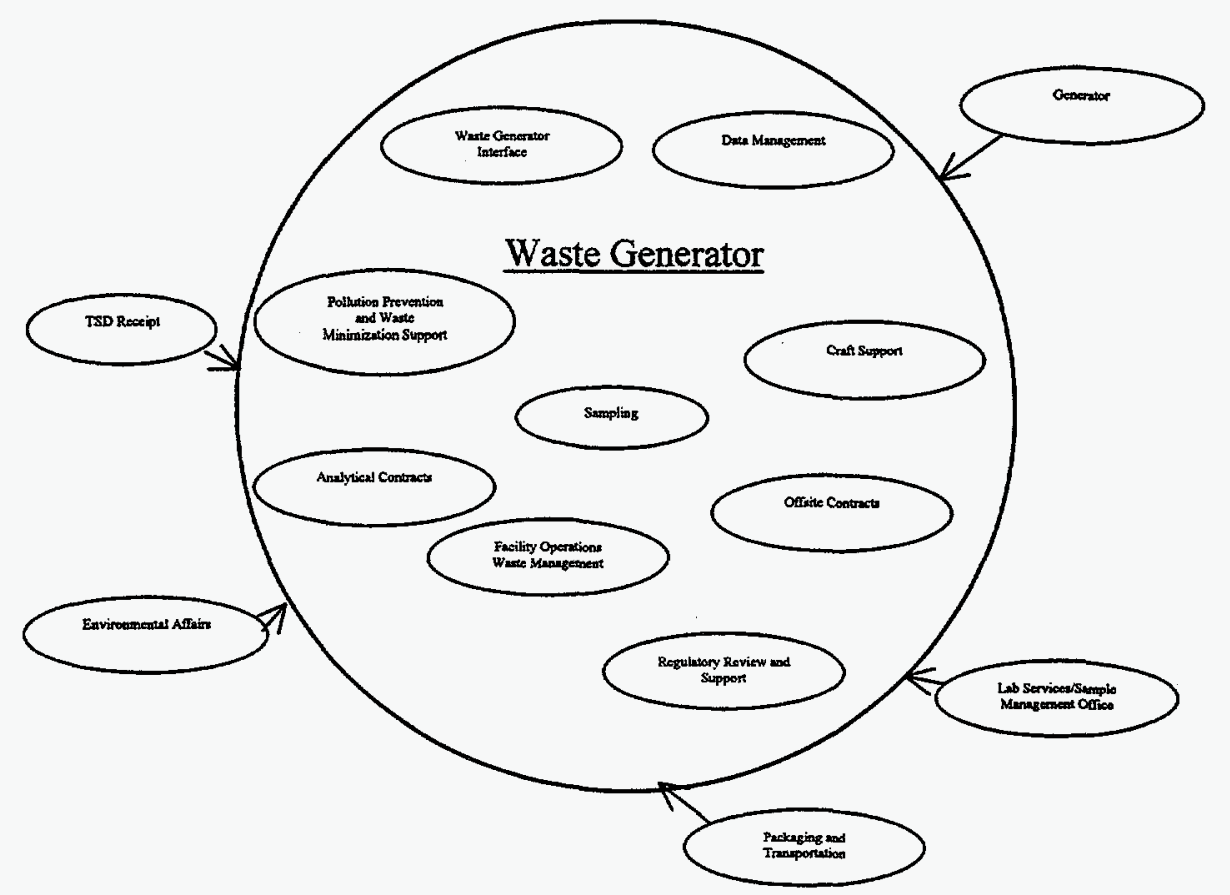

Figure 4.3. Proposed Organizational Interfaces. 


\subsubsection{Interfaces with WGS Customers}

There are two primary customers for the Waste Generator Services organization: the waste generator (or

"source") and the receiving treatment, storage, and disposal facility.

- WGS will provide a single point-of-contact for each waste-generating facility/program. This pointof-contact will serve as the single WGS interface with the source, from pre-generation planning activities through final waste disposal. A WGS Facility Team Lead will be assigned to provide this interface for each waste generating facility/program.

- Most of the waste management process will be "invisible" to the source. Once WGS has been contacted, and the waste management planning has been completed, waste management activities by the source should be minimal.

- WGS will assume responsibility for managing the waste at the time it is moved into a WGS-operated storage facility (e.g., TAA, centralized SAA). WGS will be accountable for proper management of the waste. The source will be accountable for proper management of the waste prior to transfer to a WGS-operated facility and for providing complete and accurate information for waste characterization/determination purposes.

- WGS will be responsible for ensuring that the waste meets the waste acceptance criteria for the designated receiving facility and for serving as the interface between the source and the receiving facility. There should be no need for direct communication between the source and the receiving facility.

\subsubsection{Environmental Affairs}

Environmental Affairs (EA) and WGS will not duplicate functions. The interface between these two organizations must be clear, and frequent communication will be essential to ensure regulations are consistently interpreted and applied. The WGS RCRA Regulatory Specialist will serve as the primary interface with Environmental Affairs for regulatory interpretations, review of policy and procedures, and other regulatory decisions.

The following roles and responsibilities were defined by the WGS Integrated Process Team held in late January.

- EA will serve as the company point-of-contact with regulatory agencies (State of Idaho DEQ, EPA), but will include WGS in negotiations related to WGS activities.

- EA is responsible for setting environmental policy, writing top-level company procedures, and providing regulatory interpretations on non-routine matters. These will be provided in a time frame that actively supports operational needs. The receiving facility or WGS will be included in policy decisions or interpretations that will affect the receiving facility or WGS activities.

- EA will have responsibility for independent oversight and performance assessment.

- WGS will be responsible for daily waste management functions including waste characterization and determinations, TAA management, and day-to-day RCRA guidance to operations regarding WGS activities. 
- Implementing procedures for managing waste will be written and maintained by WGS, with EA review.

- WGS will be responsible for self-assessment and routine inspection of its own activities and facilities.

Clarification of responsibilities is further defined in Table 4.3

\subsubsection{Site Treatment Plan}

When a new mixed waste is identified, the waste technical specialist will coordinate with the STP staff, also in WGS, to ensure the waste is properly documented in the STP. Because both functions are within WGS, interfaces should be efficient.

\subsubsection{RRWAC}

The INEEL Reusable Property, Recyclable Materials, and Waste Acceptance Criteria (RRWAC), DOE/ID-10381, will be managed and maintained by WGS. This document will require significant revision to reflect the accountability and process flow of WGS. This document will also be streamlined such that information covered in operational procedures is not duplicated in the RRWAC. The RRWAC should be the source document that reflects the DOE-ID/LMITCO waste acceptance criteria for INEEL TSD waste processes, and be based upon the regulatory requirements, permit conditions, and operating requirements for each of these processes. Work to revise the RRWAC will begin after the PDD for WGS is prepared and approved, and will be completed by the end of FY 1998. WGS will have the responsibility to update the RRWAC according to permit changes. WGS waste technical specialist personnel shall use the RRWAC as the basis of waste acceptance for the INEEL TSDs.

\subsubsection{Bargaining Unit Labor Interface}

The Waste Handler Technician classification worker (to be defined in the LMITCO/OCAW bargaining agreement) will participate on a cross-functional team to support the fieldwork associated with WGS. The Waste Handlers will work from a central location and perform tasks across the site through the crossfunctional team approach. Duties will include operating specific equipment (i.e., forklifts) moving and managing cold, low-level, mixed, and hazardous waste; transporting waste between INEEL facilities; operating hazardous waste, low-level waste, and mixed waste processing equipment; supporting professionals in weekly inspections, waste tracking, and waste sampling, waste packaging, and labeling.

The current Waste Handler classification in place for ICPP will be expanded to all site facilities. Work classifications required by WGS will be 1) Waste Handler Trainee, 2) Waste Handling Technician I, and 3) Waste Handling Technician II. The Waste Handler job classifications and the cross-functional team approach will be negotiated in the 1998 LMITCO/OCAW subcontract negotiations. The WGS Waste handlers would be matrixed full-time from the WROC Waste Handler pool.

Other interfaces with the bargaining unit will be to obtain radiological control technicians, crafts support, and equipment operators to support waste shipment, packaging, and sampling activities.

\subsubsection{Reporting Interface}

WGS will be responsible for managing and tracking waste inventories and shipments; as a result, WGS will also be responsible for providing waste generation information to support the preparation of various 
reports. A description of these reports, and the organizational responsibilities for preparing them, follows. The Environmental Affairs role in the review and submittal of these reports is an interface that must be clearly defined during the implementation period.

\section{RCRA Biennial Report}

This biennial report summarizes hazardous waste activity at the INEEL and must be submitted to the State of Idaho no later than March 1 of every even-numbered year. This report is currently prepared by the Environmental Affairs Directorate. Environmental Affairs requests the necessary information from all INEEL operations, including NRF and ANL-West, compiles the information, and verifies the data by comparing it with the information in the Generator Quarterly Reports, the IWTS database, and the hazardous waste manifests. Responsibility for preparation of these reports will be functionally transferred to WGS.

\section{Idaho Hazardous Waste Generator Annual Report}

Information is collected quarterly and a report generated and sent to the State on an annual basis, due by end of January each calendar year. Information is organized by RCRA waste code, quantity of hazardous waste generated, quantity remaining in storage, and quantity and method of disposition or treatment. Information is requested from all INEEL generators, including NRF and ANL-West.

These reports are currently prepared by the Waste Technology Planning and Projects Department in the Waste Operations Directorate. Responsibility for preparation of these reports will be functionally transferred to WGS.

\section{Annual Site Treatment Plan Report}

The mixed waste inventory in storage at the INEEL is updated quarterly by the Waste Technology Planning and Projects Department in Waste Operations, and submitted to the State of Idaho. An annual report summarizing progress towards meeting the Site Treatment Plan milestones, with an update of the Site Treatment Plan, is submitted to the State in November. The State releases the report and the updated STP for a public comment period.

These reports are currently prepared by the Waste Technology Planning and Projects Department in the Waste Operations Directorate. Responsibility for preparation of these reports will be functionally transferred to WGS.

\section{Pollution Prevention Reports}

The Annual Report on Waste Generation and Reduction and the Quarterly Waste Reduction Reports are submitted to DOE-HQ. These reports are prepared by Environmental Affairs and contain information on pollution prevention (P2) initiatives and the resulting waste reduction and cost savings, waste generation rates, and a summary of pollution prevention activities and programs. Since these reports contain a great deal of information in addition to waste generation rates, Environmental Affairs will continue to coordinate their preparation. However, information on waste generation rates will be provided by the WGS organization. 


\section{Annual Treatability Studies Report}

This report lists treatability studies conducted during the past year and must be submitted annually to the State of Idaho by March 15 . Treatability studies are conducted on samples to identify potential waste treatment technologies. These studies are usually conducted by AEDL personnel, and are project managed by Waste Operations personnel. Environmental Affairs is responsible for preparing the 45-day treatability study notifications for the State of Idaho and for compiling the Annual Treatability Studies Report.

Responsibility for preparing treatability study notifications and the associated annual report will be functionally transferred to WGS.

\section{TSCA Annual Reports •}

Three TSCA reports are prepared annually to satisfy the requirements of 40 CFR761.180:

- The 180 a Report must be prepared by July 1 each year and contains a summary of all PCB wastes shipped offsite for incineration, with copies of the manifests. This report must be maintained on file.

- The $180 \mathrm{~b}$ report contains a mass balance of PCB wastes generated, in storage, and shipped offsite for treatment. This report is submitted annually to EPA Region X by July 15.

- The Annual PCB National Status report must be submitted to DOE in November annually. This report contains an annual update of the radioactive TSCA inventory at the INEEL. This information is summarized Complex-wide by DOE-HQ and submitted to EPA by February each year to satisfy a Compliance Agreement requirement.

Environmental Affairs currently prepares these reports. Data is obtained from Waste Operations and the INEEL facilities storing radioactive PCBs. Information from NRF and ANL-West is included in the TSCA reporting. The role of the WGS organization in preparing these reports has not yet been determined, and will be evaluated and further defined during the implementation period.

\subsubsection{Sampling and Analysis Interface}

Currently, waste characterization sampling is performed by several organizations. The majority of this sampling is performed by the Special Request Monitoring Program (SRMP) within the Environmental Monitoring unit of Environmental Affairs.

A group of core personnel from the SRMP will be functionally transferred into the WGS organization to conduct waste characterization sampling. Additional sampling personnel will be matrixed from AEDL as needed.

The SRMP has prepared boiler-plate Abbreviated Sampling and Analysis Plans (ASAPs) that can easily be modified to incorporate task-specific safety and customer requirements. The ASAPs require review and approval by Radiological Control (if applicable), Industrial Hygiene/Industrial Safety, and the sample requestor prior to sampling. The interface with $\mathrm{Rad} \mathrm{Con}$ and IH/IS personnel often results in significant delays due to conflicting priorities and workload. During the Integrated Process Team meeting, it was recommended that one or two dedicated Rad Con and IH/IS personnel be matrixed to the WGS organization to streamline the review process. Rad Con and IH/IS support needs will be evaluated during WGS implementation. 
The INEEL Sample Management Office (SMO) is currently located within the Sample Management and Risk Technologies Department in the Environmental Restoration Directorate. The SMO provides services to all EM-funded activities at the INEEL, per DOE policy. These services include acquisition of laboratory services in accordance with DOE-ID make-buy policy, laboratory performance oversight, data validation, general consultation on analytical data quality objectives, and coordination of sample waste disposal from offsite laboratories. Since the SMO provides services to INEEL organizations other than WGS, and much of its workload is not waste-related, the SMO will not reside within the WGS organization. Rather, SMO services will be matrixed as needed.

The SMO recently established umbrella Task Order Statements of Work (TOSs) for the SRMP. These TOSs will streamline the sampling process by allowing the sampling team to procure and schedule their own analytical services with several SMO subcontracted laboratories. These TOSs will be used by the WGS Organization once it is established. The sampling team will track their samples using the SMO sample and data tracking database. This provides the SMO with the necessary performance monitoring data to evaluate laboratory performance and to make decisions regarding future allocation of analytical work.

Invoices for lab services will be received and processed by the SMO using the information in the tracking databases. Day-to-day communications with laboratories and follow-up regarding WGS samples will be conducted by the sampling team. Performance issues that may affect the subcontractual status of laboratories will be addressed by the SMO and LMITCO Procurement.

When validation is required, the sampling team will request these services from the SMO. Validation services are typically provided by subcontractors with an 18-day turnaround. Ten-day rush requests can be accommodated when capacity exists. If a shorter turnaround is needed, validation can be provided by in-house personnel at additional cost.

\subsubsection{Packaging and Transportation}

The Packaging and Transportation (P\&T) services at the INEEL were consolidated into one organization within Waste Operations in 1995. The P\&T organization has located shippers at each major waste generating operation at the INEEL. These shippers provide P\&T services for both waste and other materials shipments. WGS will utilize the existing P\&T organization and staff for waste shipments. The interface agreement with WGS will be through the WGS Projects Support Supervisor, but work requests for shipping will be the responsibility of the waste technical specialists.

\subsubsection{Safety \& Health Support}

Radiological Control, Industrial Safety and Industrial Hygiene support is routinely required for reviews of Sampling and Analysis Plans and support of waste characterization sampling activities. Radiological Engineering also provides support to INEEL waste generators for radionuclide characterization of wastes to satisfy the radiological waste acceptance criteria established by the TSD facilities. This effort requires approximately two to four FTEs of Radiological Control support annually.

During the implementation period, S\&H support requirements will be further defined and agreements will be established to obtain the necessary S\&H matrix support. Establishing a matrix agreement for full-time S\&H support to the WGS organization would alleviate bottlenecks associated with conflicting work priorities. 
Table 4.3. Waste Generator Services Work Scope Transfer Matrix

\begin{tabular}{|c|c|c|}
\hline Activity & Current Performing Org. & Future Performing Org. \\
\hline \multicolumn{3}{|l|}{$\begin{array}{l}\text { Document Reviews (work orders, project design } \\
\text { packages, procedure revisions, permit applications, } \\
\text { environmental checklists, etc.) }\end{array}$} \\
\hline $\begin{array}{l}\text { - Initial review for general environmental } \\
\text { requirements }\end{array}$ & EFS & EFS \\
\hline $\begin{array}{l}\text { - Contact WGS for identification of waste } \\
\text { management requirements }\end{array}$ & N/A & EFS \\
\hline $\begin{array}{l}\text { - Identify waste management requirements and } \\
\text { initiate waste management planning }\end{array}$ & EFS & WGS \\
\hline \multicolumn{3}{|l|}{ Waste Disposition Planning } \\
\hline $\begin{array}{l}\text { - Evaluate/document process knowledge and } \\
\text { identify additional sampling }\end{array}$ & EFS, waste generator & WGS \\
\hline $\begin{array}{l}\text { Identify source reduction and waste } \\
\text { minimization options }\end{array}$ & EFS, waste generator & $\overline{\text { WGS }}$ \\
\hline $\begin{array}{l}\text { - Complete waste characterization/shipping } \\
\text { forms }\end{array}$ & EFS, waste generators, WGI & WGS \\
\hline - Prepare Sampling \& Analysis Plan & EA, other groups & WGS \\
\hline - Collect samples & EA, other groups & $\overline{\text { WGS }}$ \\
\hline - Evaluate analytical data & EA, WGI & WGS \\
\hline - Input data into company database (IWTS) & EFS, waste generators, WO & WGS \\
\hline - Identify disposal/treatment options & WO(WGI) & WGS \\
\hline $\begin{array}{l}\text { Ensure that waste meets waste acceptance } \\
\text { criteria for receiving facility }\end{array}$ & WO(WGI) & WGS \\
\hline - Prepare Waste Certification Plans & WGI, waste generators & WGS \\
\hline $\begin{array}{l}\text { Facility point-of-contact for any outside, } \\
\text { regulatory inspections }\end{array}$ & EFS, Operations & EFS, Operations \\
\hline $\begin{array}{l}\text { Coordinate NOV response and Consent Order } \\
\text { negotiations }\end{array}$ & EA & EA \\
\hline $\begin{array}{l}\text { Provide informal environmental training to } \\
\text { operations }\end{array}$ & $\overline{\text { EFS }}$ & $\overline{\mathrm{EA}}$ \\
\hline $\begin{array}{l}\text { Provide informal environmental training related to } \\
\text { waste management }\end{array}$ & EFS, WGI & WGS \\
\hline Purchase Requisition Reviews & EA, EFS & EA, EFS \\
\hline $\begin{array}{l}\text { Provide advice to operations regarding env. } \\
\text { Requirements associated with WGS scope (waste } \\
\text { characterization, waste accumulation, and } \\
\text { TAA/SAA mgt.) }\end{array}$ & EA, EFS, WGI & WGS \\
\hline $\begin{array}{l}\text { Provide advice to operations regarding other env. } \\
\text { Requirements (Clean Air Act, Clean Water Act, } \\
\text { TSCA, Safe Drinking Water Act, CERCLA, } \\
\text { EPCRA) }\end{array}$ & EA, EFS & EA, EFS \\
\hline Answer env. Questions related to TSDF operations & EA, EFS, WGI & EA, EFS \\
\hline $\begin{array}{l}\text { Communicate new environmental requirements to } \\
\text { facility personnel }\end{array}$ & EA, EFS & EA, EFS \\
\hline
\end{tabular}




\begin{tabular}{|c|c|c|}
\hline Activity & Current Performing Org. & Future Performing Org. \\
\hline Prepare and disseminate regulatory interpretations & EA & EA \\
\hline Waste Management Authority activities & EFS & WGS \\
\hline ICMS support & EA, EFS & EA, EFS \\
\hline $\begin{array}{l}\text { Permitting Applicability Reviews and Permit } \\
\text { Preparation }\end{array}$ & $\overline{\mathrm{EA}}$ & $\overline{\mathrm{EA}}$ \\
\hline $\begin{array}{l}\text { Develop site-wide environmental policy and top- } \\
\text { level procedures }\end{array}$ & EA & EA \\
\hline \multicolumn{3}{|l|}{ Prepare Env. Reports } \\
\hline Company point of contact with regulatory agencies & EA & $\overline{E A}$ \\
\hline $\begin{array}{l}\text { Provide general independent environmental } \\
\text { oversight of facility operations }\end{array}$ & $\overline{\mathrm{EA}}$ & $\mathrm{EA}$ \\
\hline $\begin{array}{l}\text { Maintain SAA/TAA Database, register and close } \\
\text { SAAs \& TAAs }\end{array}$ & $\overline{E A}$ & WGS \\
\hline Operate "pass-through" TSDFs (i.e., CPP-1619) & WO & WGS \\
\hline $\begin{array}{l}\text { Provide routine oversight/inspection of SAAs and } \\
\text { TAAs }\end{array}$ & $\overline{E F S}$ & WGS \\
\hline $\begin{array}{l}\text { Maintain records associated with WGS activities } \\
\text { (waste characterization, inventories, manifests, } \\
\text { reports, etc.) }\end{array}$ & EA, Operations, WO & $\overline{\text { WGS }}$ \\
\hline Maintain waste management databases & $\overline{\text { WO }}$ & $\overline{\text { WGS }}$ \\
\hline \multicolumn{3}{|l|}{ Permitting } \\
\hline - Conduct permitting applicability reviews & EA & $\overline{\mathrm{EA}}$ \\
\hline - Prepare Generator Treatment Plans & EA, waste generator, WGI & WGS \\
\hline - Prepare LDR Notifications & EA, waste generator, WGI & $\overline{\text { WGS }}$ \\
\hline - Prepare Treatability Studies Notifications & EA, WO & $\overline{\mathrm{EA}}$ \\
\hline - Coordinate RCRA Part B Permitting & $\mathbf{E A}$ & $\overline{\mathrm{EA}}$ \\
\hline \multicolumn{3}{|l|}{ Pollution Prevention (P2) } \\
\hline $\begin{array}{l}\text { - Ensure that } P 2 \text { considerations are included in } \\
\text { waste management planning }\end{array}$ & EA, WGI & WGS \\
\hline $\begin{array}{l}\text { Develop specific guidance for and oversee } \\
\text { preparation of generator P2/WasteMin. Plans. }\end{array}$ & EA & $\overline{\mathrm{EA}}$ \\
\hline $\begin{array}{l}\text { - Coordinate preparation of generator P2/Waste } \\
\text { Min Plans }\end{array}$ & $\overline{\mathrm{EA}}$ & WGS \\
\hline $\begin{array}{l}\text { - Provide P2 expertise and program direction to } \\
\text { support operations }\end{array}$ & $\overline{\mathrm{EA}}$ & $\overline{\mathrm{EA}}$ \\
\hline - Materials Exchange Program & EA & $\overline{E A}$ \\
\hline - Prepare P2 Reports for DOE-HQ & EA & EA \\
\hline - Track waste generation rates & EA & WGS \\
\hline - Conduct PPOA's & EA & EA \\
\hline
\end{tabular}

Key:

$\mathrm{EA}=$ Environmental Affairs

EFS = Environmental Field Support

WGS $=$ Waste Generator Services

WGI $=$ Waste Generator Interface

$\mathrm{WO}=$ Waste Operations 


\subsection{Geographic WGS Map}

Figure 4.4 shows the anticipated location of WGS personnel. The number of FTEs at each location is split by the various organizations. 


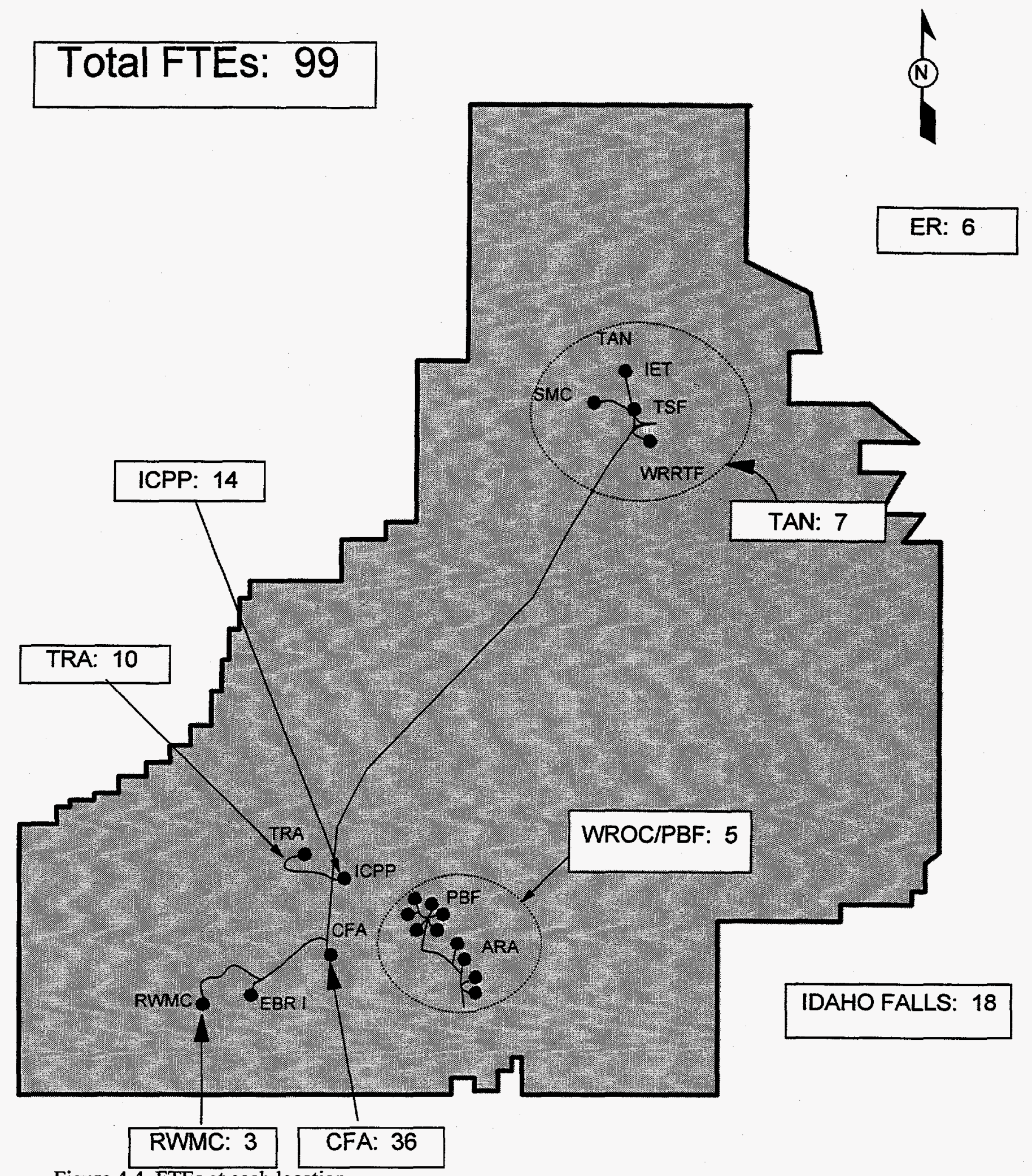

Figure 4.4. FTEs at each location. 


\section{IMPLEMENTATION APPROACH}

\subsection{Implementation Schedule}

A facility phased approach has been selected for WGS implementation. Based upon LMITCO Salary Review Board approval, WGS operations will be deployed at the ICPP beginning June 1, 1998. ICPP was selected on the basis of highest need for improvement in waste management and environmental compliance. This is based upon past identified problems, the high rate of continuing environmental and waste management problems, and the large number of temporary accumulation areas. Development and engineering of the WGS approach was expedited through request by the LMITCO Operations Executive Vice President to provide solutions to these problems. Although initial deployment at ICPP will be difficult, it will also make the most improvement in compliant waste management operations. Caution must be exercised in tailoring the system to meet only the needs of ICPP. WGS will be phased in at ICPP from June 1 - August 30, 1998. This will include all operations and facilities at ICPP including ER functions. Lessons learned will be incorporated into the WGS process and organization to meet generator and TSD needs during this time. In September 1998, an evaluation of WGS operations will be held between WO and ICPP, providing further recommendations on deployment.

Beginning in FY 1999, WGS will be deployed at the other INEEL major generator sites, again in a phased approach. The recommendation for this phasing would be TRA (October), TAN/SMC (November), CFA(January), ER (January), town facilities (February), Waste Operations TSDs (WROC/PBF and RWMC) (February).

INEEL non-LMITCO generators will have waste management service support provided as current provided through the WGI organization during implementation at the LMITCO INEEL facilities. Some revisions in the waste characterization/certification forms or IWTS material and container profiles would be the only changes they would see. Any changes for application of WGS services at the NRF or ANLW facilities would be negotiated, but the preference would be to wait until WGS is effectively working in LMITCO INEEL facilities.

The implementation schedule is presented as Figure 5.1.

\subsection{Implementation Readiness}

The months of April and May 1998 will be used to prepare the implementing process flow, procedures, staffing, and logistical functions necessary to meet the June 1, 1998, ICPP deployment schedule. Figure 5.1 defines the tasks/schedule to be completed prior to beginning field operations at ICPP on June 1, 1998. 


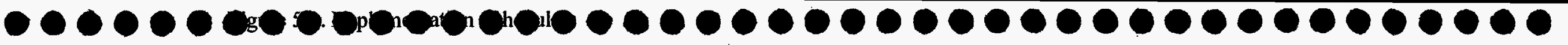

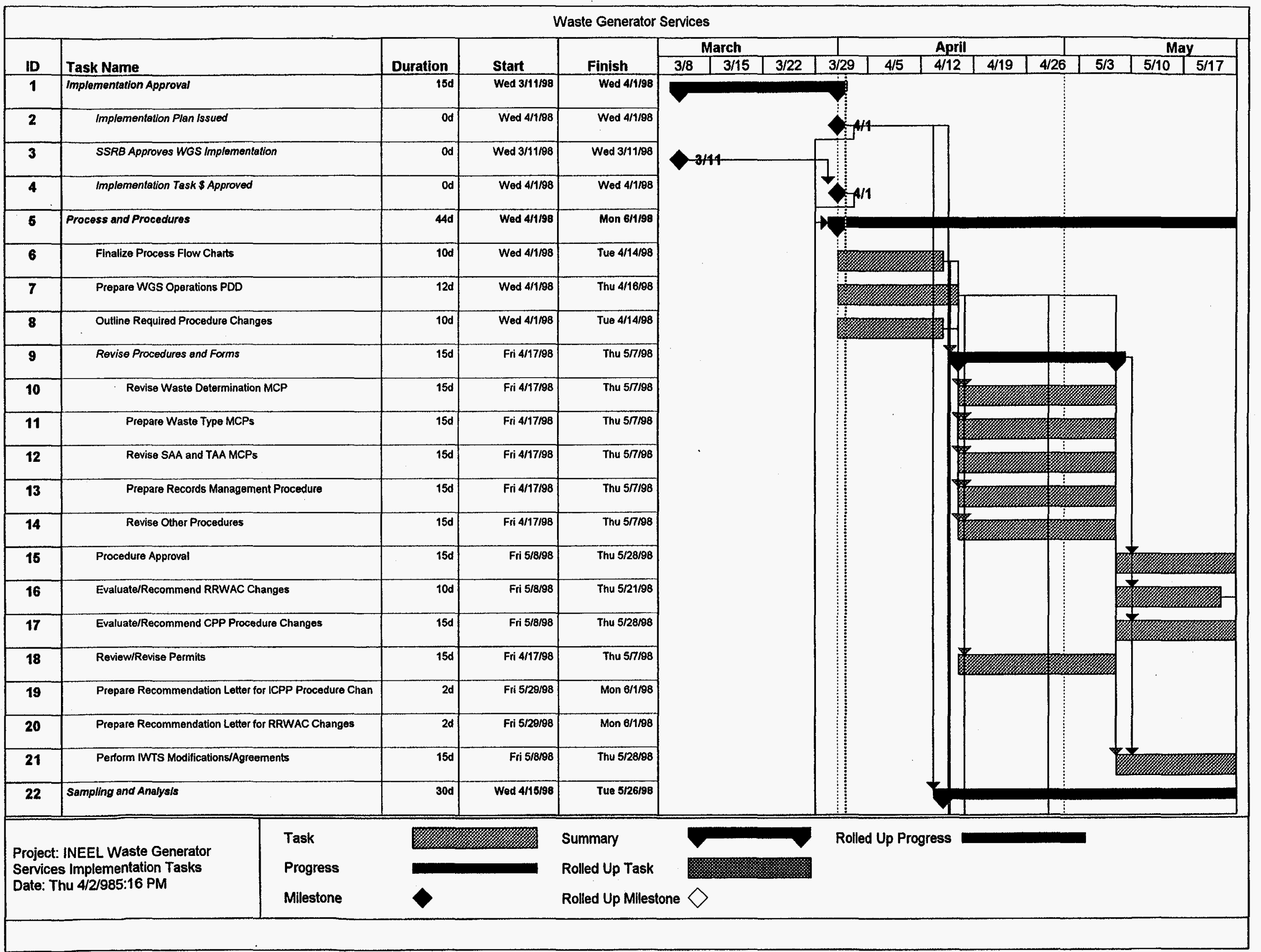




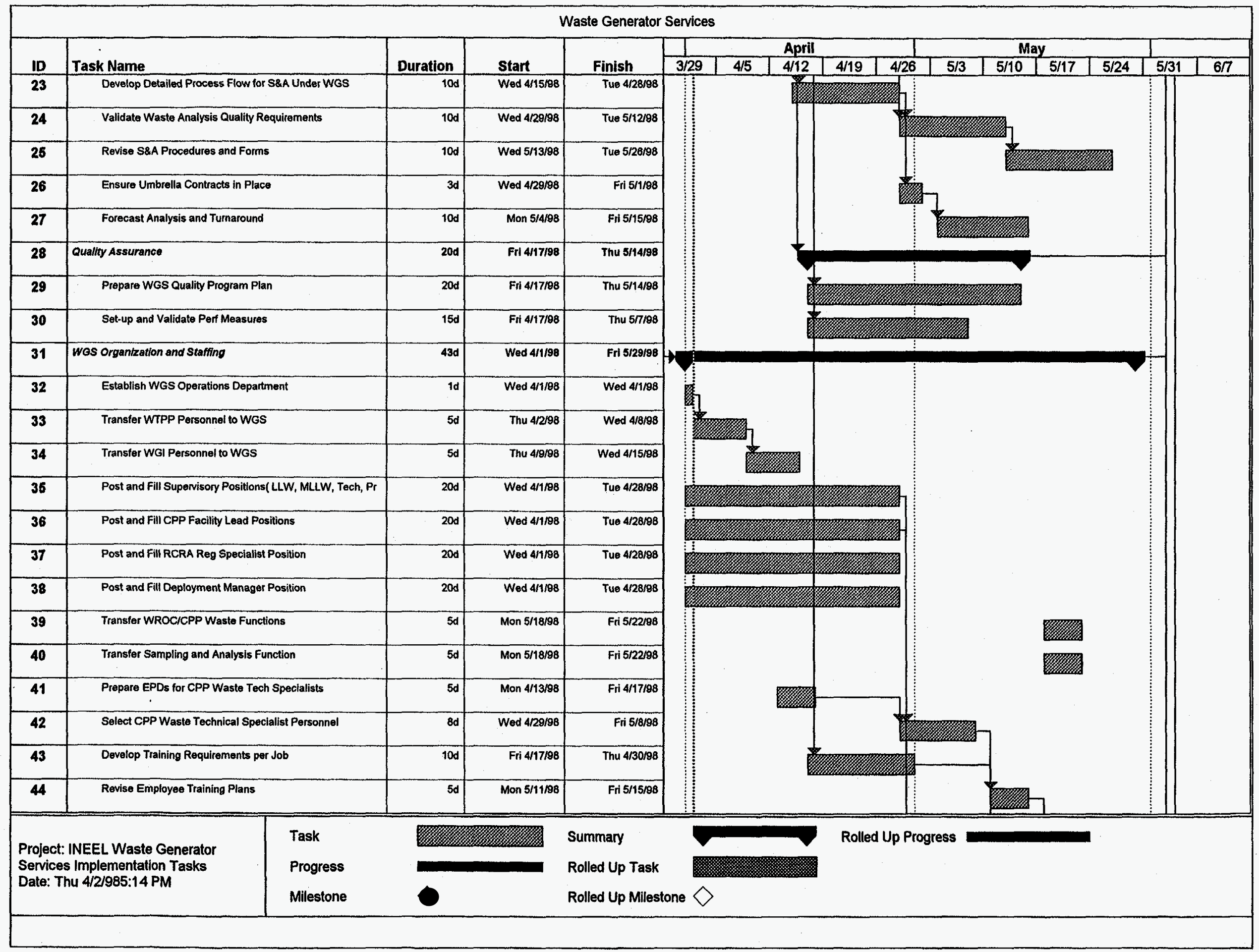




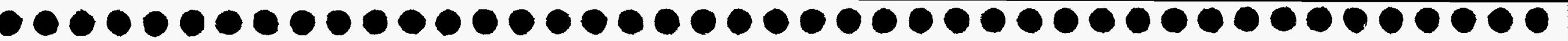

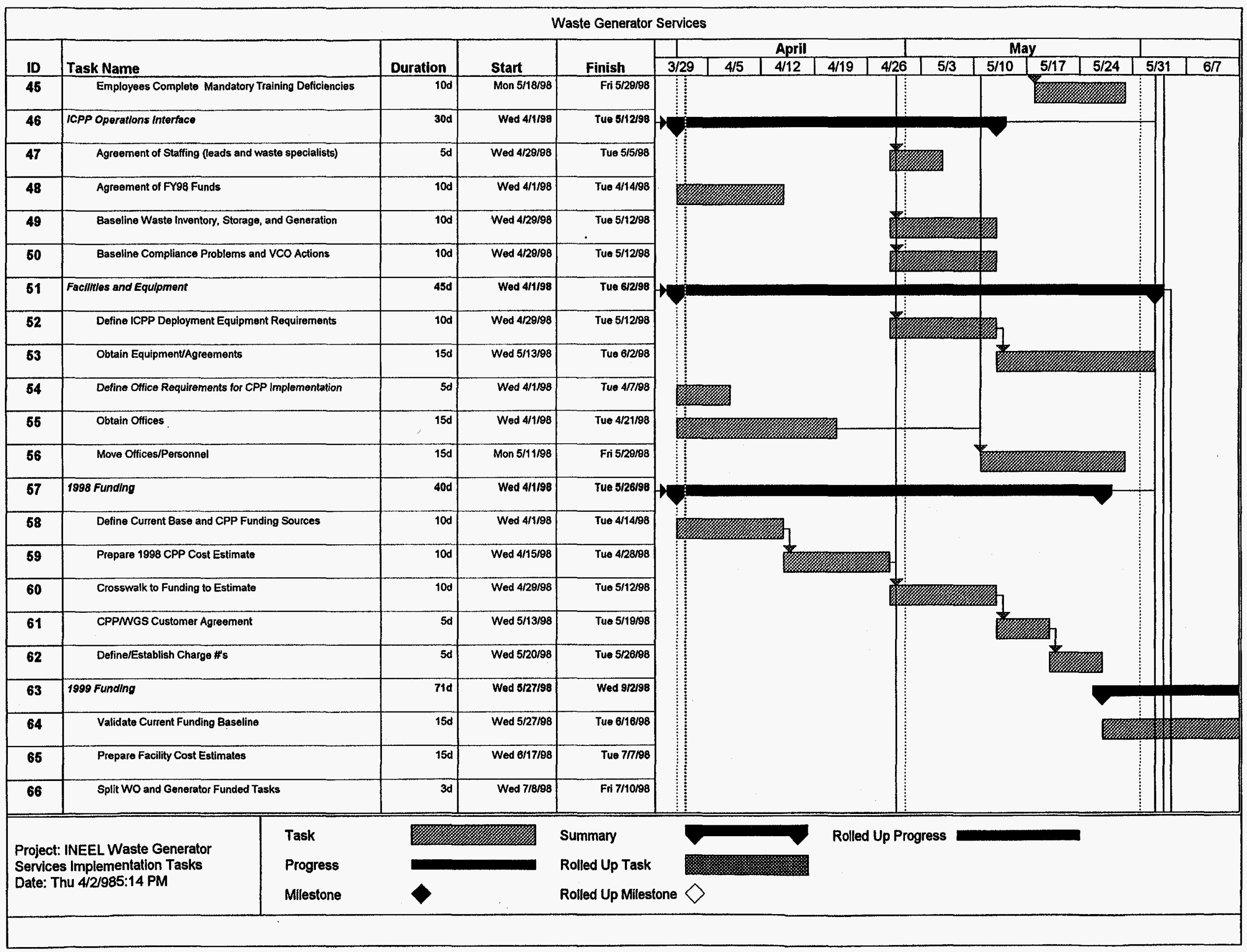




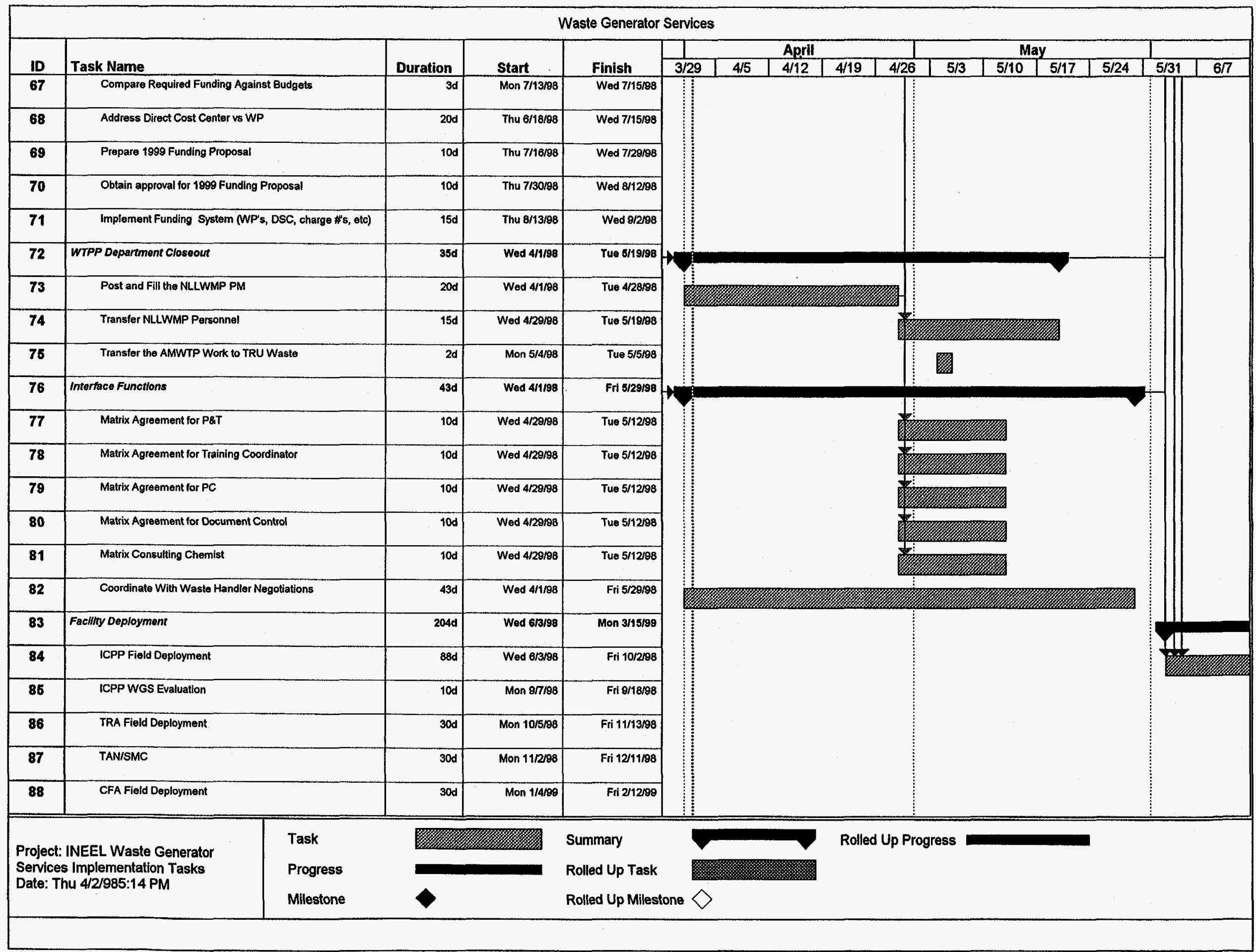




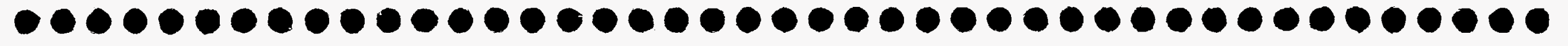

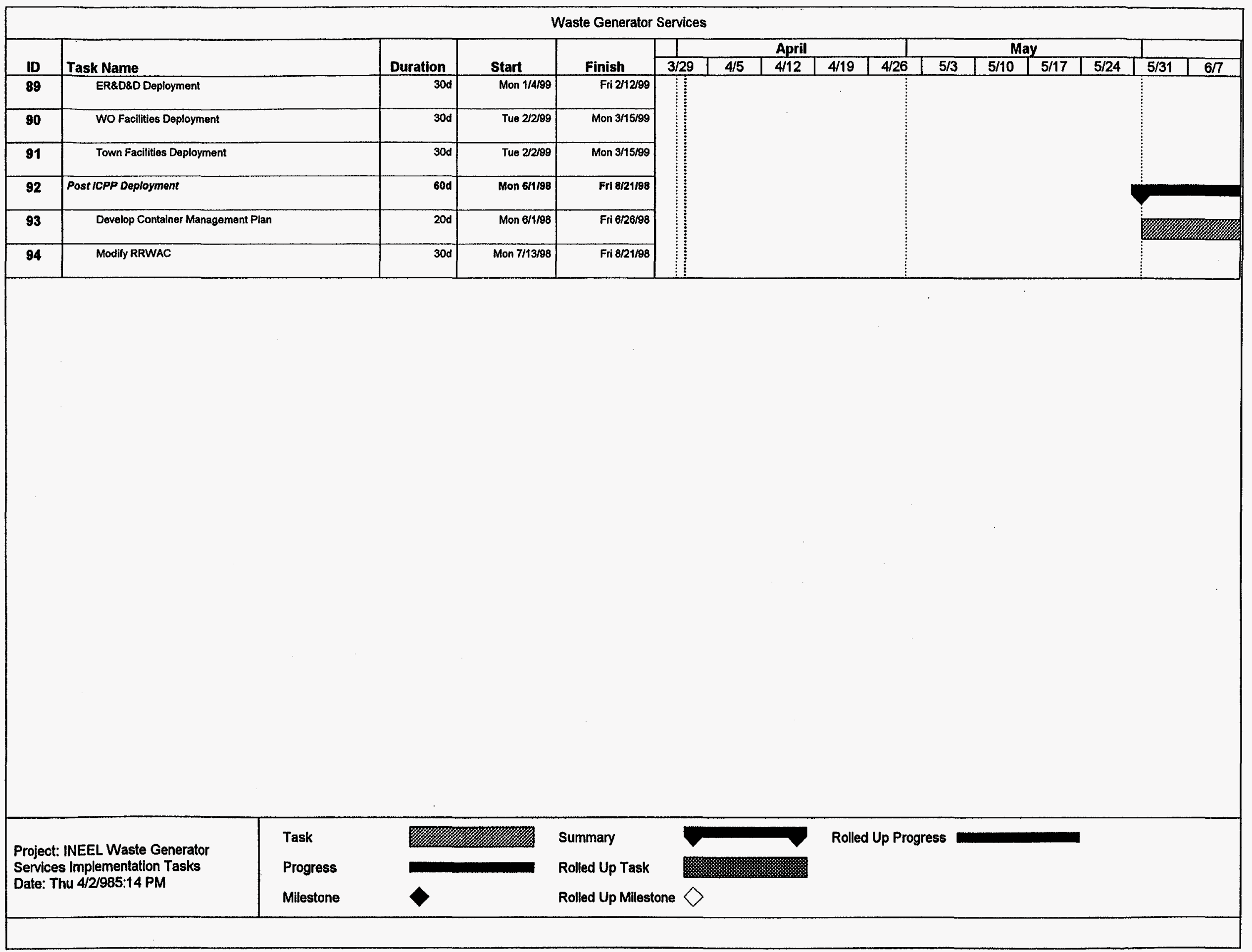




\section{WGS FUNDING PLAN}

\subsection{Current Funding Baseline}

Through a survey of the facilities, resources were identified that currently perform functions that would be transferred to WGS. This current resource baseline is shown in Section 4.4.1. The funding for these functions presently resides throughout the different facilities and programs at the INEEL. The funding exists in several EM, Non-EM and indirect fund sources.

Table 6.1 provides a rough estimate of the current costs for the functions that will be performed by WGS. This information was provided by individual areas at the INEEL on the amount of employee time spent currently performing these functions. The data was costed using each organization's average rate. The financial data is separated by direct versus indirect cost.

Table 6.1. Current Costs for Projected WGS Activities.

AREA $\quad$ FTES

$\begin{array}{ccc}\text { Annual Direct } & \text { Annual } & \text { Subcontracts } \\ \text { Labor } & \begin{array}{c}\text { Indirect } \\ \text { Labor }\end{array}\end{array}$

\begin{tabular}{|c|c|c|c|c|}
\hline$\overline{\mathrm{CFA}}$ & 5.6 & $\$ 263 \mathrm{~K}$ & $\$ 201 \mathrm{~K}$ & $\$ \overline{O K}$ \\
\hline TRA & 13.2 & $\$ 1,048 \mathrm{~K}$ & $\$ 143 K$ & $\$ 0 \mathrm{~K}$ \\
\hline ICPP & 20 & $\$ 1,964 \mathrm{~K}$ & $\$ 21 \mathrm{~K}$ & $\$ 0 \mathrm{~K}$ \\
\hline TAN/SMC & 6.8 & $\$ 534 \mathrm{~K}$ & $\$ 34 K$ & $\$ 0 \mathrm{~K}$ \\
\hline ER & 7.8 & $\$ 845 \mathrm{~K}$ & $\$ 0 \mathrm{~K}$ & $\$ 0 \mathrm{~K}$ \\
\hline TOWN & 1.7 & \$OK & $\$ 142 \mathrm{~K}$ & \$OK \\
\hline ENV AFFAIRS & 9.3 & $\$ 864 \mathrm{~K}$ & $\$ 51 \mathrm{~K}$ & $\$ 330 \mathrm{~K}^{*}$ \\
\hline WROC & 19.1 & $\$ 1,876 \mathrm{~K}$ & \$OK & \$OK \\
\hline P\&T & 5.4 & $\$ 479 \mathrm{~K}$ & \$OK & \$OK \\
\hline WTPP & 26.2 & $\$ 3,281 \mathrm{~K}$ & \$OK & \$OK \\
\hline RWMC & 2.2 & $\$ 212 \mathrm{~K}$ & \$OK & \$OK \\
\hline SMO & 1.8 & $\$ 363 \mathrm{~K}$ & \$OK & $\$ 739 \mathrm{~K}^{* *}$ \\
\hline \multirow[t]{2}{*}{ RAD ENG } & 1.6 & $\$ 281 \mathrm{~K}$ & \$OK & $\$ 0 K^{* *}$ \\
\hline & & $\$ 12,010 \mathrm{~K}$ & $\$ 592 \mathrm{~K}$ & $\$ 1,069 \mathrm{~K}$ \\
\hline WGS Totals & $\begin{array}{l}\text { Total } \quad 120.4 \text { TOTAL } \$ * * * \\
\text { FTEs }\end{array}$ & $\$ 13,671 \mathrm{~K}$ & & \\
\hline
\end{tabular}

* Paragon subcontract for analytical work

** Average annual subcontract total for analytical work and data validation.

*** Numbers are based on estimates of employees currently performing a Waste Acceptance function

Several current costs are not captured in this cost baseline. Generally, the costs that are not captured are for support activities that will not change following implementation of WGS. In other words, the support 
activities currently provided to the generator would now be provided to WGS. Costs not captured include transportation of waste to TSDFs (generally performed through subcontracted resources) and support provided by cognizant professionals. Although the costs for the current waste handlers are included, costs for any additional craft support that may exist at certain INEEL facilities is not captured.

\subsection{Recommended Funding Approach}

\subsubsection{Consideration of Alternatives}

To effectively implement and manage WGS, a funding mechanism must be selected that will be costeffective, will create an incentive for efficiency and waste minimization, and will be as simple as possible with no extra burdens placed on the generator. Several funding options were reviewed including:

- Generator funds all WGS activities

- WGS charges directly to generator's accounts

- WGS costs are allocated to the generators

- General and administrative

- Waste Operations funds all WGS activities

- Split funding approach

A brief description of each funding option, with the respective advantages and disadvantages, follows.

\section{GENERATOR FUNDS ALL WGS ACTIVITIES - WGS charges directly to generator's accounts}

Under this option, all required funding for WGS would be provided by the generator. Agreements would be documented between WGS and the generator regarding the support that WGS will provide and the cost of that support. The work scope would be covered in the waste generator's project and charge numbers would be provided by each generator.

The advantages of this option are:

1) There is financial incentive for waste minimization because the generator is paying the costs associated with WGS functions.

2) Relatively easy to establish.

3) Current financial systems can easily capture cost data.

4) No increase to the indirect cost pools.

The disadvantages of this option are: 
1) Funds reprogramming/transfer may be required because Waste Operations is currently paying for some of these functions. The waste generators have not budgeted for the full cost of these services in future years.

2) Funds WGS staff may have to charge to numerous charge numbers, which may be timeconsuming for small jobs.

3) Budgeting process for the generator will not be simplified.

4) There is no centralized accounting and cost reporting.

\section{GENERATOR FUNDS ALL WGS ACTIVITIES - WGS costs are allocated to the generator}

In this option, WGS would determine the amount of funding required to complete all of the functions within their scope. The generator would set aside the appropriate amount of funding to cover these activities. The total WGS cost would then be allocated to the generators. The allocation could be made through a service center or through a direct allocation method (similar to that used for Compliance Reengineering).

Service centers are used for those services where a rate can be tailored to the characteristics of the particular service and where the benefiting requestor can be specifically identified and, therefore, billed for service. For WGS, a billable rate would be established to recover all costs. Generators would be billed on a monthly basis for activities based on the established rate. Alternatively, the WGS costs may be directly allocated to the generator accounts at a pre-established rate by month (as has been done by Compliance Reengineering).

The advantages of this option are:

1) Current financial systems can easily capture cost data.

2) All costs fully identified to the generator on a regular basis through monthly accounting.

3) There is financial incentive for waste minimization since the generator is paying the costs associated with WGS functions.

4) The WGS charging practice would be simplified because all WGS work would be charged against one work package and then allocated to the generator accounts through an accounting mechanism.

The disadvantages of this option are:

1) Reprogramming/transfer of funds may be required because Waste Operations is currently paying for some of these functions. The waste generators have not budgeted for the full cost of these services in future years.

2) A billable rate is dependent upon volume (or an alternate variable such as number of waste streams or labor hours). A decline in volume will force an increase in the unit rate. 
3) The billable rate charged to the generator would be high because all programmatic costs (management, procedures, etc.) would be recovered through that rate. The generator may feel that WGS is not cost-competitive with services they could purchase outside the INEEL.

4) This type of funding pool must be liquidated at the end of a fiscal year. If the projections upon which the allocations are based, are not accurate, the rate would have to be changed to recover all costs.

5) A service center option would result in an increase to the indirect pool cost level as well as impact the indirect incentive fee unless an exemption is made by DOE-ID.

6) If WGS remains within the indirect pools, they will be subject to potential indirect funding reductions that may not be accomplished without serious work scope impacts.

7) Additional administrative burdens are incurred with collection and billing.

\section{GENERAL \& ADMINISTRATIVE (G\&A)}

General and Administrative (G\&A) accounts accumulate costs related or incidental to the overall management, policy determination, and administration of the Company. Under this option, WGS would determine the amount of funding required for completing the functions within their scope. These costs would be recovered by the G\&A rate, established by LMITCO and paid by all programs/projects.

The advantages of this option are:

1) No reprogramming/transfer of funds during budget execution year.

2) Current financial systems can easily capture cost data.

3) The budgeting process of the generator would be simplified.

4) The charging process for WGS staff would be simplified.

The disadvantages of this option are:

1) The generator loses visibility associated with volume of waste generated and associated costs, thus resulting in decreased incentive for waste minimization.

2) Funding WGS under this methodology assumes that there is no appropriate end cost objective (generator), thus placing the burden on all programs/projects at the INEEL. This assumption is not correct.

3) Will result in an increase to the indirect pool cost level as well as impact the indirect incentive fee unless an exemption is made by DOE-ID.

4) If WGS is funded through the indirect pools, they will be subject to potential indirect funding reductions that may not be accomplished without serious work scope impacts.

5) Would likely increase the G\&A rate currently paid by programs/projects at the INEEL. 


\section{WASTE OPERATIONS FUNDS ALL WGS ACTIVITIES}

Under this option all funding required to support the activities of WGS is provided by Waste Operations (EM-30). A control account and work packages would be created in Waste Operations and all WGS resources would be funded through these work packages.

The advantages of this option are:

1) Budgeting and charging would be easier.

2) All waste management activities would be collected in one place resulting in greater financial visibility.

3) Would be easy to implement.

4) Current financial systems can easily capture cost data.

5) There would be centralized accounting and cost reporting.

The disadvantages of this option are:

1) There is no financial incentive for waste minimization.

2) Waste Operations has not paid for all of these functions in the past; some of the functions have been paid for by the waste generator. Consequently, budgets for future years are not sufficient to cover all of these functions.

3) Budgets have not been requested by Waste Operations for this scope through the EM PBS process.

4) Because waste generators have paid for some of these functions to date, their budgets include these same functions in the future. The generation would have no scope for this budget.

\section{SPLIT FUNDING APPROACH}

This options splits the funding for WGS activities between waste generator and Waste Operations accounts. Various alternatives exist within the overall approach. Based upon an evaluation of the work scope, a determination would be made as to which activities would be charged to the generator and which would be charged to Waste Operations. For example, all work scope performed by WGS prior to receipt of any waste could be funded directly by Waste Operations; the waste generator could fund all work scope performed by WGS after waste is received. The charges to the waste generator could either be made directly to their fund source (e.g., the generator provides a charge number to WGS) or the costs could be allocated.

The advantages of this option are:

1) No reprogramming/transfer of funds would be required because the waste generator currently pays for certain activities and Waste Operations pays for others.

2) Current financial systems can easily capture cost data. 
3) There would be financial incentive for waste minimization because the waste generator pays a portion of the WGS costs.

The disadvantages of this option are:

1) Waste management funding would not be fully centralized.

2) Additional administrative burdens are incurred with collection and billing if an allocation method is used for the generator-funded activities.

3) If a service center is used to allocate the waste generator-funded activities, this will result in an increase to the indirect pool cost level as well as impact the indirect incentive fee unless an exemption is made by DOE-ID.

\subsubsection{Recommendation for FY 1998 Funding Approach}

The initial deployment of WGS will occur in June 1998 at the ICPP. Implementation in the middle of a fiscal year affects the funding approach. Changes to work packages and transfers between funding sources are difficult and time-consuming. To ease implementation, WGS activities will be charged to the current funding sources to the extent possible.

An evaluation has been conducted to identify how resources currently performing these functions are charging. This evaluation will be augmented to provide additional detail, particularly for ICPP. Cost will then be estimated for the various WGS functions and a crosswalk will be created to map the WGS functions to the current charging system. Costs will be tracked for the remainder of FY 1998 and will be used in formulating the FY 1999 budget.

Implementation during a fiscal year can also impact the current overhead pools and indirect cost structure. These pools are set at the start of the year based on the number of employees in the organizations. Transfer of a large number of employees from one organization to another, such as from Environmental Affairs to WGS, could significantly affect these pools. The extent of this impact is being evaluated. If the impact is great, employees will be matrixed from current organizations for FY 1998. This approach will allow the implementation of WGS without affecting the current overhead pools and indirect cost structure in the middle of a fiscal year.

\subsubsection{FY 1999 Recommendation}

Beginning in FY 1999, a new funding approach for WGS can be implemented without the difficulties associated with changes during a fiscal year. Various funding options have been evaluated, as shown above. A split funding approach is recommended for FY 1999 and beyond. This approach maintains a financial incentive for waste minimization. The waste generators are currently paying for a portion of the functions that will be provided by WGS, while Waste Operations are currently paying for others. Future funding requests are based upon this type of a split. Consequently, this approach will not require a transfer of funds.

Base programmatic activities, such as project management and procedure writing, would be direct-funded by Waste Operations. The activities of the WCCD staff, which occur before a waste is generated and are difficult to attribute to a specific waste stream, would also be direct-funded by Waste Operations. The waste generator would fund the remaining activities, including waste characterization, temporary storage, laboratory analysis, shipping, and waste acceptance for the receiving facility. 
A Memorandum of Agreement (MOA) would be written for each generator to document the WGS functions that would be funded by that generator. The specific responsibilities of the waste generator and of WGS would be detailed in the MOA. The funding required for these specific responsibilities would be estimated and agreed to in the MOA. The waste generator would then maintain an account to cover these activities and would provide a charge number(s) to WGS.

Several other DOE sites have implemented programs similar to the INEEL WGS concept. WGS staff have met with Hanford, Oak Ridge, Rocky Flats, and Lawrence Livermore National Laboratory. Information gathered on the funding approach used by these sites will aid in finalizing the FY 1999 funding recommendation.

The specific steps that will be taken to finalize this recommendation include:

a) Validate the current funding baseline and obtain additional charging information, particularly for ICPP.

b) Estimate the costs associated with each WGS function.

c) Identify those WGS activities that would be direct-funded through Waste Operations and those that would be funded by the waste generators.

d) Compare the split of Waste Operations versus waste generator funding to past practice. Budgets for out years are based on past practice. Consequently, significant changes to this split may create funding difficulties.

e) Evaluate the specific application requirements, such as number of Project Baseline Summaries affected, number of work packages required, number of charge numbers, etc.

f) Review the funding approach used by other DOE facilities for similar services.

g) Finalize and implement the recommendation. 
THIS PAGE INTENTIONALLY LEFT BLANK. 


\section{PERFORMANCE MEASURES}

Implementation of the WGS concept at the INEEL is expected to result in the following improvements to the current waste management process:

- Improved compliance

- Reduced number of $<90$ day storage areas (TAAs)

- Improved customer satisfaction

- Reduced waste management costs

- Reduced waste inventory in storage at the INEEL.

The following narrative describes a proposed set of performance measures that could be used to measure improvements in the INEEL waste management process and to track the WGS Organization's progress toward meeting the above goals. These performance measures will be further defined and developed during the implementation period, and the baseline data will be established. The Technical Support group in WGS will be responsible for compiling and reporting data for performance measures.

\subsection{Improved Compliance}

The following performance measures will be used to measure compliance improvement:

- Number of NOV violations related to waste characterization and TAA management

- Number of audit findings related to TAA management,

- Number of containers exceeding the 90 day limit for TAAs

- Number of containers in TAAs for more than 70 days (leading indicator)

- Turnaround time for lab analysis.

\section{Notices of Violation and Associated Proposed Penalties}

The Notice of Violation (NOV) from the November 1996 RCRA Inspection by the Idaho Department of Environmental Quality (IDEQ) will be used as the basis for this measure. In the November 1996 NOV, 66 of the proposed violations were related to waste characterization and TAA management. Since the IDEQ has not conducted a regulatory inspection at the INEEL since November 1996, this performance measure will not be updated annually. Rather, it will be updated when the data from each RCRA Inspection becomes available. NOV negotiations with the Idaho Division of Environmental Quality are currently in progress. It is expected that the negotiated violations and associated penalties will be significantly lower, the negotiated violations and penalties will be used as the baseline for this performance measure. 


\section{Audit Findings Related to TAA Management}

Internal audit findings will be tracked as a leading compliance indicator. An independent environmental audit of Temporary Accumulation Areas (TAAs) was conducted in 1997 (INEEL Audit 97-ENV-01). The results of this assessment are summarized in Table 7.2.

Table 7.2. Internal Audit Findings Associated with TAA.Management.

Audit Findings By Category.

\begin{tabular}{|l|l|}
\hline Category & \# of Audit Findings \\
\hline Procedure Deficiency & 12 \\
\hline Missing Accumulation. Start date & 1 \\
\hline Open Containers & 3 \\
\hline Inspection Errors & 6 \\
\hline Emergency Response Delinquency & 11 \\
\hline 90 Days Exceeded & 4 \\
\hline Lack of Mgmt System & 7 \\
\hline Others Compliance & 2 \\
\hline Total & 46 \\
\hline
\end{tabular}

Environmental Affairs plans to implement an assistance walkthrough assessment program in April 1998. This program will include routine walk-throughs of INEEL activities and operations. These walkthroughs will include TAA compliance. The data from these walk-throughs will be tabulated and compared to the baseline data from the 1997 assessment on a quarterly basis. WGS will work with Environmental Affairs to ensure that the frequency and criteria used for the assessments are comparable to the baseline data from the 1997 TAA assessment.

\section{Number of Containers Exceeding the 90-Day TAA Limit}

Information for this performance measure has been collected by the Environmental Affairs organization since January 1998. Information was gathered by contacting each TAA custodian on a monthly basis and is maintained in the Hazardous Waste Storage Area Tracking and Reporting System. The measurement baseline will be based on the average of the January through April 1998 data. Figure 7.1 provides current status for this performance measure. 


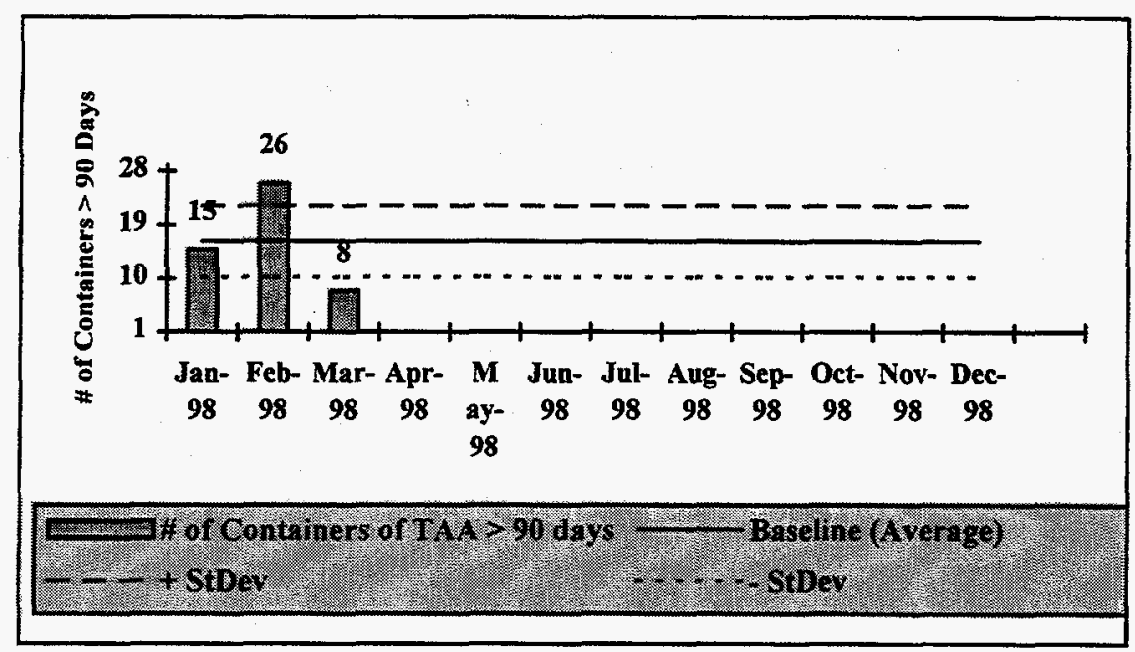

Figure 7.1. Number of Containers Exceeding the 90-day Storage Limit for TAAs.

\section{Number of Containers in TAAs for More than 70 Days}

As a leading indicator, the number of containers exceeding 70 days in storage will also be tracked. This data is not currently available. The TAA inspection log in MCP 443 will be modified to collect this information.

\subsection{Reduced Number of $<90$ Day Storage Areas}

The number of TAAs at the INEEL has increased from 17 in August 1996 to 40 in March 1998. It has been a long-standing goal of the Compliance Review Board to reduce the number of regulated waste storage areas at the INEEL. A reduced number of TAAs should result in a corresponding reduction in number of violations and audit findings associated with TAA management.

Company Procedure MCP 443 requires registration of all TAAs. Information for this measure will be obtained from the INEEL Hazardous Waste Storage Area Tracking and Reporting System, currently maintained by the Environmental Affairs organization.

\subsection{Improved Customer Satisfaction}

Improved customer satisfaction is an important measure of success for the WGS organization. A survey to measure customer satisfaction will be developed and conducted shortly after the WGS concept has been implemented across the INEEL. The survey will include both waste generators and onsite treatment and disposal facilities, and will be conducted at least annually to identify opportunities for improving customer service.

The customer satisfaction survey will be similar to the FY 1997 Customer Satisfaction Survey conducted by Waste Management Federal Services of Hanford, Inc. The survey asked customers to rank eight 
customer expectations in order of importance and to rate WMFS' performance in meeting each of the eight expectations. The eight expectations evaluated were: compliance with regulations, timely response to needs, understanding of customers' needs, defined roles and responsibilities, cost-effectiveness, efficiency of processes, technical support, and effective communications. The survey was useful in identifying the strengths and weaknesses of the WGS Organization at WMFS and will be used as a tool for continuous improvement. Specific criteria and frequency for the survey will be developed during the implementation period.

\subsection{Reduced Waste Management Costs}

It is anticipated that implementation of WGS will streamline the current waste management process, resulting in reduced waste management costs. Cost savings will be achieved through:

- reduced FTE's associated with the waste management process, and

- reduced penalties associated with Notices of Violation.

The information presented in Section 4.4 of this Plan (Current Resource Baseline) and the negotiated penalties for the 1997 NOV will serve as the basis for this measure. The number of FTEs participating in the waste management process will be updated annually and compared to the baseline. Additional cost savings will be realized through reduction of regulatory violations and their associated penalties, as discussed above. It is estimated that approximately $\$ 9.6 \mathrm{M}$ will be saved through 2002 through deployment of WGS at the INEEL.

\subsection{Reduced Waste Inventory in Storage}

Implementation of WGS at the INEEL should streamline the waste management process, resulting in a reduced backlog of waste in storage.

The Low-level Waste Backlog Inventory is tracked in the INEEL Waste Tracking System (IWTS). The Mixed Low-level Waste Inventory at the INEEL is tracked in the Idaho Mixed Waste Information System. Both databases are updated on a quarterly basis. The measurement baseline will be based on the first quarter 1998 data and will be updated quarterly. 


\section{Appendix A}

Personnel Currently Performing WGS activities.

\begin{tabular}{|c|c|c|c|c|c|}
\hline $\begin{array}{l}\text { Name } \\
\text { CFA }\end{array}$ & FTE & Facility & Org & Org\# & Function \\
\hline Ed Dal Lago & 1 & CFA & EA & 7323 & \\
\hline Sydney Flood & 0.25 & CFA & EA & 7323 & \\
\hline Dixie Lainhart & 0.9 & CFA & EA & 7323 & \\
\hline Evan Myler & 0.8 & Constr. & EA & 7323 & \\
\hline \multirow[t]{2}{*}{ Dale Snyder } & 0.8 & CFA & EA & 7323 & \\
\hline & 3.75 & & & & \\
\hline B. Brunson & 0.1 & CFA & ss & 6110 & \\
\hline S. Lyman & 0.2 & CFA & SS & 6110 & \\
\hline Bill Skinner & 0.1 & CFA & S\&H & 7121 & \\
\hline Wendy Faler & 0.5 & CFA & SS & 6610 & \\
\hline Jon O'Rullian & 0.35 & CFA & S\&H & 7137 & \\
\hline Sam Pole & 0.5 & CFA & AEDL & 4170 & \\
\hline Labor & 0.1 & & & & \\
\hline \multirow[t]{2}{*}{ Equip Op } & 0.01 & & & & \\
\hline & 1.86 & & & & \\
\hline Total CFA & 5.61 & & & & \\
\hline \multicolumn{6}{|l|}{ TRA } \\
\hline George Swaney & 0.4 & TRA & EA & 7322 & \\
\hline P. Techmeyer & 0.45 & TRA & EA & 7322 & \\
\hline Cathy Juarez & 0.85 & TRA & EA & 7322 & \\
\hline Mike MacConnel & 0.75 & TRA & EA & 7322 & TRA WMA Lead \\
\hline Bob Rivard & 0.9 & TRA & EA & 7322 & TAA mgt. \\
\hline \multirow[t]{2}{*}{ Kent Miller } & 0.3 & TRA & EA & 7322 & Env. Support Supervisor \\
\hline & 3.65 & & & & \\
\hline Rick Cain & 0.75 & TRA & AEDL & 4250 & TRA landlord wastes \\
\hline Kerry Martin & 0.1 & TRA & AEDL & *41E4 & WMA, waste stream forms \\
\hline Brett Lewis & 0.1 & TRA & ss & 6530 & TRA landiord wastes \\
\hline Mike Sorce & 0.2 & TRA & NO & 5440 & \\
\hline Rick Bonney & 0.1 & TRA & NO & 5410 & WMA, waste stream forms \\
\hline Bill Casper & 0.1 & TRA & No & 5431 & waste stream forms \\
\hline Bruce Mincher & 0.1 & TRA & AEDL & 4220 & WMA, waste stream forms \\
\hline Phil Erickson & 0.05 & TRA & NO & 5432 & WMA \\
\hline Scott Bradley & 0.1 & TRA & No & 5410 & waste stream forms \\
\hline Dave Schoonen & 0.1 & TRA & NO & 5431 & waste stream forms \\
\hline Fred Frederick & 0.05 & TRA & AEDL & 4110 & waste stream forms \\
\hline Gene Balsmeier & 0.05 & TRA & NO & 5440 & Facility ES\&H Manager \\
\hline Mac McMillan & 0.15 & TRA & No & 5420 & \\
\hline Steve McClaskey & 0.9 & TRA & NO & 5440 & \\
\hline Tom Wheeler & 0.9 & TRA & NO & 5441 & \\
\hline SubContractors & 1.5 & TRA & & & \\
\hline Rad Con Tech & 1 & TRA & & & \\
\hline Labor, Equip Op. & 3 & TRA & & & \\
\hline \multirow[t]{2}{*}{ H Support } & 0.25 & TRA & & & \\
\hline & 9.5 & & & & \\
\hline Total TRA & 13.15 & & & & \\
\hline \multicolumn{6}{|l|}{ CPP } \\
\hline Pam Cunningham & 0.5 & CPP & EA & 7321 & \\
\hline A. Dismuke & 1 & CPP & EA & 7321 & CPP WMA Lead \\
\hline Dave Daniels & 1 & CPP & EA & 7321 & \\
\hline Gary Reynolds & 0.8 & CPP & EA & 7321 & \\
\hline
\end{tabular}




\begin{tabular}{|c|c|c|c|c|c|}
\hline Mike Garland & 0.5 & CPP & EA & 7321 & \\
\hline Mike Lewis & 0.45 & CPP & EA & 7321 & \\
\hline Ron Bone & 0.8 & CPP & EA & 7321 & \\
\hline Mary Street & 0.08 & CPP & EA & 7321 & \\
\hline Lee Sturm & 1 & CPP & EA & 7321 & WMA Support \\
\hline Mike Lovejoy & $\begin{array}{r}0.1 \\
6.23\end{array}$ & CPP & $E A$ & 7321 & \\
\hline D. Trammell & 0.02 & CPP & AEDL & ${ }^{*} 41 \mathrm{E} 1$ & WMA Support \\
\hline Joe Henscheid & 0.15 & CPP & AEDL & *41E1 & lab supervisor \\
\hline Rod Hand & 0.1 & $\mathrm{CPP}$ & AEDL & *41E0 & lab manager \\
\hline R. Anselmo & 0.25 & CPP & AEDL & *41E2 & sample custodian \\
\hline G. Decoria & 0.25 & CPP & AEDL & *41E3 & TAA mgt. \\
\hline B. Boyle & 0.1 & CPP & AEDL & *41E1 & TAA mgt. \\
\hline Barry O'Brien et al & $\begin{array}{l}0.25 \\
1.12\end{array}$ & CPP & AEDL & 4114 & TAA mgt. \\
\hline Mike Ison & 0.1 & CPP & NO & 5211 & \\
\hline R. Morgan & 0.15 & CPP & NO & 5221 & TAA mgt. \\
\hline D. Makovec & 0.2 & CPP & NO & 5221 & waste char. \\
\hline Ron Hastings & 0.2 & CPP & No & 5212 & waste char. \\
\hline Dennis Chinich & 0.12 & CPP & NO & 5212 & TAA mgt, WMA. \\
\hline D. Archibald & 0.25 & CPP & NO & 5100 & \\
\hline Joe Medeiros & 0.2 & CPP & No & 5121 & \\
\hline Randy Romine & $\begin{array}{r}0.5 \\
1.72\end{array}$ & CPP & ss & 6520 & \\
\hline \multicolumn{6}{|l|}{ Waste Mgt. } \\
\hline Rad Con & 0.8 & CPP & & & \\
\hline Crafts Support & 0.75 & CPP & & & \\
\hline Equip Operators & 1 & CPP & & & \\
\hline Garry Burke & 1 & CPP & wo & 3220 & \\
\hline Tom Winder & 1 & CPP & wo & 3220 & \\
\hline D. Sorenson & 0.7 & CPP & wo & 3220 & \\
\hline Jonna Woods & 1 & CPP & wo & 3220 & Admin \\
\hline Karl Griffin & 0.4 & CPP & wo & 3220 & WHT Supervisor \\
\hline Joel Hitz & 0.7 & CPP & wo & 3220 & \\
\hline Al Arnold & 1 & CPP & wo & 3220 & CPP-1619 \\
\hline Bob Skinner & 0.3 & CPP & wo & 3220 & \\
\hline Scott Baguiey & 0.4 & CPP & wo & 3220 & \\
\hline Steve Harker & 0.4 & CPP & wo & 3220 & \\
\hline Scott Maeser & 0.4 & CPP & wo & 3220 & \\
\hline Dennis Purser & 0.4 & CPP & wo & 3220 & \\
\hline Dave Waymire & 0.4 & CPP & wo & 3220 & \\
\hline Document Control & $\begin{array}{l}0.25 \\
10.9\end{array}$ & CPP & & & \\
\hline \multicolumn{6}{|l|}{ TAN } \\
\hline Bob Moss & 0.9 & TAN/SMC & NO & 5514 & Waste Ops Supervisor, WMA \\
\hline Stuart Gerard & 0.9 & TAN/SMC & NO & 5514 & SMC Waste Ops \\
\hline Mark Marchant & 0.9 & TAN/SMC & NO & 5514 & SMC Waste Ops \\
\hline Sue Larsen & 0.3 & TAN Ops & NO & 5114 & \\
\hline Linda Bryant & 0.9 & TAN/SMC & NO & 5514 & SMC Waste Ops \\
\hline Cody Telford & 0.1 & TAN/SMC & NO & 5514 & SMC Waste Ops \\
\hline Greg Fennern & 0.05 & TAN/SMC & NO & 5514 & Shipper, forms \\
\hline Jason Orme \& all & 1 & TAN/SMC & No & 5524 & Lab Supervisor, sampling \\
\hline Darrus Martin & 0.5 & TAN/SMC & $E A$ & 7325 & RCRA support \\
\hline Karen Lewis & 0.1 & TAN/SMC & EA & 7325 & WMA \\
\hline Bob Conrad & 0.5 & TAN/SMC & EA & 7325 & TAA \\
\hline Matt Bannister & 0.5 & TAN Ops & EA & 7325 & TAA \\
\hline Marty Edwards & 0.1 & TAN & EA & 7325 & Env. Support Supervisor \\
\hline
\end{tabular}


Total TAN

ER

Dennis Patterson

Lori Lopez (Wilson)

Bill Clarke

Roger Jones

Walker Howell

Mike Jorgensen

Dale Snyder

Donna Nicklaus

Blair Willis

Sam Pole

Roger Mockli

Ray Sayer

Total ER

SMO

Patricia Berrier

Adrian Chapman

Tracy Elder

Dorinda Funk

Darwin Gregg

Janice Jackson

Theron McGriff

Beth Mcllwain

Matt Nelson

Berta Oates

J. David Stewart

Dave Thompson

Jill Bird

Marie Christopherson

Terri Dockstader

Freeda Goodspeed

Fawn Gosswiller

Mary Hudson

Eddie Johnsen

Michelle Johnson

Leigh Riggs

Jodie Doherty

Laura Garcia

Tim McCracken

Tai Fei Pau

TOTAL SMO

Idaho Falls

Dan McDonald

Colleen Stander

Carole Pruett

Total IF

Env. Affairs - Sitewide

Dona Bates

Donna Haney

Linda Hodges

Mary Joy Prendergast

Randy Rice

Steve Ugaki

Mark Verdoorn

Ben Bues

Ann Boehmer

Darrell Lake

$\begin{aligned} 0.5 & \text { All D\&D } \\ 1 & \text { All D\&D } \\ 1 & \text { All ER } \\ 0.25 & \text { All ER } \\ 0.9 & \text { All D\&D } \\ 0.9 & \text { WAG 1,2 } \\ 0.1 & \text { WAG 5 } \\ 0.8 & \text { D\&D } \\ 0.1 & \text { WAG3 (CPP) } \\ 0.25 & \text { All D\&D } \\ 1 & \text { All ER } \\ 1 & \text { All ER } \\ 7.8 & \end{aligned}$

$\begin{array}{ll}\text { ER } & 3110 \\ \text { ER } & 3110 \\ & 3140 \\ \text { ER } & 3020 \\ \text { EA } & 7323 \\ \text { EA } & 7323 \\ \text { EA } & 7323 \\ \text { Parsons } & \\ \text { AEDL } & 4160 \\ \text { AEDL } & 4170 \\ \text { ER } & 3110 \\ \text { ER } & 3110\end{array}$

AEDL $\quad 4120$

ER $\quad 3170$

AEDL $\quad 4120$

AEDL $\quad 4120$

ER $\quad 3140$

AEDL $\quad 4120$

AEDL $\quad 4120$

AEDL $\quad 4110$

ER $\quad 3170$

AEDL $\quad 4120$

ER $\quad 3170$

ER $\quad 4110$

ER $\quad 3170$

ER 3170

ER 3170

ER 3000

ER 3170

ER $\quad 3170$

AEDL $\quad 4110$

ER $\quad 3170$

ER $\quad 3170$

AEDL $\quad 4120$

ER $\quad 3170$

AEDL $\quad 4150$

ER $\quad 3170$

1.75

0.8

0.8

0.1

1.7

0.05

1
0.15

0.15

1

1
0.05

0.9

0.25

0.15
IRC,CFA

IRC,CFA

IF

All
All
All
All
All
All
All
All
All
All
D\&D sampling

waste forecast reports

Program ES\&H Manager

D\&D sampling

D\&D sampling 


\begin{tabular}{|c|c|c|c|c|c|}
\hline Glade Gilchrist & 0.35 & All & EA & 7331 & P2 Reports \\
\hline Rachel Damewood & 0.15 & CPP, TRA & EA & 7331 & P2 Support to CPP/TRA WMAs \\
\hline P2 IRM Support & 0.25 & All & & & \\
\hline Dave Janke & 0.1 & TAN & EA & 7331 & P2 support to TAN WMA \\
\hline Dave Blumberg & 0.1 & All & EA & 7310 & \\
\hline Gary Adamson & 0.5 & All & EA & 7310 & RCRA procedure modifications \\
\hline Bill Becker & 0.5 & All & EA & 7310 & TSCA Reports \\
\hline John Espinosa & 0.5 & All & EA & 7310 & GTPs, Treatability Study Reports \\
\hline Tom McIntire & 0.3 & All & EA & 7310 & RCRA Biennial Report \\
\hline Dennis Trump & 0.9 & All & EA & 7300 & liability assessments \\
\hline Anne Fix & 0.9 & All & EA & 7300 & liability assessments \\
\hline Total EA Sitewide & 9.25 & & & & \\
\hline \multicolumn{6}{|l|}{ Waste Operations } \\
\hline \multicolumn{6}{|l|}{ WERFMROC } \\
\hline Jennifer Bruxton & 0.75 & WROC & wo & 3220 & IWTS data entry \\
\hline Dave Rizor & 1 & WROC & wo & 3220 & WGI, haz. waste subcontracts \\
\hline Dick Johnson & 1 & WROC & wo & 3220 & WGI, haz. waste subcontracts \\
\hline L. H. Shepherd & 1 & WROC & wo & 3220 & WGI - industrial waste \\
\hline Dale Wells & 1 & WROC & wo & 3220 & WGI-LLW, RRWAC \\
\hline Harvey Weich & 1 & ANL,CPP,IRC & wo & 3220 & WGI-LLW \\
\hline Darris Bright & 1 & TRA,PBF & wo & 3220 & WGI \\
\hline Laurie Beitel & 1 & WROC & wo & 3220 & WGI, offsite LLW, MLLW \\
\hline Tom Shea & 1 & WROC, SMC & Wo & 3220 & WGI \\
\hline Greg Andrews & 1 & WROC,TAN,Pit 9 & wo & 3220 & WGI-MLLW \\
\hline Isabel Waddell & 1 & WROC,ER & wo & 3220 & WGI-MLLW \\
\hline Leroy Ewing & 1 & WROC,CFA & wo & 3220 & WGI \\
\hline Lynn Schwendiman & 0.8 & WROC & wo & 3220 & WGI supervisor \\
\hline Open Position ${ }^{\star}$ & 1 & WROC & wo & 3220 & WGI \\
\hline Open Position" & 1 & WROC & wo & 3220 & WGI \\
\hline M. Jorgensen-Waters & 0.25 & WROC & AEDL & 4170 & Offsite MLLW shipments \\
\hline Mark Elliott & 0.3 & WROC & & & Offsite shipments \\
\hline Jim Curnutt & 0.8 & WERF & wo & 3220 & WGI LLW,MLLW \\
\hline Stu Sato & 0.8 & WERF & wo & 3220 & TAA mgt, LLW, MLLW \\
\hline Anna Barker & 0.8 & WERF & wo & 3220 & AWU student \\
\hline Dan Knoll & 0.6 & WERF & wo & 3220 & sampling, waste char. \\
\hline Sheryl Gibson & 0.33 & WROC & wo & 3220 & document/records mgt. \\
\hline Sharon Hathaway & 0.33 & WROC & wo & 3220 & document/records mgt. \\
\hline Donna Altman & 0.33 & WROC & wo & 3220 & document/records mgt. \\
\hline \multicolumn{6}{|c|}{ *Note: The funding from these two open positions has been used to fund Weymiller, Abbott and Quigley in the past year. } \\
\hline Total WROC & 19.09 & & & & \\
\hline \multicolumn{6}{|c|}{ Packaging \& Transportation } \\
\hline Kim Berrett & 0.1 & All & wo & 3280 & coordinates shipments \\
\hline Chrissy Chugg & 0.7 & All & wo & 3280 & offsite manifests \\
\hline Greg Dineen & 0.15 & All & wo & 3280 & packaging, procurement \\
\hline Reed Fanning & 0.4 & All & wo & 3280 & haz mat shipper \\
\hline Larry Jones & 0.8 & All & wo & 3280 & shipper \\
\hline Gene Kanemoto & 0.1 & All & wo & 3280 & packaging \\
\hline Steve Keating & 0.4 & TRA & wo & 3280 & shipper \\
\hline Donna Miley & 0.6 & RWMC & wo & 3280 & IIWTS input \\
\hline Lonney Nate & 0.35 & TAN & wo & 3280 & shipper \\
\hline Keith Nelson & 0.3 & All & wo & 3280 & supervisor \\
\hline Don Petersen & 0.1 & All & wo & 3280 & packaging \\
\hline Debbie Rowley & 0.9 & IRC & wo & 3280 & lab packs \\
\hline Roger Smith & 0.4 & CPP & wo & 3280 & shipper \\
\hline Karen Wilburn & 0.05 & All & wo & 3280 & doc. control, manifests \\
\hline Total P\&T & 5.35 & & & & \\
\hline \multicolumn{6}{|c|}{ Waste Tech. \& Planning } \\
\hline Dan Lisee & 1 & & wo & 3240 & IWTS \\
\hline
\end{tabular}


Scott Auvil

Monte Davis

Doug French

Kirk Green

John Harris

Lisa Harvego

Andy Jacobs

Kevin Kooda

Jeff Mousseau

Carlan Mullen

Bob Piper

Roger Piscitella

Dave Sheldon

Ron Tallman

Karen Taylor

Dennis Wilkinson

Rich Willson

Jim Wilburn

Randall Allen

Don Amour

Bob Thompson

Karen Peck

Colleen Sargent

Pam Summers

Lynn Ball

Juan Garcia

Mary Magelby

Brian Seggerty

AJ Smith

Carol Lavery

Gaila Allen

Total Waste Tech:

$\begin{array}{ll}\text { WO } & 3240 \\ \text { WO } & 3240 \\ \text { WO } & 3240 \\ \text { WO } & 3240 \\ \text { WO } & 3240 \\ \text { WO } & 3240 \\ \text { WO } & 3240 \\ \text { WO } & 3240 \\ \text { WO } & 3240 \\ \text { WO } & 3240 \\ \text { WO } & 3240 \\ \text { WO } & 3240 \\ \text { WO } & 3240 \\ \text { WO } & 3240 \\ \text { WO } & 3240 \\ \text { WO } & 3240 \\ \text { WO } & 3240 \\ \text { QA } & 7210 \\ \text { QA } & 7210 \\ \text { QA } & 7210 \\ \text { QA } & 7210 \\ & 2260 \\ & \text { V110 } \\ & \text { V110 } \\ \text { WO } & 3240 \\ \text { AEDL } & 4170 \\ \text { WO } & 3240 \\ \text { WO } & \text { Y320 } \\ \text { WO } & 3240 \\ \text { WO } & 3240 \\ \text { WO } & 3240\end{array}$

IWTS

STP, offsite MW

IWTS, reports

IWTS

MW, offsite generator contact.

MW, offsite

MW,offsite

MW, offsite

Manager

SCW planning

LLW backlog, offsite subcontracts

LLW backlog, offsite disposal

LLW offsite disposal

IWTS support

WTS

MW offsite generator contact MW offsite, STP

generator assessments, audits generator assessments, audits generator assessments, audits generator assessments, audits financial support training

training

SCW mgt. Support

IWTS

waste projects

IWTS Lead

administrative

tech. editing

graphics 